\title{
THE EFFECT OF TECHNOLOGICAL CHANGE AND REGULATION ON THE EVOLUTION \\ OF THE NEW ZEALAND \\ TELECOMMUNICATIONS MARKET
}

By

Antony Srzich

A thesis

submitted to the Victoria University of Wellington

in fulfilment of the requirements for the degree of

Doctor of Philosophy in Economics

Victoria University of Wellington

2010 


\section{Acknowledgments}

I would like to thank Professor Lewis Evans for his encouragement, patience, and helpful supervision.

I am grateful to Dr Shuntian Yao, Dr Stephen Burnell and Professor Neil Quigley for comments on early drafts that greatly improved the quality of the thesis.

I am thankful for the wonderful encouragement and support of my work colleagues at Telecom. I would like to thank Tristan Gilbertson for allowing me to take time away from the office in order to complete this thesis. I would also like to thank my team and colleagues for carrying my share of the work load while I was out of the office. More generally I would also like to thank the large number of people who I have worked with over the years at Telecom who have stimulated my curiosity on many topics discussed in this thesis.

My sister Sonja must take credit for proof reading and tidying the thesis, whereas I must take credit for any remaining typographical errors.

Finally, this thesis would not have been possible without the love, patience and support of my wife, Vivienne, and the joyful distraction of my son, Sam. 


\begin{abstract}
The absence of industry specific regulation of access to the incumbent's telecommunications network in New Zealand for an extended period, between 1989 and 2001, is unique compared with other countries with developed telecommunications markets that were opened to competitive entry. This feature of the New Zealand market provides an opportunity to compare the conduct and performance of antitrust regulation with industry specific regulation introduced in 2001.

Of particular interest is the place of the concepts of natural monopoly and perfect competition in the regulation of a dynamic market. This thesis establishes the characteristics that contribute to dynamic supply and demand conditions in the telecommunications market including network effects, discontinuity in demand due to participation, ongoing technological progress of hardware, sunk costs of software development, and the irreversible investment of augmenting capacity to meet expected growth in demand. The economic literature on conjectural variations indicates that under such conditions the concepts of natural monopoly and perfect competition do not explain competitive conduct due to an unstable market equilibrium. The implication is that forming a reasonable view of competitive conduct is limited to the present period of time.

It is shown that decisions made under antitrust regulation are limited to the particular context of disputed competitive conduct, and these decisions do not speculate on future competitive conduct. In contrast, industry specific regulation has formed a sequence of views of competitive conduct, looking forward, that is based on concepts of natural monopoly and perfect competition. It is observed that with time, these views of competitive conduct have evolved with the changing market conditions. If regulatory actions evolve with a changing view of competitive conduct they risk reducing dynamic efficiency.
\end{abstract}




\section{Contents}

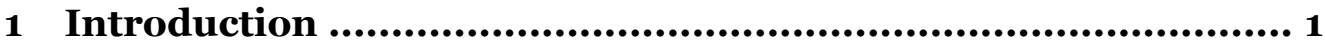

1.1 Transformation of market structure …..................................................

1.2 New Zealand regulatory setting ..................................................

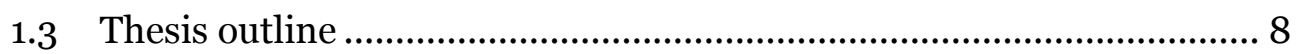

2 Dynamic competition in the presence of network effects and innovation ........................................................................9 9

2.1 Network effects and dynamic competition ........................................... 9

2.1.1 Unexploited gains of direct network effects .................................................13

2.1.2 Unexploited gains of indirect network effects ...........................................16

2.2 The cost of innovation and services ...................................................18

2.3 Reducing dynamic competition to static competition ......................... 19

2.4 Dynamic competition, timing of investment, and uncertainty ...........25

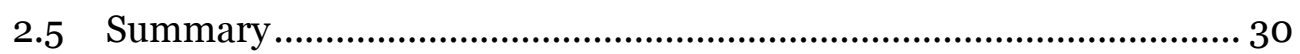

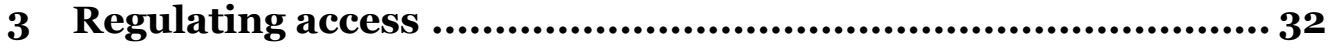

3.1 Structure of the telephony market presented in the literature ........... 34

3.2 Telecommunications industry structure with the internet..................37

3.3 Conduct and market structure ........................................................ 38

3.4 Implications of separating access and calling................................... 40

3.4.1 Description of consumer behaviour ........................................................... 42

3.4.2 Numerical example illustrating the effect of competition........................ 45

3.5 Dynamic efficiency of regulating access to natural monopoly ........... 50

3.5.1 Dynamic efficiency of regulation...............................................................51

3.5.2 Description of industry specific regulation .............................................. 53

3.5.3 Description of antitrust regulation ........................................................... 57

3.6 Regulatory intervention and dynamic competition ............................59

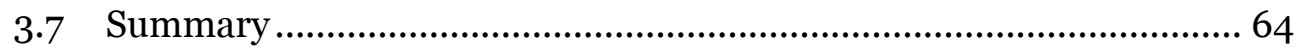

4 International experience ..................................................66

4.1 International comparison of regulatory developments ..................... 66

4.2 Development of internet and mobile services ................................... 69

4.3 International comparison of industry performance ............................. 71

4.4 International experience of the effect of regulation on efficiency.......79

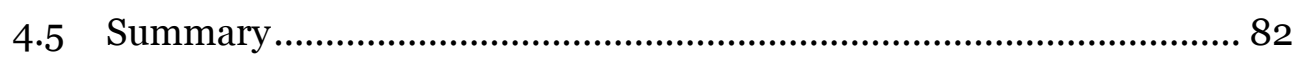


5 New Zealand experience

5.1 Defining competition under ATR ...................................................... 85

5.2 Adaptation of contracts in a dynamic market under ATR .................. 90

5.3 Adaptation of contracts to a dynamic market under ISR .................. 98

5.4 Entry and exit as an indicator of market performance...................... 101

5.5 Non-price competition in the access market.......................................107

5.6 General price trends ....................................................................... 110

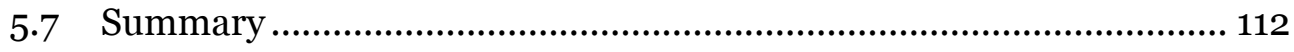

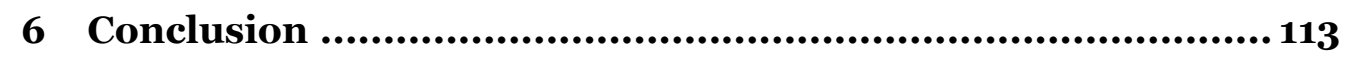

Appendix A: Evolution of the internet...................................124

A.1 Definition of service and network providers......................................124

A.2 The range and growth of service providers ......................................... 125

A.3 Growth of the internet ..................................................................128

A.4 Internet access demand growth......................................................130

A.5 Fixed-line telephone and mobile access demand growth .................. 131

A.6 Telecommunications company revenue ...............................................133

A.7 Technological conditions of supply ....................................................134

A.8 Internet's technical performance and cost ......................................138

A.8.1 Implications of a relatively simple communications network ................ 140

A.8.2 Best efforts communication network ......................................................141

A.9 Internet access technology dynamics ................................................ 141

A.9.1 Modems and internet access.......................................................... 142

A.9.2 Disruptive innovation and the Web browsers ........................................ 144

A.10 Internet peering and transit ..............................................................144

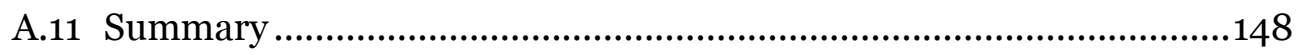

A.12 Annex: Selection of service providers............................................148

Appendix B: Two-part tariffs in the presence of heterogeneous consumers.................................................................154

B.1 Literature on the theory of two-part tariffs...................................... 154

B.2 Influence of income on consumer behaviour .................................. 157

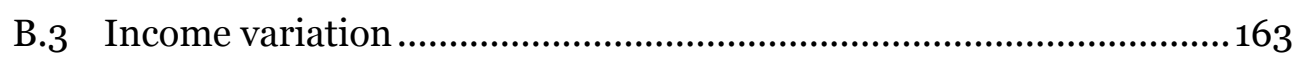

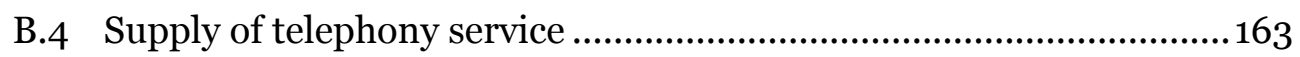

B.5 Profit maximising two-part tariff ........................................................164

B.6 Constrained, consumer-surplus maximising two-part tariff .............168

B.7 Summary ..................................................................................... 174 
References ..............................................................................176

\section{Tables}

Table 1: Numerical example of performance of optional tariff .............................47

Table 2: Telecommunications regulation, 1999 .............................................67

Table 3: Performance of New Zealand telecommunications prices based on

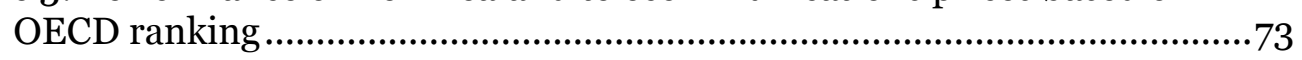

Table 4: Market entry of firms with telephony service and interconnection agreement during 2007 and 2008 .........................................................103

Table 5: Market entry date of wholesale operators in operation in 2009..........105

Table 6: Fixed Network internet access growth rates ...................................... 131

Table 7: Mobile and fixed telephone network access growth rates.....................132

Table 8: OECD average advertised broadband speeds by technology, September

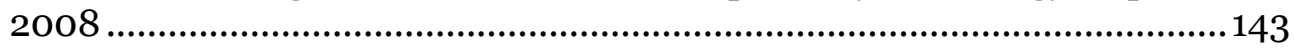

Table 9: Alexa internet traffic rankings ............................................................149

Table 10: comScore World Metrix Rankings .....................................................149 


\section{Figures}

Figure 1: Comparison of telephone calling and internet services markets ............3

Figure 2: Telephony market structure with long-distance competition ...............35

Figure 3: Telephony market structure with LD and local-loop competition ........37

Figure 4: Internet market structure....................................................................37

Figure 5: Network total cost function of contracts under (potential) partial

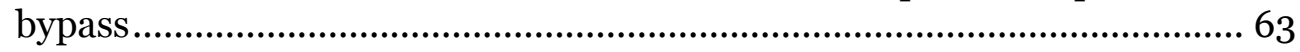

Figure 6: Launch of fixed-line and mobile broadband services.............................77

Figure 7: Technology rivalry between mobile operators .....................................110

Figure 8: Comparison of telecommunications and CPI indices............................111

Figure 9: Top 250 ICT firms' revenue trends by sector, 2000-2006................. 127

Figure 10: Internet host count history ...............................................................129

Figure 11: Internet access subscribers ............................................................... 131

Figure 12: Mobile and fixed telephone access path subscribers .........................132

Figure 13: Change in Telecom's ratio of revenue to fixed Telecom connections, mobile subscribers, and broadband connections........................................133

Figure 14: OECD telecommunications revenue per total communications access

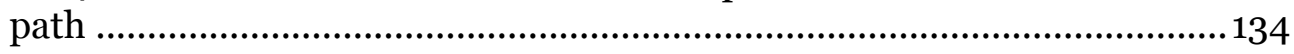

Figure 15: Schematic description of the internet................................................136

Figure 16: Historical modem speeds 'Moore’s Law' prediction ...........................142 


\section{Introduction}

The New Zealand telecommunications market has undergone significant change since it was opened to competition in 1989. This change has been dynamic, enabled by technological developments that greatly increased the scope of communicating information beyond making a voice call over the traditional telephone network. This change includes the emergence of the internet which transformed the organisation of the market for services resulting in significant growth in demand. There is also the appearance of new mobile technologies, resulting in call substitution between mobile and fixed-line telephony networks, evolving into the substitution of internet services between mobile and fixed-line broadband networks. In conjunction with these developments, there has been an evolution in regulatory processes since the market was opened up to competition in 1989 .

This thesis follows the technological and regulatory developments in the New Zealand market, using economic theory to explain and examine the consequences of a unique set of regulatory circumstances on efficiency. One reason for an interest in New Zealand is created by the fact that, up until 2001, general competition law enforced by the courts regulated competitors' access to the incumbent's network. This process of regulation is referred to here as antitrust regulation (ATR). In 2001, industry specific regulation (ISR) arrived with the establishment of an industry specific regulator to regulate price and non-price terms of access to the incumbent's network. The absence of ISR for an extended period, between 1989 and 2001, is unique when compared with other countries with developed telecommunications markets that were opened to competitive entry. Other countries introduced ISR contemporaneously with allowing competitive entry.

This thesis makes three contributions to economic study of the telecommunications market. The first is a comparison between the application of ATR and ISR in New Zealand, with particular emphasis on their treatment of the conduct of competition by a firm with market power. The reason for regulating the conduct of a firm with market power is that if it uses this market 
power to lessen competition then this may also lessen efficiency. ATR defined conduct as being anticompetitive if the disputed conduct by the firm with market power could have been carried out by the same firm but hypothetically without market power. This requires the courts to first determine whether or not the firm has market power, and then consider whether the conduct was anticompetitive within the very specific circumstances of a particular dispute. Under ISR, once it has been determined that the firm (i.e. the incumbent telecommunications provider) has market power due to its natural monopoly, then regulation is seen as being required to ameliorate incentives created by a firm integrating natural-monopoly assets with downstream retail services. A difference between ATR and ISR in New Zealand is that under ATR a determination of anti-competitive conduct is not a consequence of finding market power, whereas the practice of ISR in New Zealand has associated the terms of access to the incumbent's network with competition in downstream markets.

Regulation of a natural monopoly can enhance efficiency; however, the definition of natural monopoly, and the related idea of the degree of market power on the interval between monopoly and perfect competition, relies on static supply and demand conditions. The second contribution this thesis makes is an examination of the general demand and supply conditions present, highlighting the fact that these conditions are not static, and identifying the features of the dynamic processes at work in the telecommunications market. This has led to a process of dynamic competition that has transformed industry structure. This transformation of industry structure cannot be explained by static supply and demand conditions. The literature explains that in dynamic conditions such as these, the concept of natural monopoly and perfect competition risks inaccurate inferences being drawn about market conduct.

The third contribution to the economic study of the telecommunications market is the development of a comprehensive theory of two-part tariffs and relating this to the process of fixed-line to mobile substitution. The novelty of the twopart tariff theory is the explicit treatment of subscription to a telecommunications service as a normal good within a general description of the utility function. A distinction is made between substitution effects and participation effects in the telecommunications market. This theory is used to 
illustrate fixed-line to mobile substitution, and explain the empirical observation that differences in the form of fixed-line to mobile substitution depend on income. Consumers can either substitute their participation in fixed-line (mobile) telephony with mobile (fixed-line) telephony, or they can participate in both fixed-line and mobile services and just substitute the calls. These different forms of call substitution depend on not only the respective benefits that consumers may receive from subscribing to a fixed-line or mobile service, but also the income of consumers. If the benefits of fixed-line and mobile services are sufficiently different, then a consumer with sufficient income may participate in both services, whereas those on a lesser income may participate in only one.

An overview of the transformation of the industry structure and a description of the regulatory setting is given here in order to provide the factual context for the thesis.

\subsection{Transformation of market structure}

Figure 1 illustrates the key differences between the organisation of the telephony market prior to the arrival of commercial broadband internet access in New Zealand in 1999.

Figure 1: Comparison of telephone calling and internet services markets

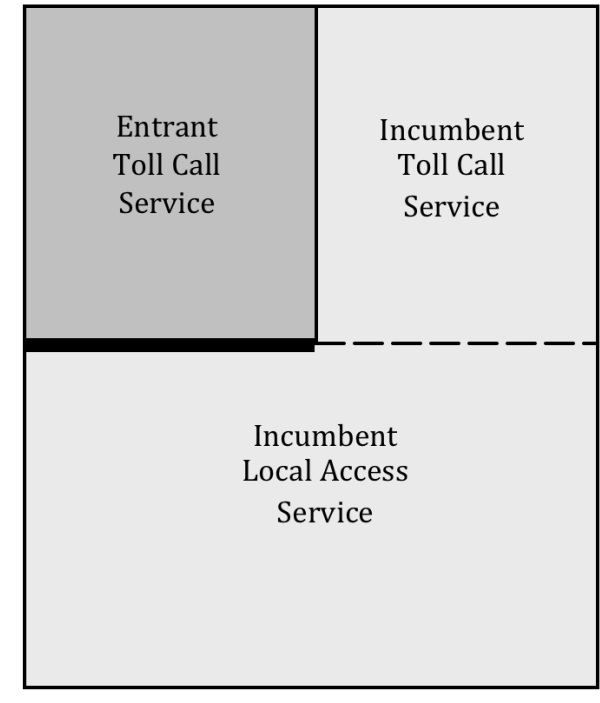

Telephone Services

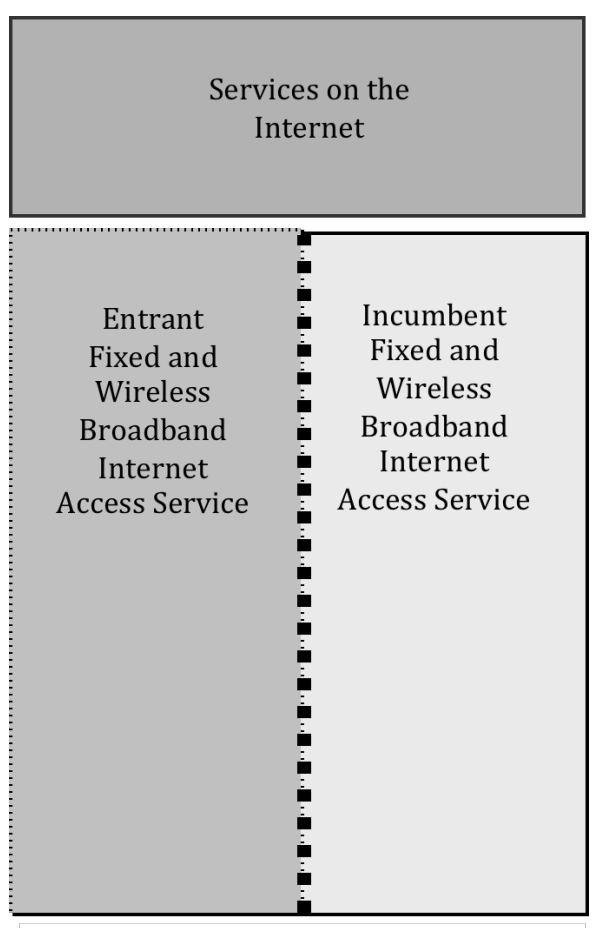

Internet Services 
Up until 1999, industry structure was largely determined by a view of the traditional telephone industry, with separate local access and long-distance tollcalling markets. This began to change gradually after 1999 with the introduction of commercial broadband internet access.

The diagram on the left of Figure 1 illustrates the provision of retail local access and toll-call services by the vertically integrated incumbent, Telecom, and an entrant's toll-call service. The entrant is required to interconnect with the incumbent's local access network so that customers connected to the incumbent's local access network can make calls over the entrant's toll-call network and receive calls carried over the entrant's toll-call network. The heavy solid line represents the interconnection between the entrant's network and the incumbent's local access network. Determining the terms of interconnection was particularly contentious, as the entrant's toll-call service was in competition with the incumbent's toll-call service. This in turn was vertically integrated with the local-access network. The perception at that time was the local access network had features of a natural monopoly, and therefore there was a limited opportunity for competitive bypass of the local access network by an entrant.

The diagram on the right of Figure 1 represents the industry structure that emerged with the internet. The main difference between the telephone services diagram and the internet services diagram is the separation of the provision of services from the network. The structure of the internet means services, including calling, are provided independently of the communications network. This is illustrated in the diagram above by the gap between the box representing services on the internet and the box representing the broadband internet access service. The implication for calling services provided over the internet is they do not rely on service-specific interconnection contracts. In contrast, servicespecific interconnection contracts are required for calling between telephone networks. These interconnection contracts are represented by the heavy solid line in the telephone services diagram on the left of Figure 1.

Furthermore, with the internet there is no equivalent to the separation of services into local-call, national toll-call or international toll-call services, as the technical elements of services are incorporated into a retail broadband internet access service. Broadband internet access is both the local network and the internet, which is international in scope. Even though these network elements 
are integrated into a single retail service, they are not owned by one network operator and do not even have the same physical characteristics. The diagram of internet services shows the incumbent network operator owning both the local access network, which connects to the customer, and the transmission network elements needed to connect to the internet. In this diagram the entrant has the network elements needed to connect to the internet, but in order to provide consumers with a broadband internet service, it leases the access data circuits to consumers from the incumbent. This wholesale arrangement is represented by the heavy dashed line. The terms of this wholesale service are regulated, as the local access network is perceived to be a natural monopoly.

\subsection{New Zealand regulatory setting}

Before 1987, New Zealand Post Office, which was a Department of the State, provided telecommunications services as a statutory monopoly. ${ }^{1}$ On 1 April 1987, it was separated to form the State Owned Enterprises (SOE), Telecom, NZ Post Ltd (the postal service), as well as other SOEs. SOEs are corporations owned by the government and are required, with specific exceptions, to operate on a commercial basis, subject to the same regulatory and tax regimes as comparable private-sector companies. This is in contrast to the pre-1987 New Zealand Post Office, which was organised as a conventional government department under the direction of a Minister. ${ }^{2}$

On 17 December 1987, the Minister for State Owned Enterprises (1987) announced the government's decision to end Telecom's exclusive right to operate a telephone network and associated services, thereby permitting competition in the telecommunications market. Reasons given for deregulating were to improve efficiency in the provision of services, to improve the allocation of the benefits to consumers, and to improve investment in new services. ${ }^{3}$ The market was deregulated and opened to competition in April 1989.

\footnotetext{
${ }^{1}$ See the Touche Ross (1988, pp. 6-9) report for further background material regarding the corporatisation process.

${ }^{2}$ Refer to Touche Ross (1988, p. 6).

3 The Minister for State Owned Enterprises (1987) stated:

“... deregulation was required in order to achieve:

- a telecommunications system of an internationally competitive standard
} 
The initial regulatory conditions established in 1989 included the following:

1) Competition was only subject to ATR. General competition law under the Commerce Act 1986 governed the wholesale terms of access to Telecom's network. Note that ISR of access to the incumbent's network was not established in 1989.4

2) Should the Commerce Act have failed to ensure effective competition, there was the threat of further regulation. 5

3) A universal service obligation called the Kiwi Share Obligation (KSO) required Telecom to provide a standard residential telephone service under the following conditions: 6

a) The monthly rental for the standard residential telephone service was not to increase in real terms above the rental as at November 1989, provided that profitability was not unreasonably impaired;

b) Calls within a local call area were to be free;

\footnotetext{
- $\quad$ efficient use of resources with an adequate return on taxpayers' investment

- $\quad$ a service that satisfies customers

- $\quad$ a service that keeps pace with technological change."
}

4 Minister for State Owned Enterprises (1988).

5 The Minister for State Owned Enterprises (1988) stated "Should the Commerce Act fail to ensure effective competition in telecommunications, the Government will be prepared to re-examine whether further measures are needed." It is unclear if the Minister had envisaged any particular circumstance; however, as well as regulating competition - i.e. ATR - the Commerce Act 1986 included the provision to regulate price under Part IV i.e. ISR - where competition in a market for a service was limited..

The threat of further regulation, as government policy, was explicitly mentioned, later in a report prepared by the Ministry of Commerce \& The Treasury (1995, pp. 1,11). A statement by Telecom's Corporate Policy Manager also indicates an awareness of threat: "Consistent with [the Government's] policy, at no point has there been formal government intervention although it chose on occasion to give stern reminders about policy objectives for competition. The Government continues to monitor competition and would undoubtedly intervene should it think necessary" (Saunders, 1994, p. 496).

${ }^{6}$ The Kiwi Share is a single non-voting share in Telecom that is held by the Minister of Finance on behalf of the Crown. As well as the limitations of pricing on the residential local telephone service, the KSO restricts foreign ownership of Telecom. The Government placed the KSO on Telecom recognising its dominant position in the market at the time of privatisation (Ministry of Economic Development, 2001, p. 5). In addition, there was strong public support for these provisions (Ministry of Commerce \& The Treasury, 1995, p. 37). 
c) The service would be available to all residential customers; and,

d) The incumbent would make the residential telephone service as widely available as at 11 September 1990.

In October 1990, the government privatised Telecom by selling all its shares, except for the Kiwi Share, to a consortium of Bell Atlantic and Ameritech for NZ\$4.25 billion. As a term of the sale, the consortium sold its shareholding in Telecom down to 49\%, publicly listing Telecom on the New Zealand, Australia, and New York stock exchanges. Telecom was initially listed on the New Zealand and Australian stock exchange in 1991.

The next significant institutional change to the regulatory setting occurred in 2001 with the advent of ISR, which the government instituted under the Telecommunications Act 2001.7 Regulatory controls were placed on the terms of interconnection between Telecom's and other network operators' networks. ${ }^{8}$ The purpose of access regulation was “... to promote competition in telecommunications markets for the long-term benefit of end users of telecommunications services ...” (Telecommunications Act 2001, s 18). In addition, the Telecommunications Service Obligation (TSO) was introduced, which carried over the obligations on Telecom set out in the KSO, with the additional inclusion of a requirement for Telecom to offer dial-up internet access. A mechanism for funding the TSO was also provided. The Act required the industry specific regulator (the Commerce Commission) ${ }^{9}$ to investigate whether or not to regulate access to individual 'copper pairs' in Telecom's local

7 The Commerce Commission was and still is responsible for the administration of both ATR and ISR.

${ }^{8}$ Regulated, interconnection prices were either cost based or bill-and-keep. A cost-based price for interconnection is calculated using the total service long run incremental cost (TSLRIC) methodology. 'Bill-and-keep' is applied to local access interconnection (see section 3.1). It generally means two operators do not exchange money for call traffic exchanged between their local access networks. Sometimes an additional condition includes limiting bill-and-keep to traffic volume that is in balance - i.e. the traffic volume originating on one network and terminating on the other is approximately the same as the traffic volume in the reverse direction. In this case, if the traffic is out of balance then a uniform price per minute is charged for the portion of traffic that is out of balance.

9 The Commerce Commission is New Zealand's competition enforcement and regulatory agency. 
loop, which connect consumer premises to Telecom's telecommunications network. The regulator commenced its investigation in 2003, and this ultimately led to the government regulating access to the local loop in 2006.

\subsection{Thesis outline}

In chapter 2, a description of the process of dynamic competition as it relates to the internet is provided. The features of this process include the direct and indirect network effects of consumers' choices; rapid technological change of hardware and the significant sunk cost of software; and the presence of large, irreversible investments required to meet demand. Chapter 3 draws on the literature that argues that market structure is determined by the conduct of rivals, and the structure cannot be assumed to be constant or stable as implied by the idea of natural monopoly or perfect competition. In contrast, it's proposed that the literature on regulating access to a telecommunications network proceeds from the proposition that market structure is static and there are network assets that exhibit natural-monopoly characteristics. Chapter 4 compares the performance of the New Zealand telecommunications market with markets in other countries. Chapter 5 describes the evolution of ATR and ISR in New Zealand and relates this back to aspects of market performance.

Conclusions are brought together in chapter 6. A detailed description of the development of the internet, highlighting economic features, are provided in appendix A. Finally, a theory of participation with two-part tariffs is developed in appendix B. 


\section{Dynamic competition in the presence of network effects and innovation}

There are processes of dynamic competition within the telecommunications market between the providers of services available over the internet, the providers of network protocols and technologies that carry services over networks including the internet, and the providers of access to networks, including the internet. Dynamic competition takes place between "a small number of firms acting independently but aware of one another's existence" (Carlton \& Perloff, 2004, p. 157). This awareness of rivals means that firms can engage in as many actions (and perhaps more) as there are theories explaining oligopoly. In contrast to the many theories of oligopoly, Carlton \& Perloff (2004, p. 157) observe there is only one model of monopoly because there are no rivals to consider, and there is only one model of perfect competition because there are too many rivals for a firm to consider individually.

This chapter uses theories of dynamic competition to examine and explain competitive conduct associated with the development of the internet. It starts by drawing out the basic market conditions that led to a substantial transformation of the telecommunications industry. This, then, serves as an exemplar for applying theories to examine the features of dynamic competition present within the telecommunications market. ${ }^{10}$ In particular, conditions under which dynamic competition can be logically reduced to static models of natural monopoly and perfect competition, and the importance of the timing of investment decisions, are considered. The conclusions drawn here provide a model of dynamic competition for assessing the conduct of regulations.

\subsection{Network effects and dynamic competition}

Evans \& Schmalensee (2002) highlight some basic conditions ${ }^{11}$ of the software market that influence the conduct of dynamic competition. These include (i) network effects; (ii) innovation and rapid technological change; and, (iii) large,

10 Other examples of dynamic competition within the telecommunications industry, specifically between access providers, are documented later in this thesis.

${ }^{11}$ This is an expansion of characteristics identified by Katz \& Shapiro (1999), who also included durability. 
sunk costs to build the capability or capacity to supply services and, once built, low marginal costs to supply services. They describe a process of dynamic competition in an industry with risky investment in high-cost intellectual property, decreasing average costs in production, network and systems effects, and input factors including some technologies that decrease in cost over time. ${ }^{12}$ This implies that competition is not based on output volume and price at the margin. Competition is based on providing better quality and/or lower-cost services in order to gain a competitive advantage with the risk that a new competing service will emerge that will result in asset stranding. ${ }^{13}$ The discussion in this and the following subsections will examine each of these basic conditions for the internet.

Much of the economic and social value associated with the internet is due to network effects. ${ }^{14}$ That is, consumers' and service providers' valuation of a physical or virtual network depends on the size of the consumer and service provider population connected to the network.

The literature classifies network effects as either being direct or indirect. ${ }^{15}$ Direct network effects result when users directly benefit from the presence of others on a communications network. The classic example of a network that exhibits direct network effects is the telephone network. Other examples of services available on the internet that rely on direct network effects include Yahoo! Mail's instant

12 Evans \& Schmalensee (2002, p. 1) note that "In many of these industries, firms engage in dynamic competition for the market - usually through research-anddevelopment (R\&D) competition to develop the 'killer' product, service, or feature that will confer market leadership and thus diminish or eliminate actual or potential rivals. Static price/output competition on the margin in the market is less important."

${ }^{13}$ This is supported by Brynjolfsson \& Smith (2000) observing "while there is lower friction in many dimensions of internet competition, branding, awareness and trust remain important sources of heterogeneity among internet retailers.” That is, with dynamic competition, firms trading on the internet attempt to differentiate from each other.

${ }^{14}$ This is a generalisation of the concept of direct network externality proposed by Katz \& Shapiro (1985) and Tirole (1998, p.405). Whether or not these network effects are externalities depends on the particular circumstances as discussed by Liebowitz \& Margolis (1994) and follows the classification set out in Liebowitz \& Margolis (2002, p. 77).

${ }^{15}$ See Liebowitz \& Margolis (2002, p. 77) for discussion on classification of direct and indirect network effects. 
messaging service, social networking websites such as Facebook ${ }^{\mathrm{TM}}$, and telephone over the internet provided by Skype. The value of using any of these services increases with the number of service participants, because participants benefit from being able to communicate with a larger number of other participants.

Indirect network effects occur when a user's valuation of a good depends on the availability and number of complementary services, which in turn depends on the number of users. The standard examples of indirect network effects in the economic literature include the pairing of DVD players and DVDs, consoles and games, computers and applications, cars and trained mechanics, auction sites and sellers, amongst others. In this case, for instance, a consumer's valuation of a DVD player depends on the availability of films and other video content on DVDs where, in turn, the availability of films and video content on DVDs will depend on the size of the customer base. A hardware platform derives its value from the complementary software that operates on it.

Rohlfs' (1974) analysis highlights that networks are inherently dynamic. In the case where demand amongst consumers is interrelated due to consumers' preferences to communicate with each other (i.e. direct network effects), Rohlfs (1974), using a static model, observes that for a single service (voice calling over the traditional telephone network), there is potential for multiple equilibria, depending on who participates. That is, assuming there is a population of individuals who have an equal preference for communicating with each other, then the number of network participants will depend on whether or not the number of network participants is initially greater than or less than some critical value. If the number of participants is initially less than the critical value, then there would be no network participants, whereas if the number of network participants initially is greater than the critical value, it will be a positive number of participants subscribing to the network and communicating with each other. Rohlfs also argues that due to interrelationship in demand, even if all else including price is held constant, demand could change over time either as it 
converges to an equilibrium, or the equilibrium itself follows a pattern of changing demand that is periodic. ${ }^{16}$

Katz \& Shapiro (1994) raise the point in relation to indirect network effects that consumers' consumption choice will be influenced by their expectation of the consumption choices made by others. ${ }^{17}$ For example, an expectation that hardware will become popular induces the production of more software than otherwise, resulting in the hardware becoming even more popular. They go on to say:

The resulting positive-feedback effects have proven troublesome to economic theory, both technically (equilibrium may not exist, or multiple equilibria may exist) and in terms of market performance (the fundamental theorems of welfare economics may not apply) (Katz \& Shapiro, 1994, p. 94).

Although recognising the dynamics of these markets, particularly with the introduction of new services, the analysis draws conclusions based on static models. The static models only consider the transition from one equilibrium to another following the introduction of new hardware; however, they do not consider the options created for consumers or an ongoing process of dynamic competition. For example, Farrell \& Saloner (1985) introduce the concepts of excess inertia and excess momentum. Excess inertia occurs when there is a lessthan-optimal rate of uptake of a new hardware platform due to positive network effects associated with the existing hardware. Alternatively, if consumers expect other consumers will switch to a new hardware platform then this may result in a more-than-optimal rate of uptake of the new hardware, and thus there will be excess momentum.

The literature on network effects presents many other examples of proposed market failures due to network effects resulting from the potential for multiple

\footnotetext{
${ }^{16}$ Furthermore, although not explored by Rohlfs (1974), it is possible to envisage models of interrelated demand that dynamically evolve over time in unpredictable ways.

${ }^{17}$ See Katz \& Shapiro (1985) for their first reference to this particular proposition.
} 
equilibria, particularly the presence of network externalities. ${ }^{18}$ Liebowitz \& Margolis's (1994, p. 135) response to the reference to network externalities is: “we reserve the term 'network externality' for a specific kind of network effect in which the equilibrium exhibits unexploited gains from trade regarding network participation.”

The following section will expand on the idea that the presence of network externalities, within the context of the internet and associated services, provides the incentive for service providers to compete in order to internalise the "unexploited gains".

\subsubsection{Unexploited gains of direct network effects}

Consumers value communicating with each other. Services available on the internet which enable or facilitate communication include Skype's telephone service over the internet, Yahoo!'s instant messaging service, as well as Facebook's social networking website. The theory of network effects suggests that the value consumers place on these sites will depend on the number of other users of these sites, particularly for individuals who belong to the same community of interest.

Service providers have adopted various strategies to maximise the consumer benefits, due to direct network effects, in order to derive a competitive advantage. For example, Yahoo! Messenger service allows users to send instant messages to users of other instant messaging services ${ }^{19}$, thereby increasing the

18 For example, David (1985) argues that the failure of the Dvorak keyboard to displace the Qwerty keyboard is a market failure due to network effects. Katz \& Shapiro (1992) consider the effect of direct network effects on the dynamics of uptake or a new hardware platform. Church \& Gandal (1992) analyse the problem of competing software providers' effect on determining whether or not there will be a single hardware platform or multiple incompatible hardware platform market, concluding that when consumers place a high value on software variety there is a suboptimal amount of standardisation in the market for hardware. Church, Gandal, \& Krause (2002) extend this by considering adoption externalities, where consumers' private decisions take into account the benefit others derive from the resulting increase in software variety. Farrell \& Saloner (1992) consider the role of converters in a market where there are incompatible hardware platforms, which allow software developed for one platform to operate on other hardware platforms.

19 Yahoo! Messenger allows users of its service to send instant messages to users of Windows Live ${ }^{\mathrm{TM}}$, Office Communications Server, Lotus Sametime, and Reuters Messaging. 
value of participation in its service, even though it may reduce the ability to differentiate its service from competitors. In contrast, social networking sites such as Facebook do not allow access to an individual's content from competing social networking sites, presumably in order to use the direct network effects to differentiate their services from competitors'. Nevertheless, this does not prevent a consumer from entering the same information on Facebook and another site. Skype does not charge its customers for telephone or video calls to other Skype customers, but it does charge for calls to customers on a traditional telephone network. In this case, consumers benefit from being able to access consumers on both Skype's network and a traditional telephone network; however, Skypes' pricing reflects the differences in cost of terminating calls on different networks.

These various strategies can be seen as a response to potential for dynamic equilibria due to network effects. If there was no interconnection or exchange of information between services in a static model, decreasing average cost quantity, and individuals' preferences were homogeneous, then one service provider would monopolise the market. In contrast, in a dynamic market, new service providers such as Skype will seek interconnection in order to provide their customers with the same benefits associated with network effects available to established service providers, but with another technology, i.e. the internet. Furthermore, as there is a distinct possibility that a dominant service provider will lose customers to a new competitor, there is value in the incumbent allowing interconnection in order to mitigate the risk of a rapid change in market share due to a process of excess momentum. These strategies can be viewed as service providers responding to network effects.

Service providers do not generally charge users for many of their services. ${ }^{20}$ Instead, service providers earn revenue from advertising placed on their sites. The more consumers use a particular service, the more valuable the service is to advertisers. Even though these communications services are free, there is an incremental cost to providing them, which consumers do not directly bear as

${ }^{20}$ An exception in the examples listed is Skype charging for calls terminating on a traditional-telephone network. It is assumed that these charges reflect the cost of interconnecting with a fixed-telephone network. 
they are recovered from advertising revenue. Therefore, these services operate as a two-sided market.

Rochet \& Tirole (2006, p. 646) define a two-sided market as “... one in which the volume of transactions between end-users depends on the structure and not only the level of the fees charged by the platform." In this case, the platform is the internet service, and the end-users are the consumer and the advertiser. The prevalence of not charging for services and earning revenue from Web marketing and advertising, as discussed in appendix A.2, suggests that price structure is important. It seems reasonable to assume that if one of these service providers were to charge consumers for their services and lower their advertising charges while their competitors did not, then consumers would switch to their competitors who did not charge. In turn, the loss of customers is likely to reduce the value of advertising on the service provider's site. ${ }^{21}$

Katz \& Shapiro (1994, p. 101) raise the concern that "the total surplus generated by a service is maximised when the marginal benefits associated with a new user, including the benefits flowing to other users, just equals the marginal cost of serving the new user."22 The problem raised is that an individual's participation decision is based on their private benefits, which do not include the benefits received by other users from their participation. Therefore, if a service is provided at cost, then participation in the service may not be socially optimal.

If the population of potential users of one of the services listed above is taken to be those consumers with access to the internet, then the fact that these services are available at no charge could potentially militate against such an externality. ${ }^{23}$ Furthermore, if the objective of service providers is to maximise the number of

${ }^{21}$ Even though some of the services available on the internet exhibit features of a twosided market, the internet itself, including access for consumers, does not. Economides \& Tag (2007) also make the observation that the traditional internet is a one-sided market within the context of the analysis of the issues related to the Network Neutrality debate. The issues concern some network providers proposing to integrate the quality of connectivity provided to consumers with specific services offered by service providers resulting in a two-sided market. This specific issue is not considered here.

${ }^{22}$ Emphasis added.

23 There is always the possibility that it may be efficient to simply pay some consumers to subscribe to the service. 
consumers who use their service, then it would be rational to allow consumers to benefit from the network effects.

Alternatively, if the population of consumers is taken to be the sum of those who subscribe to the internet and those who do not, then it might be argued that increasing the number of users would not only benefit the new users but also benefit existing users due to the direct network externality. Determining whether or not existing users benefit requires distinguishing between marginal and infra-marginal users of the internet, either by some observable characteristic ${ }^{24}$ or implied by the observed consumption of services. ${ }^{25}$ In theory, there may seem to be direct network externalities; however, if there is insufficient information to distinguish between the marginal user and inframarginal users then it may not be possible to directly make an allowance for the externality in the optimal price.

In addition to the problem of distinguishing between marginal and inframarginal users, assumptions would need to be made regarding the extent to which marginal users are part of an infra-marginal users' community of interest, and thus the extent to which infra-marginal users benefit from their presence. This would require information about the structure of communities of interest. However, as already noted, it seems reasonable to assume that communities of interest are continually changing unpredictably, which not only raises significant analytical challenges but also provides service providers with potential, unexploited gains and therefore commercial opportunities.

\subsubsection{Unexploited gains of indirect network effects}

Katz \& Shapiro (1994) claim that indirect network effects reinforce a marketdetermined equilibrium that may be locally but not globally optimal. The literature identified in the preceding discussion proposes a range of adverse consequences including, among others, sub-optimal rates of technological change, a market settling for a range of hardware technologies rather than a

24 Examples include the distinction between business and residential consumers, or the incremental network cost of providing consumers with access to the internet.

25 An example includes assuming that, in the general population, individuals' private valuation of subscribing to a telephone network increases their observed demand for calling and that demand increases with income. 
single hardware technology, or the market settling on a particular sub-optimal technology. ${ }^{26}$ However, these analyses rely on static models and do not recognise that preferences change and competing technologies develop by the process of dynamic competition.

According to this static approach, the public switched telephone network (PSTN) should have remained an enduring equilibrium due to its scale and the technical efficiency of its design for the supply of the telephone call, which had evolved for over a century. However, due to technological and commercial developments (described in detail in appendix B) over the past 10 years, the internet has eroded the dominance of the traditional PSTN.

The internet is itself the product of indirect network effects, where the hardware is the internet and the software are the available services. ${ }^{27}$ In comparison with the PSTN, a wide range of services is available on the internet, whereas only one service dominated the PSTN, namely calling.

The process by which this happened was the result of the unexploited gains that existed in the PSTN market structure, that the internet and the services available over the internet were able to exploited. Another gain was to enable a wide range of service providers to make services available which consumers valued, resulting in increased internet access and users, and the introduction of new services. The size of these substantial gains are illustrated by significant and rapid growth in revenues earned by internet service providers reported in Figure 10, and the growth in the range of different internet services reported in appendix A2.

\footnotetext{
${ }^{26}$ See footnote 18 and discussion citing Katz \& Shapiro (1994) and Farrell \& Saloner (1985) in section 2.1 for background.

${ }^{27}$ Examples of services available on the internet that exhibit features of indirect network effects include Google, Trade Me, YouTube and Wikipedia. The value of each of these services depends on the availability of complementary services or information which in turn depends on the popularity of the service. Trade Me depends on sellers auctioning products and services, which in turn depends on the number of buyers, who benefit from there being more sellers. YouTube users may value the number of videos posted on the site, which in turn depends on the number of users. Wikipedia users value the range of content available on Wikipedia, which in turn depends on the number of users of Wikipedia.
} 


\subsection{The cost of innovation and services}

These dynamic network effects result in an ongoing stream of decisions to invest in new opportunities that often take the form of intellectual property associated with a service. Abstracting from the particular architecture of the internet and the switched telephone network, this investment in intellectual property includes the cost of implementing the service either in the core or at the edge of a communications network. ${ }^{28}$ The effect of such an investment is a change to the core or the edge of the communications network. Where this change occurs can have a significant bearing on the cost of the investment. The cost of the change is the product of the rate at which changes are made and the complexity of the communications network that is being changed, where complexity increases with system size.

As the Internet Engineering Task Force (IETF) (2002, p. 3) states “... complexity [in a system] is the primary mechanism which impedes efficient scaling, and as a result is the primary driver of increases in both capital expenditures (CAPEX) and operational expenditure (OPEX)" ${ }^{29}$ It is for this reason that the IETF (2002, p. 3) recommends that the complexity of the internet belongs at the edge of the network. ${ }^{30}$ The IETF (2002, pp. 6,7) argues that one effect of moving this complexity to the edge of the network allows the internet to scale more efficiently than a traditional switched telephone network in response to technological improvements, growing demand and new services. ${ }^{31}$ The other

\footnotetext{
${ }^{28}$ See appendix A.7 for an explanation of the network edge and core with respect to the internet.

29 Factors that contribute to complexity and thus the subsequent costs result from growth in the number of nodes and interconnectivity in the network. Large-scale networks have the potential to exhibit behaviour that does not occur in small- or medium-scale networks. The IETF describes two principle causes for this complexity. First, in large-scale networks, small perturbations in network traffic may become amplified resulting in network instability. This amplification is due to non-linearities which do not occur in small- or medium-scale networks (Internet Engineering Task Force, 2002, p. 4). Second, as networks become large, they often exhibit increased interdependency amongst components resulting in the possibility that two or more will interact in unforeseen ways (Internet Engineering Task Force, 2002, p. 5).

${ }^{30}$ See appendix A.7 for an explanation of the network edge.

${ }^{31}$ The IETF (2002, pp. 6, 7) notes that the competition amongst the traditional telephone companies involved adding features such as call-waiting, messaging services, and caller identification services to the PSTN, which increased the complexity of the PSTN. This complexity was software, not hardware, driven. The IETF states: "Consider
} 
effect is to reduce the cost of adding a new service to the edge of the network because changes to the network do not need to be made. ${ }^{2}$ The effect is highlighted by the rapid growth in the range of services available on the internet and the global span of the internet.

Evans \& Schmalensee (2002, p. 8) observe that in the case of new-economy industry products such as software, the development of intellectual property is labour intensive and entry costs are low, which means that “... the risk that a dangerous rival will emerge seemingly from nowhere can be quite high.” It follows that service providers need to continually update their intellectual property to ensure they do not lose customers to new entrants. This in turn suggests a competitive process of dynamic competition amongst service providers where there is ongoing investment in research and development into new services in order to gain or maintain a competitive advantage.

In contrast, the relative stability of internet intellectual property suggests there are relatively fewer total resources working on changing the intellectual property of the industry. However, this does not mean that the intellectual property of the internet is not a critical asset; it is just that the economic consequences of constant change differ. 33

\subsection{Reducing dynamic competition to static competition}

In the previous section the process of dynamic competition is described in general terms. That is, firms seek to gain a competitive advantage by investing in services and technology, in order to exploit gains from network effects and technological advancements. The process is dynamic because firms' decisions

the cost of providing new features in a complex network. The traditional voice network has little intelligence in its edge devices (phone instruments), and a very smart core. The internet has smart edges, computers with operating systems, applications, etc., and a simple core, which consists of a control plane and packet forwarding engines. Adding a new internet service is just a matter of distributing an application to a few consenting desktops who wish to use it. Compare this to adding a service to voice, where one has to upgrade the entire core." The cost of an upgrade to the entire core is significantly greater than the cost of upgrading the application on a few consenting desktop computers.

${ }^{32}$ However, as discussed in appendix A.8.2 the quality of communication over the internet, defined by the best efforts principle, may place limits on services.

33 Constantly changing the intellectual property of the internet would result in complexity and costs as discussed in appendix A.8.1. 
unfold over time in response to new information regarding demand, technological innovations, or the actions of rivals. In contrast to the description of dynamic competition, antitrust and industry specific regulatory authorities have mostly relied on static models of market conduct when assessing the effect of conduct on market performance. This raises the question of whether it is valid to reduce the process of dynamic competition to a model of static competition. Understanding the conditions under which dynamic competition logically reduces to a static competition defines the scope of the conclusions that can be logically inferred from static regulatory models. In other words, if inferences are to be drawn regarding the effect of actions of firms or a regulator on a process of dynamic competition, from observing conduct through the lens of static competition, then a theory is required to explain how these observations relate to dynamic competition.

The theory of conjectural variations provides a useful framework for examining the conditions under which models of dynamic competition can be reduced to static competition, for two reasons. 34 Firstly, the conjectural-variations model of static competition is analogous to static models used by antitrust and industry specific regulators examined later in the thesis, where a price greater than marginal cost indicates the potential use of market power. It also extends to the proposition that firms are assumed to compete by their choice price or output settings. The second reason is that Dockner (1992), Cabral (1995), and Figuières, Jean-Marie, Quérou, \& Tidball (2004) provide conditions under which models of dynamic competition reduce to the conjectural-variations model of static competition.

34 Examples of the use of conjectural variations for assessing conduct in telecommunications markets include Kaestner \& Kahn's (1990) assessment of the effect of deregulation on of U.S. interstate toll-call prices. MacAvoy (1998) estimates conjectural variations as an indicator of the change in the competitiveness in the U.S. long-distance toll-call market from 1988 to 1996. He concludes that over the 1988 to 1996 period, estimates of conjectural variation suggest that MCI and Sprint were consistent followers of AT\&T, and therefore long-distance markets experienced decreasing competitiveness. Parker \& Röller (1997) analyse conduct of mobile operators in the U.S. as the market developed from a monopoly to a duopoly through the $1980 \mathrm{~s}$ and into the 1990s, concluding that mobile prices were significantly above competitive as well as non-cooperative duopoly levels. More recently, Grzybowski (2008) takes Parker \& Röller's framework and benchmarks country specific conjectural variations of mobile telecommunications markets across 15 EU countries from 1998 to 2002, concluding that the liberalisation of the fixed-line networks and the introduction of mobile number portability led to an increasingly competitive mobile market. 
Bresnahan (1989) casts conjectural variations as an empirical means for evaluating market power. Price-setting or quantity-setting conduct, in a single product market, is explained by the general price relation 35 :

$$
P_{t}=\frac{\partial C\left(Q_{i t}, W_{i t}, Z_{i t}\right)}{\partial Q_{i t}}-\frac{\partial D\left(Q_{t}, Y_{t}\right)}{\partial Q_{t}} Q_{i t} \theta_{i t}
$$

The dependent variable is market price $P_{t}$, where $t$ is an index of observations over time, and each firm's quantity is $Q_{i t}$, where $i$ is an index of the firms. The single product market implies that $Q_{t}=\sum_{i} Q_{i t}$. Furthermore, the inverse demand function is:

$$
P_{t}=D\left(Q_{t}, Y_{t}\right)
$$

where $Y_{t}$ are variables shifting demand, and the firm's total cost function is:

$$
C_{i t}=C\left(Q_{i t}, W_{i t}, Z_{i t}\right)
$$

where $W_{i t}$ are all input factor prices paid by firm $i$, and $Z_{i t}$ are other variables that shift cost.

Bresnahan (1989, pp. 1019-1031) notes that the parameter $\theta_{i t}$ is an indicator of market power. Equation (1) is interpreted as an oligopoly setting price or quantity such that marginal cost is equal to the 'perceived' marginal revenue, where "The parameters $\theta$ index the competitiveness of oligopoly conduct" (Bresnahan, 1989, p. 1016). If $\theta_{i t}=0$ for all firms, then the firms' conduct is perfectly competitive. If $\theta_{i t}=\mathbf{1}$ for all firms, then their conduct is consistent with Cournot competition. Furthermore, if all firms act to maximise total industry

35 This relation and notation is based on Bresnahan's (1989, pp. 1014-1016) discussion, excluding Bresnahan's reference of equation pararmeters and error terms, except for the $\theta_{i t}$ term. Bresnahan included the additional model parameters and the error terms, excluded here, as he was discussing the equation specification and the econometric estimation of equation parameters. These parameters and the error term have been excluded as they are not necessary for the present discussion. 
profit, then $\theta_{i t}>1$ for all $i$. The value that $\theta_{i t}$ takes if all firms act to maximise total industry profit will then depend on firm $i$ 's share of total industry output. For completeness, $\theta=1$ for a monopoly.

Bresnahan (1989, pp. 1026-1027) highlights two conflating explanations for the parameter $\theta_{i t}$. The first of these follows from Stigler's (1964) theory of collusive oligopoly, which suggests that there are periods of collusion and then periods of price wars. Each firm makes a decision, which is repeated in successive periods to produce a designated quantity or to deviate from the designated quantity. Firms trade off the potential for greater profits in the current period, by producing more or dropping price, against a loss in future periods as a result of competitors retaliating to the firm's deviation from the designated behaviour.

Within this context the value of $\theta_{i t}$ may vary over time as a market moves from a period of collusion to a price war.

The second explanation uses the language of conjectural variations. The conjectural-variations approach assumes that firms anticipate their rivals' reaction as a function of their own pricing or quantity decisions (Tirole, 1988, p. 244). ${ }^{36}$ If firms each believe that an increase in their own output will induce their rivals to increase output, then this leads to tacit collusion amongst the firms as they limit supply, thus increasing the sum of each firm's profit. In this case, industry conduct converges on a monopoly. Alternatively, if firms each believe that an increase in their own output will induce their rivals to decrease output, this guides conduct towards perfect competition, as firms will increase output. Finally, if firms each believe that their output decision has no effect on their rivals' decisions then this is a Cournot oligopoly. Bresnahan (1989, p. 1027) notes that the language of conjectural variations makes the following substitution in equation (1):

$$
\theta_{i t}=1+r_{i t}
$$

36 Tirole (1988, p. 244, footnote 11) notes conditions when the choice variable is price and quantity, highlighting that for homogeneous goods, use is generally made of Cournot competition. 
where $r_{i t}>0(<0)$ indicates that firms believe their output decisions and their rivals' output decisions are positively (negatively) correlated, and $r_{i t}=0$ indicates firms believe their output decisions and their rivals' output decisions are not correlated, thus implying a Cournot oligopoly. ${ }^{37}$

Tirole states that conjectural variations subsume the dynamic interaction between rivals “in some kind of 'reduced-form' static competition” (Tirole, 1988, p. 224). However, as Tirole explains, there is a theoretical inconsistency between the concept of static competition and the proposition that competitive rivals react to each other because, by definition, static competition is where each firm's choices are independent of its rivals'.$^{8}$ Not withstanding this criticism, Tirole (1988, p. 245, footnote 12) proposes that the conjectural-variations approach may have been useful for empirically estimating the degree of market power in an industry. 39

Cabral (1995) and Figuières, Jean-Marie, Quérou, \& Tidball (2004, pp. 53-60) address this criticism by identifying conditions under which a process of dynamic competition would reduce to a static outcome described by equation (1).

37 Bresnahan (1989, p. 1027) notes that whether or not $\theta_{i t}$, and by implication $r_{i t}$, is constant across firms or over time, or whether they are restricted to particular values or the values vary within a range, depends on prior assumptions implied by theory or inferences drawn from data.

${ }^{38}$ Friedman (1983, p. 110) levels the same criticism at the conjectural-variations framework, noting that dynamic interpretations are not possible as the models are not dynamic. Also, firms are assumed to maximise one-period profits rather than the discounted stream of profits over a given planning horizon, and firms have expectations about how their rivals will behave that need not eventuate. Furthermore, Farrell \& Shapiro (1990, p. 120, footnote 27) state "Although the conjectural variation model is logically flawed, it is a useful way of parameterizing the degree of competition among oligopolists. Such behaviour might, for example, arise as the equilibrium of an (unmodelled) dynamic oligopolistic game."

39 This is pragmatic interpretation of the application of conjectural variations to analyse conduct by Schmalensee, who asserts that estimates of conjectural variations are "best interpreted as reduced form parameters that summarize the intensity of rivalry that emerges from what may be complex patterns of behaviour" (Schmalensee, 1988, p. 650). Also, Farrell \& Shapiro (1990, p. 120, footnote 27), while recognising the logical flaw, suggest that conjectural variation "is a useful way of parameterizing the degree of competition among oligopolists. Such behaviour might, for example, arise as the equilibrium of an (unmodelled) dynamic oligopolistic game." 
Cabral (1995) shows for any linear oligopoly structure, where firms make successive quantity-setting decisions over time in a repeated game, that each firm's optimal quantity-decision path follows a conjectural-variations solution described by equation (1). In this case, the process of competition is where each firm decides in successive periods whether or not to produce a designated quantity, and if one firm deviates, then they are punished in the subsequent periods. Cabral defines a linear oligopoly as one where firms have a linear cost function and the demand function is linear, and claims that if these assumptions do not hold then the conjectural-variations "solution can only be taken as an approximate reduced form" (Cabral, 1995, p. 402).

Figuières, et al. (2004, pp. 53-60) cast their analysis within the context of a differential game for a duopoly. They conclude that reducing the process of dynamic competition to a static conjectural-variations framework relies on identifying the conditions under which a stable, long-run, steady-state, equilibrium exists. $4^{0}$ They assume that, in a duopoly, a firm's objective is to maximise the present value of a continuous stream of instantaneous pay-offs and costs. There is one state variable for each firm, which is each firm's productive capacity, that determines their pay-offs and costs. Costs are not only a function of the capacity but also a continuous function of a change in capacity. Figuières, et al. assume firms choose feedback (subgame-perfect) strategies, and they design the firms' optimal policies as decision rules dependent on the state variable. ${ }^{41}$ Figuières, et al. analyse a linear-quadratic pay-off and cost functions, and identify particular conditions that, under their description of dynamic competition, would reduce to equation (1).

\footnotetext{
${ }^{40}$ The points identified in the following discussion are also consistant with analysis by Driskill \& McCafferty (1989) and Dockner (1992).

${ }^{41}$ See Dockner (1992) for the description of feedback (subgame-perfect) strategies, which he refers to as closed-loop (subgame-perfect) strategies. In contrast to the feedback strategies, an open-loop strategy is the firm's optimal policy expressed as a function of time that is independent of the current state of the market. In this case, as the firm's path of actions over the entire game is set at the beginning of the game, then the use of open-loop strategies requires the firm to commit to a pre-announced plan. Therefore, open-loop strategies are static as there is no flexibility to make decisions once the firm commits to a pre-announced plan. Dockner also defines the Cournot-Nash equilibrium corresponding to closed-loop and open-loop strategies that maximise a firm's profits assuming that their rivals hold their strategies constant.
} 
The basic conditions of the internet and the telecommunications market do not suggest a linear oligopoly structure nor a steady-state equilibrium. The fixed cost of telecommunications-network capacity is significant and sunk, whereas the marginal cost of a consumer making a call is small. This is not consistent with a constant-average cost structure implied by Cabral (1995), and nor is the cost of capacity deployment reversible as implied by Figuières, et al. (2004).

Furthermore, the potential for network effects to influence demand implies that demand cannot be assumed to be a single, linear function. Therefore, considering the basic conditions of supply and demand, Cabral's (1995) and Figuières, et al.'s (2004) conditions do not support the proposition that the process of dynamic competition described above can be reduced to a model of static competition described by equation (1). This raises uncertainty regarding the inferences that can be drawn from the static economic models for assessing market power and/or the effect of regulatory action on the process of competition.

An important feature of telecommunications markets that is not considered by Cabral (1995) and Figuières, et al. (2004), is the process of technological innovation of factor inputs. The process results in product differentiation and uncertainty. Cabral does note that his conclusion is robust to shocks in supply and demand; however, this is predicated on the linear oligopoly structure. Figuières, et al. do not consider the challenges in identifying a steady state equilibrium for firms that choose feedback (subgame-perfect) strategies if the cost of factor inputs are changing at potentially random intervals.

\subsection{Dynamic competition, timing of investment, and uncertainty}

The process of dynamic competition in the market for telecommunications services has firms making irreversible investments when there is uncertainty in supply and demand. Under these conditions, Dixit \& Pindyck (1994, pp. 136140), utilising the real-options framework, point out that there is significant value in the timing of an investment, particularly in the option to delay an investment. The value of delay is that it allows the uncertainty to be resolved in time, thereby avoiding a potential loss of the sunk cost of an earlier, irreversible investment.

Dixit \& Pindyck (1994, pp. 136-140) emphasise that it is not optimal for a firm to make an irreversible investment unless the current value of the investment is 
greater than the sunk cost plus a margin that at least covers the firm to invest at a future time. Furthermore, they emphasise that the value of the option to invest at a future time is not only a function of uncertainty in the basic conditions of supply and demand, but also the expected changes in supply and demand (Dixit \& Pindyck, 1994, pp. 136-140). One of the features of the telecommunications market seems to be an inherent expectation of technological progress. This is captured by the concept of 'Moore's Law', which is an assertion based on historical trends and a survey of trends in research and development, that the power of integrated circuits doubles approximately every two years. Integrated circuits are a key hardware input for the supply of telecommunications services. In addition, there is software - the programs and applications - which run on the hardware. The Moore's Law concept has been extended from integrated circuits through to network technologies. ${ }^{42}$ Therefore, in order to understand the effect of uncertainty and rivalry on the timing of investment decisions, it is useful to start by excluding these factors and consider the timing of investment decisions for the deterministic case.

Dixit \& Pindyck (1994, pp. 138,139) analyse the case of the optimal timing of a monopoly investing when there is no uncertainty. The future value of an irreversible investment is known to be $V(t)=V_{0} e^{\alpha t}$, where $\alpha$ is the rate at which the value of the project changes. The objective is to find the time $T$ when it is optimal to pay a sunk cost $I$ that maximises the present value of the investment opportunity:

$$
F(V)=\left(V_{0} e^{\alpha T}-I\right) e^{-\rho T}
$$

where $\rho$ is the discount rate.

Dixit \& Pindyck (1994, p. 138) highlight that if the value of the investment is increasing at a rate that is greater than the discount rate, or $\alpha>\rho$, then it would be rational to delay indefinitely the investment. In the case of telecommunications networks, if there is no or insignificant uncertainty that the performance of electronic technologies in the network would double

\footnotetext{
${ }^{2}$ See appendix A.8 for detailed discussion of the history and role of Moore's Law.
} 
approximately every two years, as suggested by Moore's Law, then $\alpha \sim 0.34$. In this deterministic case, suppose that the discount rate is equivalent to a firm's cost of capital of $10 \%$. This implies that $\alpha$ is less than $\rho$, which indicates that a monopoly would not invest, as the value of equation (5) would become indefinitely large by choosing a larger $T$.

However, for the deterministic case, Dixit \& Pindyck (1994, p. 138) show that the monopoly will invest, when $0<\alpha<\rho$, if:

$$
V_{0} \geq \frac{\rho}{\rho-\alpha} I>I
$$

That is, the investment will be made once the current value of the investment is equal to or greater than the sunk cost. This result follows from the observation that exercising the option to invest forgoes the future investment, thus resulting in an opportunity cost. The key point is that it is not optimal to make the irreversible investment unless the current value of the investment is greater than the sunk cost plus the cost of any future investment opportunities.

Introducing competition into the deterministic case may induce firms to invest earlier; however, as discussed in section 2.3, any competitive equilibrium will depend on the nature of the rivalry that is assumed to exist. For example, suppose consumers incur a cost when switching between rivals, then the future value of the competing firms' irreversible investment is not only a function of the timing of the investment but also the timing of any subsequent competing investment. 43 If in the extreme case where switching costs are zero, thus allowing consumers to easily switch to the firm with the better performing technology, then competing firms are likely to wait to invest until just after their competitor invests. The reason is that if a firm attempts to invest before its competitor then its irreversible investment would become stranded once the competitor invests in a later, better-performing technology, giving it a

43 Farrell \& Klemperer (2007, p. 1977) define a consumer's switching cost between sellers as an investment the consumer has made with respect to the current seller that the consumer must duplicate for a new seller. Examples Farrell \& Klemperer highlight include investment in equipment, setting up relationships, learning to use a product, and extends to non-linear tariffs involving volume discounts. 
competitive advantage. Therefore, there would be no incentive to invest as each firm would wait until the other firm to invest before it invested.

If consumers incur significant switching costs then each firm may have the incentive to invest before their rivals, as they will not lose all customers to their competitors. Network effects may induce switching costs. Consumers may benefit from other consumers purchasing a service either directly due to an ability to communicate with each other, or indirectly due to technical compatibility with a greater range of support and secondary services. If consumers expect to lose these benefits if they switch to a rival product, then this may induce firms to invest earlier rather than later. However, this will depend on the size of the switching cost relative to the rate of technological improvement, and whether improvements will obviate any benefits induced by the network effects. The greater the switching cost, the longer a competitor will have to wait for the performance of the technology to improve and thus gain a competitive advantage sufficient to overcome the switching costs. Thus, the absence of a technology with a competitive advantage allows the firm making the initial investment to derive value from this investment.

Reintroducing uncertainty, Grenadier (2002) and Novy-Marx (2007) show that the structure of production costs and the description of the strategic interaction between firms are significant determinants of the value of the real option premium required to induce competing firms to invest. Grenadier (2002), using a continuous-time Cournot-Nash description of a market for a homogeneous good, and production costs that vary linearly (and therefore continuously) with output, shows that the firms' real option premia erode with the increasing number of competing firms. Grenadier concludes that the real option premium is positive and a maximum for a monopoly, and converges on zero as the number of competing firms increases to infinity. Grenadier also identifies the market with an infinite number of firms with a perfectly competitive market. 44 The firms' real option premia in the case of the oligopolistic equilibrium is between the extremes for the monopoly and perfect competition.

44 In an industry with production-technology costs that are linear and incremental, Kogan (2001) and Leahy (1993) show that competition reduces the value of the real options back to the zero net present value investment rule. 
This suggests that the real option premium for an irreversible investment in a telecommunications technology is greater than zero as the number of firms in a telecommunications market is generally not exceptionally large. 45 Grenadier (2002) also shows that the magnitude of these premia is socially optimal, given the objective is to maximise the present value of future consumer surplus assuming that the number of firms competing in the market is exogenous. No conclusion can be drawn regarding the optimal number of firms and the implied value of the premia, as Grenadier does not have the process of competitive entry.

Novy-Marx (2007) models competition in a market that has many features consistent with a process of dynamic competition in telecommunications markets. Novy-Marx assumes competing firms' assets are costly, built in increments, and produce a flow of goods or service flow. In the case of telecommunications, once the capacity of a network is installed, the marginal cost of a call is insignificant. Adapting Novy-Marx's analysis to the telecommunications market, Novy-Marx assumes that the market-clearing price for calling conforms to a constant-elasticity inverse demand function, where demand stochastically evolves.

Novy-Marx (2007) concludes:

... in industries in which opportunity costs and heterogeneity are important, real option values are significant, investment decisions are delayed, and investment is lumpy and intermittent. Moreover, this is true even when competition drives oligopoly rents to zero, because significant rents still accrue to the production technology. (Novy-Marx, 2007, p. 1462)

Taking opportunity costs and heterogeneity into account leads to option premia greater than suggested by Grenadier, and firms continue to place significant value on the timing of investment even if an industry converges on vigorous competition.

45 See section 5.4 for discussion on entry and exit in the New Zealand market. In the case of telephony services, up until 2009 there were two mobile network operators and up to three standalone fixed-line operators in some regions. 
Given irreversible, lumpy investments and uncertainty on timing, Novy-Marx (2007) shows that it is optimal for a firm to adopt a mixed strategy of either investing before or after its rival, but it is not optimal to invest at the same time nor on the same scale as the rival. The reason that this is optimal is because it minimises the inter-temporal competition between firms. The result is a heterogeneous mix in the scale and in the timing of investments amongst rivals.

This suggests that there is potentially a complex mix of investment patterns amongst rivals in a dynamically competitive market as firms not only consider the uncertainties in technological developments and demand, but also actions of rivals. This will be illustrated later in this thesis when international evidence on timing of broadband investments is presented, along with evidence on the timing of investments in mobile technology in New Zealand. ${ }^{46}$

\subsection{Summary}

The internet exhibits the basic market conditions of (i) network effects; (ii) rapid development of hardware; (iii) significant sunk cost required to develop software; and (iv) large, sunk costs to build the capability or capacity to supply services and, once built, low marginal cost to supply services. These basic conditions have a significant effect on the conduct of dynamic competition. That is, the conduct of competition is not based on output volume and price at the margin. It is based on providing better quality and/or lower-cost services in order to gain a competitive advantage with the risk that a new competing service will emerge that will result in asset stranding.

This process of dynamic competition is inconsistent with conditions that would logically reduce dynamic competition to static competition. Firstly, the models of dynamic competition that are reduced to static competition assume that competitive conduct is based on a firm's choice of output quantity or price for a homogeneous good or service, which is consistent with conduct where firms seek competitive advantage through investment. Not withstanding this first inconsistency, and assuming that competition is based on a choice of quantity or price, dynamic competition is reduced to static competition for a linear

46 International evidence on timing of broadband investments is presented in Figure 6 and evidence on the timing of investments in mobile technology in New Zealand is presented in Figure 7. 
oligopoly structure or there is a stable steady-state market equilibrium in the long run. The description of the basic market conditions indicates that neither of these conditions hold. The average cost of telecommunications services is not constant with output due to incremental, fixed costs that are sunk, and demand is not linear due to network effects.

The role of innovation and investment is a central feature of the conduct of dynamic competition within telecommunications markets. The resulting uncertainty and irreversibility associated with these investments implies that firms place significant value on the timing of these investments. Furthermore, the effect of the level of competition on the timing of the investment is sensitive to the structure of costs. If costs vary continuously with capacity, then at the limit with an infinite number of competing firms, investment timing has no value. However, if the investment in capacity is made in significant increments, then even at the limit with an infinite number of firms, firms will place a value on maintaining flexibility when making investment decisions. 


\section{Regulating access}

A justification for regulating segments of a telecommunications network is because they exhibit natural-monopoly characteristics. It is usual to start an analysis of optimal access pricing by proposing that some segments of a telecommunications network, particularly the local access network, are natural monopolies.47As an incumbent typically vertically integrates the local access network to its own services that are available in competitive retail markets, and competitors in the retail market require access to the local access network, regulation of access to the local access network is seen as a means to promote welfare.

If the sunk cost of building the alternative access network is sufficiently large relative to the size of the market, then it is uneconomic for a competitor to bypass the local loop. It follows that without a competitor the incumbent faces a downward sloping demand curve, thus making it profitable for the incumbent to raise prices above the competitive level. Equation (1), section 2.3, is an index of the exercise of market power. It measures the extent to which prices in a market deviate from the perfect competition standard, where the deviation is measured by $\theta$. However, a condition of drawing inferences from $\theta$ regarding market power depends on the existence of a stable, steady-state, equilibrium.

The telecommunications industry has undergone a transformation with the emergence of the internet that suggests the market equilibrium is not stable. The literature on the optimal pricing of network interconnection cited in sections 3.1 and 3.2 assumes that retail access to a telephony network and calling are in separate markets, and that there is a stable association between these retail services and physical elements of a telephony network. $4^{8}$ The development of the

\footnotetext{
47 Analyses of optimal access pricing that start by proposing that access to a telecommunications network is a natural monopoly include Mitchell \& Vogelsang (1991, p. 14), Vickers (1995), Armstrong, Doyle, \& Vickers (1996), Armstrong (1998), Laffont \& Tirole (1994) and (2000, p. 16), Armstrong (2002, p. 297), Dewenter \& Haucap (2007, pp. 2, 5), and Gans (2007, p. 42).

${ }^{48} \mathrm{~A}$ distinction is made throughout this chapter between telephony services and the internet. Telephony services are the traditional access to, and calls carried over, a publicswitched telephone network. The internet is access to the internet, which includes dial-
} 
internet altered this association, resulting in the significant transformation of the industry structure. It is this transformation that is of particular interest as it suggests that industry structure was not as stable as assumed by this literature.

Carlton \& Perloff (2004, p. 4) show that market structure depends on demand and supply conditions. If these basic conditions are stable, then market structure will be stable and thus exogenous to the optimisation problem. However, as discussed in the preceding chapter, these basic conditions are not stable. Uncertainty has a significant influence on firm conduct and thus industry structure. Furthermore, under these conditions, when investment is irreversible, optional regulated wholesale access prices compensate for the cost of a firm's forgone investment opportunities. Not compensating for these forgone opportunities is likely to lead to under investment that is detrimental to dynamic efficiency.

Defining separate markets for an access service and calling service, or alternatively treating access and calling as part of a single telephony service, determines the structure of any search for competitive substitutes. Defining and then finding a lack of competition in a 'market for access' or a 'market for calling' may result in suboptimal outcomes if the effect of a constraint on the access fee or calling price recognises neither a firm's nor a consumer's incentives.

A numerical example, based on the theory of two-part tariffs set out in appendix $\mathrm{B}$, is used to illustrate the effect on these incentives on the structure of a twopart tariff and market performance. The central observation is that market performance is not separable into an optimal access fee or an optimal call price that can be determined independently. The optimal access fee and call price are not independent of each other, and the structure of the optimal two-part tariff differs depending on whether the objective is to maximise a firm's profits or to maximise consumer surplus subject to a non-negativity constraint on the firm's profits.

This chapter starts by examining the assumptions made in the literature on optimal pricing of network interconnection about the structure of the telephony 
market, and considers the role of conduct on determining industry structure. The discussion then turns to the implications of treating access and calling as separate services on allocative efficiency. This is followed by a discussion on the economic objective of regulation, which is proposed to be to optimise dynamic efficiency, explaining the distinction between industry specific and antitrust regulation. Finally, attention turns to factors to consider when determining whether or not a market is competitive, particularly when that market is dynamic.

\subsection{Structure of the telephony market presented in the literature}

Much of the literature on pricing of interconnection access to a telephony network relies on the premise that there is a stable association between physical network elements and pricing of telephony services. 49 The development of the internet illustrates that this association is not stable, and that it is the product of the conduct of industry participants given uncertain consumer demand and uncertain supply of technological innovation. Industry structure followed from the technological and contractual arrangements that firms employ to make services available. As discussed in appendix A, both the telephony network and the internet network employed essentially the same basic technological inputs; however, it is the change in the arrangement of these basic inputs that has led to the observed change in industry structure.

\footnotetext{
49 For example, see Armstrong, et al. (1996), Burnell, Evans, \& Yao (1996), Armstrong (1998), Laffont \& Tirole (1994), Laffont, Rey, \& Tirole (1998a) (1998b), Carter \& Wright (1999), Laffont \& Tirole (2000, pp. 97-136), Armstrong (2002, pp. 297, 298-337), Vogelsang (2003), Dessein (2003), and Dewenter \& Haucap (2007, p. 6).
} 
Laffont \& Tirole's (2000, p. 100 Figure 3.2) illustration of one-way (OW) interconnection, presents the generally accepted view of industry structure:50

Figure 2: Telephony market structure with long-distance competition

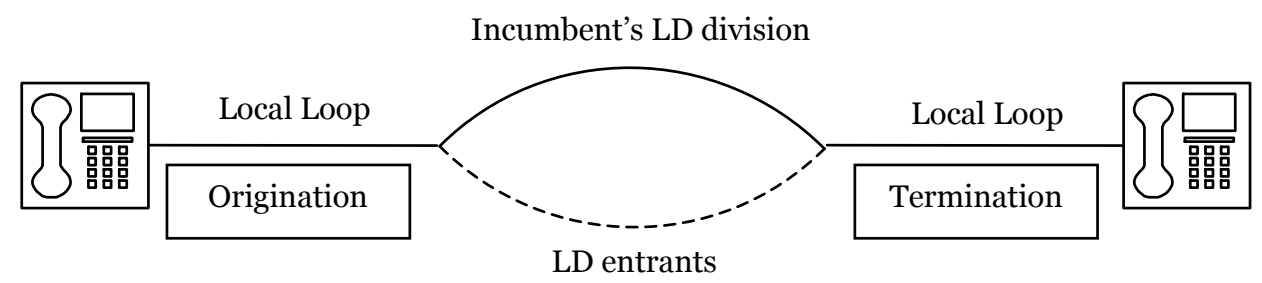

Source: Laffont \& Tirole (2000, p. 100 Figure 3.2)

Using Laffont \& Tirole's (2000, p. 100) terminology, the structure shows that the incumbent owns the local loops ${ }^{51}$ and a long-distance (LD) toll-call network, and the competing entrants own a separate LD network. In order to provide a competing LD service, entrants require OW interconnection to the incumbent's local loop to originate and terminate toll calls with consumers connected to the incumbent's local loop. LD calls remain distinct and separate from calls that remain within the local loop.

The industry structure implied by Figure 2 conflates the access and calling prices with segments of the network's physical elements. That is, the physical elements that make up the local loop are associated with access prices and the physical elements that make up the LD network's LD prices. The effect is that access and calls are treated as separate services that are determined by grouping network elements into specific geographic areas defined by the network architecture. The

\footnotetext{
$5^{50}$ The structure of one-way interconnection assumed by Armstrong, et al. (1996), Burnell, Evans, \& Yao (1996), Armstrong (1998), Laffont \& Tirole (1994), Laffont, Rey, \& Tirole (1998a) (1998b), Carter \& Wright (1999), Laffont \& Tirole (2000, pp. 97-136), Armstrong (2002, pp. 297, 298-337), Vogelsang (2003), Dessein (2003), and Dewenter \& Haucap (2007, p. 6) is consistent with Figure 2.

${ }^{11}$ The local loop is the fixed-line, copper-wire access to the telephony network. Alternative access technologies include optical fibre and wireless.
} 
topology of the local loop defines the local-calling areas, and the network elements that connect the local call areas form the LD call services.

An implication of separating the access and LD calling services, on the pricing of OW interconnection, is that the structure of the pricing of OW interconnection follows the structure of LD prices. In New Zealand, the OW interconnection tariff structure is typically a uniform price per minute. However, as Burnell, et al. (1996) explain, the efficiency of two-part tariffs is superior to a uniform price per-unit time OW interconnection contract, emphasising that the incumbent has the incentive to negotiate a two-part tariff contract that is consistent with a decreasing average cost structure of the network, if there is competitive partial bypass of the local loop and subject to competition law..$^{2}$

This association between the telephony tariff and the physical network elements continues through to two-way (TW) interconnection.53 TW interconnection differs from OW interconnection in that OW interconnection is where entrants need to purchase interconnection from the incumbent and the incumbent does not need to purchase interconnection from entrants, whereas TW interconnection is where all firms need to purchase interconnection from each other. 54 TW is illustrated by Figure 3 .

The industry structure for TW interconnection continues the OW model by associating the local loop with consumers' access to a telephony service and the LD network with the toll call. It follows that OW and TW interconnection contracts are distinct. 55 Similar to OW interconnection, separating the access and LD calling services has resulted in the structure of TW interconnection prices following the structure of local-call prices. 56

$5^{2}$ See section 3.6 for further discussion of Burnell, et al. (1996).

53 See Laffont, et al. (1998a), Laffont \& Tirole (2000, pp. 118-119, 179-215), and Armstrong (1998, 2002, pp. 358-359).

54 Armstrong (2002, p. 297).

55 This point is made by Laffont \& Tirole (1994, pp. 1690-1692, 2000, pp. 118-119), and Armstrong (2002, pp. 316-321).

${ }^{56}$ In New Zealand this has resulted in a transition to significantly different TW interconnection prices over time with the development of the internet, which is expanded on in section 5.2 . 
Figure 3: Telephony market structure with LD and local-loop competition

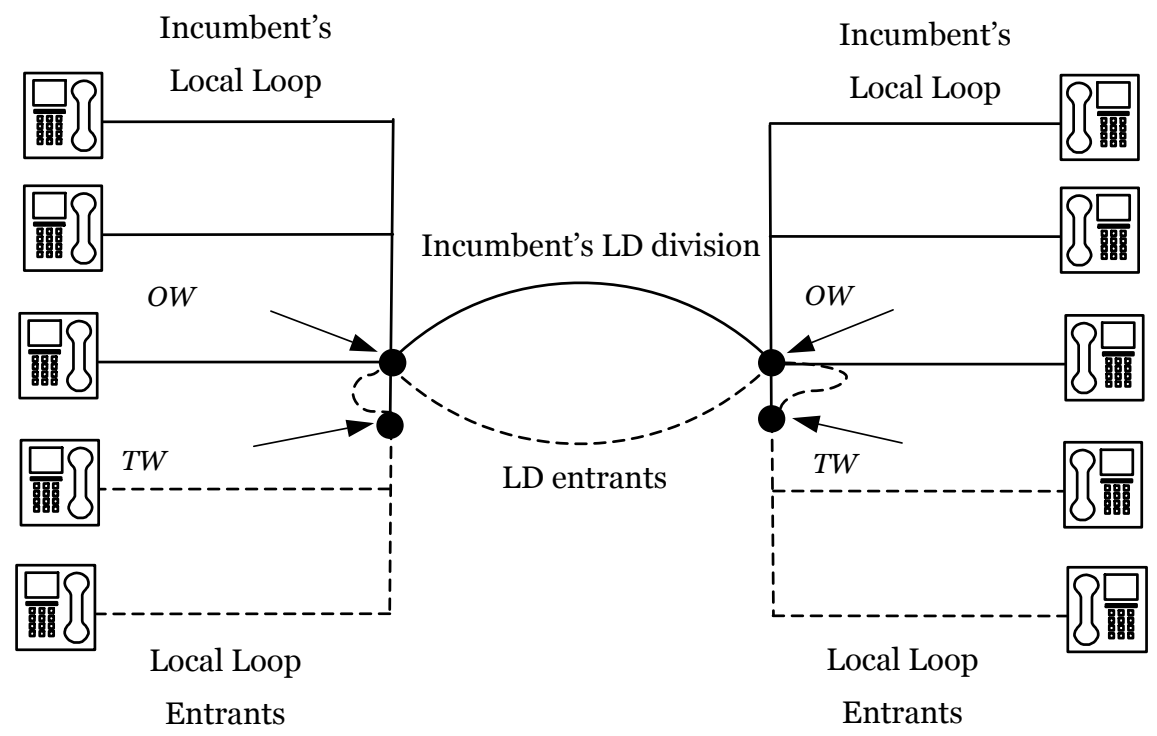

\subsection{Telecommunications industry structure with the internet}

Figure 4, below, illustrates the industry organisation associated with the internet, which replaced the telephony market structure, shown in Figure 3. Comparing Figure 4 with Figure 3 indicates the differences between the structure of the telephony market and the internet market.

Figure 4: Internet market structure

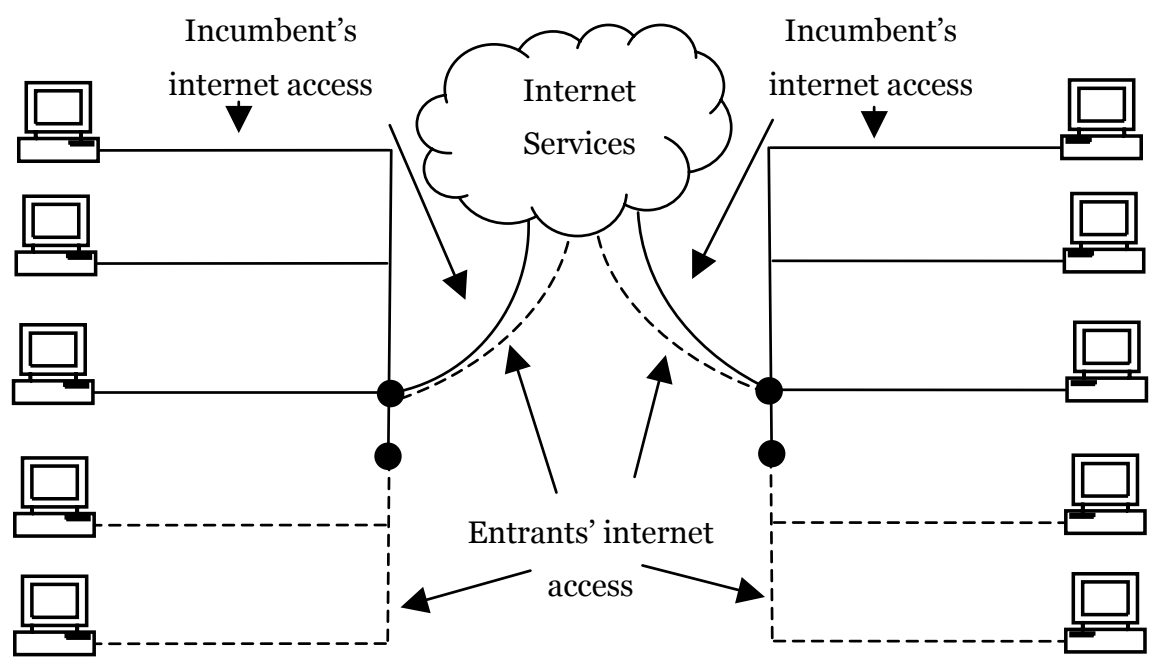


In contrast to the telephony market structure, the structure of the internet does not associate specific physical network elements with access or internet services. In the internet market, access to services may extend beyond the local loop and may or may not include those physical network elements that had previously been considered part of the LD service. The analogue to local loop point of interconnection of the telephony market is the peering point of the internet. The development of peering and transit contracts, which interconnect the transmission networks around the internet, has relaxed the association between services and physical network elements. ${ }^{77}$ These contracts are negotiated between firms, who agree on either a peering or transit contract, and the location of the point of interconnection. Furthermore, the wholesale service is not determined by any of the retail services carried out over the internet. This has allowed services provided over the internet, including calling, to be generally, technically and contractually independent of the telecommunications network that their customers are connected to. $5^{8}$ This has also facilitated a significant increase in the range of services carried over the telecommunications network, compared with just one voice calling service available on a telephony network, as well as allowed the availability of the internet services to be international. 59

\subsection{Conduct and market structure}

A proposition that generally underpins an analysis of one-way and two-way interconnection is that the conduct of an incumbent and rivals proceeds from a stable industry structure. ${ }^{60}$ The same proposition, that industry structure is stable, underpins the conjectural-variations framework discussed in section 2.3. The conjectural-variations framework defines an index $\theta$ equation (1) of market power along a continuum between the extremes of perfect competition and

\footnotetext{
57 See appendix A.10 for a discussion on the structure of the internet peering and transit contracts.

$5^{8}$ See appendix A.9 for a discussion on the provision of services over the internet.

59 See appendix A.3 for a discussion on the growth of the internet.

6o See sections 3.1 and 3.2 for examples of literature on one-way and two-way interconnection.
} 
monopoly. ${ }^{61}$ The analysis of optimal interconnection prices is essentially the same as determining the value of $\theta$ that optimises efficiency. However, when dynamic factors are present - such as network effects, technological change, and dynamic competition - the validity of inferences drawn from the conjecturalvariations framework, and by implication interconnection pricing that relies on static models, must be considered with caution.

Sutton (2007) explains that in a market with stable demand and supply conditions, the firms' competitive conduct is a key determinant of industry structure. He proposes that an increase in the intensity of competition leads to a decrease in the number of firms in a market. That is, the conduct of rivals determines market structure. The alternative is the model of the market structure that associates a monopoly with a single firm, and perfect competition that is price based with the presence of many firms in a market. Sutton draws support for his proposition from the observation that the introduction of antitrust regulation (ATR) prohibiting cartels has led to industry consolidation, and countries that are lenient on cartels have less market concentration than those that are not. Sutton does not attempt to distinguish between the competitive strategies; however, the central observation relevant here is that even within a static model, market structure is dependent on the conduct of rivals.

Sutton (2007) focuses on the effect of firms' competitive conduct on the number of firms participating in a market, particularly market concentration. In contrast, this thesis focuses on the effect of contractual and technical associations on industry structure in a market with unpredictable demand and supply conditions. Not withstanding this difference, Sutton's analysis is useful as it isolates how the competitive conduct of firms, given stable basic conditions, can determine market structure. It lends weight to the proposition that the transformation of the structure of the telecommunications industry, defined by the association of technological and contractual elements, is uncertain as it depends on the conduct of market participants. However, Sutton limits uncertainty to the competitive conduct of firms. The fact that uncertainty in telecommunications markets extends beyond the conduct of firms to encompass

${ }^{61}$ See discussion in section 2.3 regarding equation (1). 
uncertainty in demand and supply conditions would seem to add further weight to Sutton's proposition that structure follows from the conduct of rivals. This is because the conduct of firms, and particularly their investment decisions, is also influenced by the general scope of uncertainty in the telecommunications market in supply and demand conditions.

\subsection{Implications of separating access and calling}

Consumers have the option to subscribe or not to subscribe to a mobile service, as well as the option to subscribe or not to subscribe to a fixed-line telephony service, resulting in four outcomes are: (i) consumers do not subscribe to either service; (ii) they subscribe to only the fixed-line service; (iii) they subscribe to only the mobile service; or (iv) they subscribe to both the fixed-line and mobile services.

Mao, Tsai, \& Chen (2008) observe two forms of fixed-to-mobile substitution. First, Mao, et al. observe that in G7 and new industry economies (NIE) countries $^{62}$, where there is a high penetration of fixed-line access, consumers mostly substitute their call traffic between their fixed-line and mobile services. Second, they observe that in countries without a high historical penetration of fixed-line access to a telephone network and where there is less than one fixedline phone per household, the pattern of fixed-to-mobile substitution is mostly substitution between fixed-line and mobile access. Mao, et al. conclude that for the Association of South East Asian Nations (ASEAN), and Brasil, Russia, India and China (BRIC), ${ }^{63}$ the pattern of fixed-to-mobile substitution mostly takes the form of access substitution. 64

Extrapolating Mao, et al.'s (2008) results to a New Zealand context suggests that most fixed-to-mobile substitution would take the form of consumers

\footnotetext{
62 G7 countries include France, United Kingdom, Germany, Canada, Italy, United States, and Japan. The NIE countries are Taiwan, Singapore, Hong Kong, and South Korea.

63 ASEAN countries include Malaysia, Thailand, Philippines, and Indonesia.

64 In addition, Rodini, Ward, \& Woroch (2003) estimate cross-price elasticities between a household's demand for a second fixed line and a mobile service, using data from a United States household survey conducted over the period 2000-2001, and conclude that second fixed lines and mobile services are substitutes. The authors did not analyse the substitution effects between a household's demand for a first fixed line and mobile services, as at that time the demand for the first line was constant.
} 
substituting their calling between fixed-line access and mobile access, as nearly all households in New Zealand had a fixed-line phone at the time the market was opened to competition in 1989. Table 7 in appendix A.5 reports that from 2000 to 2007 the penetration of mobile services in New Zealand grew at a compound average growth rate (CAGR) of $13 \%$. There has been a small but noticeable decline in the penetration of fixed-line telephone access of $1 \%$ for New Zealand. ${ }^{65}$ That is, the significant growth in mobile penetration in New Zealand cannot be correlated with a corresponding reduction in the penetration of fixed-line access.

Mao, et al.'s (2008) results raise a question regarding the definition of 'the market'. It may suggest there are separate markets for access and calling. Competition analysis would then consider whether or not there is competition within the 'access market' and the 'calling market', and thus whether competition between fixed-line and mobile services within these 'markets' is sufficient to constrain firms' actions. Taking this approach, Mao, et al.'s results suggest that for the G7 and NIE countries, there is competition in the calling markets but not in the market for access, whereas in ASEAN and BRIC countries, there is competition in the market for access. However, drawing this conclusion for the G7 and NIE countries would fail to recognise that access and calling are not markets but are pricing elements of a two-part tariff for a single market.

The theory of two-part tariffs expounded in appendix B shows that the access fee and call price are elements of a two-part tariff for services in a telephony market. In particular, the theory examines the effect of income on the optimal two-part tariff, separating out the effect of income on the demand for calling from an individual's participation decision, showing how different assumptions regarding these effects leads to different tariff structures. This result would suggest that a reason (in addition to the historic penetration and coverage of the fixed network) for the observed difference in the form of substitution between ASEAN/BRIC countries and the G7/NIE countries is the difference in the income of consumers between these countries.

65 For comparison, from 1998 to 2005 the penetration of mobile access across OECD countries grew at a compound average growth rate (CAGR) of $19 \%$, and the penetration of fixed-line telephone access declined at a CAGR of -2\% across OECD (see Table 7, Appendix A.5). 
Mao, et al. (2008) provide data which indicates that the expenditure share of income on telecommunications services for the ASEAN and BRIC countries is significantly greater than for the G7 and NIE countries, due to the lower income in ASEAN and BRIC countries. Chen, et al. (2008) examine in more detail the role that income plays in the uptake of the mobile services and the substitution with fixed-line access and calling. They define an income effect based on their observation that once, on average, expenditure share of income, represented by the average revenue per user on fixed and/or mobile services over GDP per capita, drops below $5 \%$ then mobile penetration increases considerably. This decrease in expenditure share is presumably due to price decreases and not decreases in demand. Using data spanning 1997 to 2005, Chen, Tsai, \& Mao (2008, p. 630) highlight that G7 countries' expenditure on the sum of fixed and mobile services dropped from an expenditure share of $5.8 \%$ in 1997 to $4.6 \%$ in 1999 and 3.6\% in 2004. For NIE countries this expenditure share dropped from $8.6 \%$ in 1997 to $4.8 \%$ in 2000 and to $4.0 \%$ in 2004 . There was a corresponding increase in the penetration of mobile services with an observed decrease in the penetration of fixed-line services. However, the expenditure share of the sum of mobile and fixed-line services did not drop below $5 \%$ for ASEAN and BRIC countries, although for all countries in these groups there was a significant decline in the expenditure share solely of mobile services, which for some countries dropped below $5 \%$. For the ASEAN and BRIC countries this led to substitution between fixed and mobile services.

Chen, et al. (2008) and Mao, et al. (2008) support the proposition that a telecommunications service is a normal good, and that income influences whether competition between mobile and fixed-line services manifests itself as either access or calling substitution.

\subsubsection{Description of consumer behaviour}

A theory of consumer behaviour and two-part tariffs is presented in appendix B that brings together the access fee and call price within a coherent model of consumer behaviour. The model of consumer behaviour is based on the standard assumptions of utility maximisation, with the additional assumptions that consumers have the option to not subscribe to a telephony service, and that consumers who do not subscribe will subscribe as their income increases - i.e. 
normal participation behaviour. The model is used to analyse optimal two-part tariffs with endogenous participation.

Suppose all individuals in the population have the same preferences, income differentiates consumers, and that consumers derive utility from making telephone calls $x$ on a mobile network and consuming a composite non-mobile $\operatorname{good} z$ that includes telephone calls on a fixed-line network:

$$
u(x, z)
$$

Utility is twice continuously differentiable everywhere, strictly increasing, and is strictly concave for all individuals.

Individuals consume the composite non-mobile good that includes the fixed-line telephony service, and individuals have the option to not make telephone calls as there are other modes of communication, which implies:

$$
\begin{aligned}
& x \geq 0 \\
& z>0
\end{aligned}
$$

If a unit of the non-mobile composite good has a unit price, and an individual with total income $y$ does not make any mobile calls, then the utility derived is:

$$
u(0, y)
$$

A necessary condition for individuals to subscribe to the mobile service and make mobile calls is that their utility from subscribing and calling is greater than or equal to their utility from not subscribing:

$$
u(x, z) \geq u(0, y)
$$

The arguments of the utility functions on either side of the inequality are not the same, resulting in a discontinuity in demand due to the participation decision. The term on the left-hand side of the greater-than-or-equal-to sign is the utility derived from subscribing and making mobile calls, whereas the term on the right-hand side is the utility derived from not subscribing and making mobile calls. If the term on the left is strictly greater than the term on the right then the individual is an infra-marginal mobile subscriber. If the equality holds, then the individual is a marginal mobile subscriber. In this case, the individual is 
assumed to subscribe even though they are indifferent to subscribing and not subscribing. If the condition does not hold then the individual will not subscribe. In the following discussion, an infra-marginal mobile subscriber and marginal mobile subscriber will be referred to as an infra-marginal subscriber, marginal subscriber, or just a subscriber. It is assumed that irrespective of whether or not consumers subscribe to the mobile service, they will continue to subscribe to the fixed-line services. This is consistent with the observations made in the literature, and in the case of New Zealand. ${ }^{66}$

Subscribers' outlay on a mobile service is determined by a uniform two-part tariff that includes a fixed-monthly fee $f$ for access to the mobile network and a price $p$ per call for calls made by the subscriber. A subscriber's total outlay on non-mobile goods and the telephony service must satisfy the budget constraint:

$$
z+p x+f \leq y
$$

where $y$ is an individual's income. Individuals base their consumption decision on the trade off between making mobile calls and consuming non-mobile goods including fixed-line telephony calls. If they subscribe they will pay the access fee, resulting in a reduction in the available funds to outlay on calls and non-mobile goods.

Following from the concavity of utility and the budget constraint, a subscriber's optimal demand for mobile calls and non-mobile goods are, $x(p, y-f)$ and $z(p, y-f)$. Substituting these demand functions into equation (10) gives an alternative representation of the subscription decision in terms of the indirect utility:

$$
v(p, y-f) \geq u(o, y)
$$

This is an individual's participation constraint. Furthermore, it is assumed there is an income $i$ that will satisfy the equality:

$$
v(p, i-f)=u(\mathrm{o}, i)
$$

\footnotetext{
${ }^{66}$ See discussion in appendix A.5.
} 
This states that the income of marginal subscribers is $i$.

In addition, two general conditions - equations (35) and (36) - sufficient to ensure that participation in the mobile network is a normal-good are presented in appendix B.2. These conditions have influenced the choice of utility function used for the numerical example. They ensure that for a given two-part tariff, continuing to increase the income of consumers that initially do not subscribe as their initial income $y<i$ will eventually lead to them subscribing to the mobile service when $y>i$.

\subsubsection{Numerical example illustrating the effect of competition}

The theory of two-part tariffs described in appendix B has influenced the choice of the Stone-Geary function:

$$
u(x, z)=(x+60)^{0.2} z^{0.8}
$$

where $u(x, z)$ is utility, which is a function of mobile calls $x$ and non-mobile goods $z$. An individual's objective is to choose $x$ and $z$ that maximise utility subject to the budget constraint equation (11). The parameters are $p$, the price per call, $f$, the access fee, and $y$, an individual's income. Faced with this optimisation problem, an individual's demand functions are:

$$
\begin{gathered}
x(p, y-f)=\frac{0.2(y-f)}{p}-48 \\
z(p, y-f)=0.8(y-f)+48 p
\end{gathered}
$$

This allows the determination of the indirect utility function, and with equation (13), yields the income $i$ of the marginal subscriber:

$$
0.8(4 p)^{-0.2}(i-f+60 p)=60^{0.2} i^{0.8}
$$

It is assumed that individuals are uniformly distributed over the income interval $[0,1000]$, and that the total population size is 1000. This allows the total number of subscribers to be determined by: 


$$
M(i)=\int_{i}^{1000} d y
$$

Also, the aggregate of individual subscribers' demand for calling is determined by:

$$
X(p, f, i)=\int_{i}^{1000} x(p, y-f) d y
$$

The firm's profit function is:

$$
\Pi(p, f, i)=p X(p, f, i)+(f-g) M(i)-H(X(p, f, i))
$$

Network costs are separated into mobile network elements with properties that are representative of networks in the real world. The marginal cost of providing a consumer with access to the network is represented by the parameter $g$. In addition, to access network elements there are core network elements, which in the case of a mobile network includes switching and transmission equipment. The cost of the core network element is represented by the cost function $H(X)$, which is the minimum cost to supply the total demand for calling. It is assumed that the marginal cost of a call is positive, $H_{X}(X)>0$, and is concave in calling. A key aspect of this assumption is that the core network is a common cost. All of these costs are static. For the numerical example, suppose that the marginal cost per call is $H_{X}(X)=0.01$ and $H_{X X}(X)=0$. The fixed cost of the network, which is common to calling and access, is $H(\mathrm{o})=75,000$, and the cost per mobile network participant is $g=10$.

Table 1 presents the performance of the optimal two-part tariff under four scenarios. The column headed " $\Pi(*)$ max." gives the values of $f$ and $p$ that maximises profit, equation (20), subject to the participation constraint, equation (13). ${ }^{67}$ The next column gives the value of the profit maximising two-part tariff, subject to the constraint that $p=0.01$. Under this scenario, the firm's choice of the access fee is not subject to competition as it has a monopoly for mobile

${ }^{67}$ See appendix B.5 for a description of general conditions of profit maximising two-part tariffs. 
service; however, there is Bertrand competition between fixed-line and mobile calls which leads to the price of mobile calls being set equal to the marginal cost of a call. Allowing for fixed-to-mobile call substitution is consistent with Chen, Tsai, \& Mao's (Chen, et al., 2008) observations. The column titled $\Pi(*)=0 p=0.01$ includes the potential for the entry of a competing mobile service. The potential for entry results in the firm setting prices so that it breaks even subject to $p=0.01$. An implication of $p=0.01$ is that the common cost $H(\mathrm{o})=75$, ooo is recovered by a mark-up included in the access fee. The last column presents the two-part tariff that maximises total consumer welfare subject to the breakeven constraint on the firm's profits. ${ }^{68}$

Table 1: Numerical example of performance of optional tariff

\begin{tabular}{|c|c|c|c|c|}
\hline & $\Pi(*) \max$. & $\begin{array}{c}\Pi(*) \max . \\
p=0.01\end{array}$ & $\begin{array}{c}\Pi(*)=0 \\
p=0.01\end{array}$ & $\begin{array}{c}\text { Welfare } \\
\text { Max. }\end{array}$ \\
\hline Call Price $p$ & 0.022 & 0.01 & 0.01 & 0.012 \\
\hline Access Fee $f$ & 248 & 313 & 105 & 85 \\
\hline Marg. Customer $i$ & 499 & 541 & 213 & 185 \\
\hline Total Calls & $2,216,049$ & $4,172,282$ & $7,848,959$ & $6,828,940$ \\
\hline Profit & 71,889 & 63,972 & 0 & 0 \\
\hline Agg. Cons. Welfare & 416,848 & 424,788 & 620,914 & 623,116 \\
\hline Total Welfare & 488,737 & 488,760 & 620,914 & 623,116 \\
\hline
\end{tabular}

The table shows that the profit-maximising choice of $f$ increases and $p$ decreases to $p=0.01$, compared with the scenario where the firm can choose both $f$ and $p$. The introduction of the constraint $p=0.01$ reduces the firm's profits and the number of subscribers (as indicated by the increase in $i$ ), increases the aggregate consumer welfare, and results in a relatively small increase in total welfare. Even though the number of subscribers decreases,

${ }^{68}$ See appendix B.6 for a description of general conditions for constrained, consumer surplus maximising two-part tariffs. 
there is a substantial increase in total calls due to the reduction in $p$. The presence of the substantial profit may be sufficient to induce or raise the potential for competitive entry. This would result in an additional constraint on the firm's profit $\Pi(*)=0$ which reduces $f$. This in turn increases the number of subscribers (as indicated by the decrease in $i$ ), total calls, and aggregate consumer surplus and total welfare. The two-part tariffs under the scenarios headed $\Pi(*)=0 p=0.01$ and under the consumer welfare maximising scenario are similar.

Table 1 also illustrates that the objective function not only determines the level but also the structure of the optimal two-part tariff, as implied by RamseyBoiteux pricing (Boiteux, 1971). It is optimal for a firm that produces many products with a profit constraint to price each product such that the ratio of the mark up, which is the difference between a product's price and marginal cost, over the marginal revenue with respect to the quantity of the product demanded, is constant across all products. The value of the constant will depend on the value of the profit constraint. Comparing $f$ and $p$ under profit maximising and welfare maximising headings illustrates that this condition may not hold in the case of two-part tariffs. To illustrate this point, if the access and calling conforms to a constant elasticity demand function, then Ramsey-Boiteux pricing implies that the following equality will hold:

$$
\frac{\left(f_{\Pi \max }-g\right)}{f_{\Pi \max }} / \frac{\left(f_{C S \max }-g\right)}{f_{C S \max }}=\frac{\left(p_{\Pi \max }-H_{X}(*)\right)}{p_{\Pi \max }} / \frac{\left(p_{C S \max }-H_{X}(*)\right)}{p_{C S \max }}
$$

where $f_{\Pi \max }$ and $p_{\Pi \max }$ are the profit maximising access fee and call price, and $f_{C S \max }$ and $p_{C S \max }$ are the constrained consumer-surplus maximising access fee and call price. Substitution of the appropriate values from Table 1 into this equation shows that the equality does not hold: 


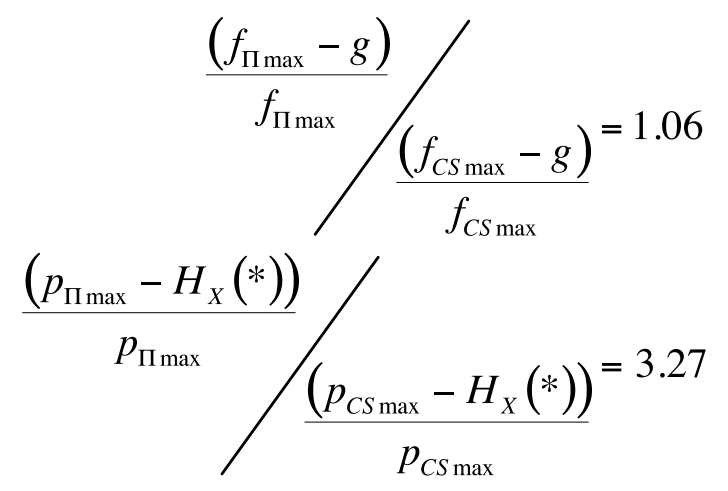

This illustrates that the objective function not only determines the level but also a structure of the optimal two-part tariff that differs from a structure implied by Ramsey-Boiteux pricing (Boiteux, 1971). The reason it is desirable that two-part tariffs must jointly consider access and usage is that consumer utility is not separable into these elements and vary with characteristics such as income.

The results presented in Table 1 do not provide a definitive conclusion regarding the efficiency or even the relative efficiency of particular two-part tariffs. The reason for this is that these models are static and do not take into account uncertainty in demand and supply conditions, nor uncertainty in competitive conduct. For example, mobile and fixed-line networks have invested in broadband internet access technologies, which suggests a process of dynamic competition. ${ }^{69}$ As the discussion on the conjectural-variations framework shows, ${ }^{70}$ drawing inferences about dynamic processes from static models requires a stable steady-state equilibrium. ${ }^{71}$

${ }^{69}$ Quigley \& Sanderson (2005) emphasise that competition between mobile operators in Canada and the United States is dynamic, where the operators seek to gain a competitive advantage by investing in new services. They also highlight that the mobile markets had progressed to the point where mobile telephony and fixed-line telephony should be considered in the same market as competitive substitutes. The implication for industry specific regulation is that if fixed-line telephony and mobile telephony are in the same workably competitive market then a regulator should exercise forbearance or otherwise risk decreasing dynamic efficiency.

70 See section 2.3 for further discussion on conjectural variations.

${ }^{71}$ The assumption that there is only one uniform two-part tariff is also a limitation, whereas a schedule of two-part tariffs or nonlinear tariffs may lead to a superior outcome. Willig (1978), noting that even though a single two-part tariff can enhance aggregate consumer welfare compared with a single uniform price per-unit, demonstrates that a single two-part tariff may enrich consumers with high incomes at 
When analysing the performance of observed prices, the two-part tariff results illustrate that the access and pricing elements of a two-part tariff cannot be analysed in isolation of each other. This is illustrated with the profit maximising prices. Furthermore, the relationship between the access fee and call price differs from the Ramsey-Boiteux pricing. The implication of separating the calling and access into separate markets is that Ramsey-Boiteux pricing may not be optimal. If access and calling were in separate markets, then the optimal access fee and call price would equal the marginal cost of calling plus a mark-up that is proportional to the inverse price elasticity of calling.

\subsection{Dynamic efficiency of regulating access to natural monopoly}

Now consider the regulation of an incumbent that vertically integrates an asset with natural monopoly characteristics, which is a necessary input to a downstream competitive market. An example is an incumbent that vertically integrates a local-loop monopoly and long-distance calling market, as illustrated by Figure 2. In this case, the access contract of interest is interconnection. Another example involves, again, the local-loop monopoly, but this time where the downstream market is broadband internet access, as illustrated by Figure 4 . The form of the access contract of interest here is the unbundled local-loop service. ${ }^{72}$

It is assumed in this section that the sunk costs of the local loop are sufficiently large relative to the size of the market to make it uneconomic for competitive entry, thus resulting in the natural monopoly. ${ }^{73}$ Furthermore, it is assumed that the natural monopoly allows the firm not only to determine the price of access to

the expense of consumers with low incomes. Therefore, Willig concludes, it is Paretosuperior to offer consumers both uniform and two-part tariffs.

${ }^{72}$ The unbundled local-loop service consists of leasing a firm's access to the individual copper wires between the incumbent's exchange and a consumer's premises. The firm then installs its own equipment in the incumbent's exchange and connects it to the end of the copper wires in order to provide consumers with a broadband internet service.

${ }_{73}$ Sunk costs include the direct cost sunk and opportunity cost of the real options sunk when making the investment and building the asset. Regarding the opportunity cost of real options, Pindyck (2005b, p. 2) points out that "uncertainty over future market conditions 'amplifies' the direct sunk cost of entering a market, and can thereby reduce the extent of entry and raise prices." 
the monopoly asset, but also the timing of irreversible investments in the monopoly. The timing of this investment is assumed to have significant value, due to the significant scale of the irreversible investment and uncertainty in the basic market conditions.

\subsubsection{Dynamic efficiency of regulation}

It is proposed that the objective of regulation is to maximise dynamic efficiency. 74 In order to clarify the key relationships between dynamic efficiency and the setting of regulatory policy, dynamic efficiency is defined by 75 :

$$
D E_{\mathrm{o}}=\frac{\max }{\gamma_{-1}} E_{\mathrm{o}}\left(\sum_{t=0}^{T\left(\gamma_{-1}\right)} \frac{W_{t}\left(p_{t}\left(\gamma_{-1}\right)\right)}{(1+\rho)}+\sum_{t=T\left(\gamma_{-1}\right)}^{\infty} \frac{W_{t}\left(p_{t}\left(\gamma_{-1}\right) \mid I\right)}{(1+\rho)} \mid I, T\left(\gamma_{-1}\right), \alpha, \sigma, \rho\right)
$$

where dynamic efficiency $D E_{\mathrm{o}}$ is taken at $t=0$. The dynamic efficiency is the expected, present value of current and future total market surplus $W_{t}(*)$ within period $t$, conditional on the timing of the incumbent making an irreversible investment that costs $I$ at $t=T$, where $T \geq 0$. That is, for $0<t<T$ the total market surplus is not subject to the investment. This is represented by the notation $W_{t}\left(^{*}\right)$, whereas after $T$ the total market surplus is subject to the investment. This is represented by the notation $W_{t}(* \mid I)$. Dynamic efficiency is also conditional on the variance in the supply and demand conditions $\sigma$, the change in the value of the investment $\alpha$ over time, and the social discount rate $\rho$.

\footnotetext{
${ }^{74}$ Even though this might be the intended outcome of regulation, Stigler (1971) notes that regulatory outcomes are also influenced by stakeholders lobbying for outcomes that maximise their individual utility.

75 This expression is based on Evans \& Hahn (2010), with the addition of the parameters representing the timing of the firm's investment decision $T$, and the expected change in the consumer's value of the investment $\alpha$. The parameters in equation 23 are the same as those in equation (5), section 2.4, except that in equation 23 they are over discrete time intervals, whereas in equation (5) time is continuous.
} 
The aim of regulation is to maximise dynamic efficiency by choosing a suitable policy $\gamma_{-1}$ at $t=-1$, recognising that prices $p_{t}\left(\gamma_{-1}\right)$ and the timing of the firm's investment decision $T\left(\gamma_{-1}\right)$ may depend on this policy.

The parameter $\alpha$ represents the change in the value of the investment $I$ over time due to technology. In the case of telecommunications, the example presented in section 2.4 to illustrate how the value of $I$ might change, follows from Moore's Law, which suggests that the performance of electronic technologies within a network doubles approximately every two years. Holding all else constant, speculation might suggest that this rate of increase in technological performance corresponds to a doubling every two years in value to consumers of the investment $I$. The variance parameter $\sigma$ captures the uncertainty in the value of the investment $I$. This includes the uncertainty in demand for new services due to uncertainty in consumer preferences and network effects, as well as uncertainty in the supply of new technologies and in the industry's efficacy to realise the value of the technological progress by developing new software. ${ }^{7}$

The incumbent's objective is to maximise the value of an irreversible investment opportunity, with a direct sunk cost of $I$ at time $T$, represented by:

$$
F(V)=\frac{\max }{p_{t}, T} E_{\mathrm{o}}\left(\sum_{t=0}^{T} \frac{\pi_{t}\left(p_{t}\right)}{(1+\rho)^{t}}+\sum_{t=T}^{\infty} \frac{\pi_{t}\left(p_{t} \mid I\right)}{(1+\rho)^{t}}-\frac{I}{(1+\rho)^{T}} \mid I, \gamma_{-1}, \sigma, \alpha\right)
$$

where $F(V)$ is the value at $t=0$ of the investment opportunity. The value of the investment is the expected value of the sum of the present value of the firm's current and future profits $\pi_{t}\left(^{*}\right)$ within period $t$, conditional on the investment $I$ made at $t=T$. That is, for $t<T$, profits are not subject to the investment $\pi_{t}(*)$, whereas for $t>T$, profits are subject to the investment $\pi_{t}(* \mid I)$. The value of the investment is also conditional on variance in the supply and demand conditions $\sigma$, the change in the value of the investment $\alpha$ over time, the

${ }^{76}$ See discussion in appendix A.8.1 on the internet and a telephony network, and the efficacy with which the networks translate the technological developments of basic electronic input's improved performance. 
discount rate $\rho$, and the regulatory policy $\gamma_{-1}$. For completeness, if $T=0$ then the investment would be made immediately, whereas if $T=\infty$ investment is not expected at any time in the future. Equation (24) shows that the incumbent selects $p_{t}$ and $T$ to maximise $F(V)$. However, this is subject to the regulatory policy and competitive conditions. The choice of $p_{t}$ and $T$ are variable only to the extent that the regulatory policy and the process of competition allow.

\subsubsection{Description of industry specific regulation}

Two general forms of regulation of interest are industry specific regulation (ISR) and ATR. A key difference between ISR and ATR is that, under ISR, a regulatory body determines the price and non-price terms under which firms (known as access seekers) can access the incumbent's monopoly assets, whereas under ATR the access seeker and incumbent commercially negotiate the price and non-price terms subject to court interpretation of competition law. In New Zealand, competition law requires that the incumbent cannot use its market power - in this case due to the natural monopoly - to limit competition in the downstream, retail market. An implication of this difference is that ISR explicitly considers the conduct of the market participants looking forward, or ex-ante, in effect attempting to explicitly estimate equation (23). Conversely, ATR explicitly considers the conduct or a specific act of the participants in relation to an existing commercially negotiated contract, and thus does not attempt an explicit calculation of $D E_{\mathrm{o}} \cdot{ }^{77}$

Another substantive difference between ISR and ATR is that there is a significant possibility that under ISR the regulator may revisit its estimation of $D E_{\mathrm{o}}$ and revise regulatory policy going forward, whereas under ATR this possibility is much less likely. The risk that ISR may revisit past decisions has led to a regulatory 'commitment problem'. Armstrong \& Sappington (2007, pp.

77 Note that the definition of ATR is limited to the question of whether or not a firm has used its market power in order to limit competition. It might be argued that competition law is forward looking where there is a merger or acquisition. In this case the courts would assess whether or not a merger between two firms or the acquisition of one by another would lessen competition and, if it did, whether there were efficiency gains due to, say, gains in economies of scale or scope which could justify the action. Therefore, regulation of mergers and acquisitions has features that are similar to ISR. 
1631-1632) underscore that this is a fundamental problem in the presence of sunk costs, as a regulator with limited commitment to a regulatory policy may choose not to compensate the firm for past investments in order to maximise $D E_{0}{ }^{78}$ Armstrong \& Sappington note that the expropriation may take the form of low regulated prices or permitting entry. If the incumbent anticipates expropriation of some form they will typically undertake too little investment.

As already noted in section 2.4, Dixit \& Pindyck (1994, pp. 136-140) emphasise that it is not optimal for a firm to make an irreversible investment unless the current value of the investment is greater than the direct sunk cost plus a margin that is at least equal to the opportunity cost to invest at a future time, which implies:79

$$
V_{\mathrm{o}}=\sum_{t=\mathrm{o}}^{\infty} \frac{\pi_{t}\left(p_{t} \mid I\right)}{(1+\rho)^{t}} \geq V^{*}>I
$$

Dixit \& Pindyck (1994, pp. 140-147) define the optimal timing of the investment decision in terms of a threshold value $V^{*}$ for the investment. If $V_{\mathrm{o}} \geq V^{*}$ then the optimal time to invest is at $T=0$, whereas if $V_{\mathrm{o}}<V^{*}$ will not and the optimal time to invest will be $T>0$. The investment will be made if its current value is greater than or equal to the sum of the sunk cost of the irreversible investment $I$ and the opportunity cost of waiting. When the investment is irreversible and market conditions are uncertain there is value in waiting to gain additional information as the market conditions develop. Dixit \& Pindyck show, in general, both growth due to technological developments $(\alpha>0)$ (as discussed in chapter $2)$, and uncertainty $(\sigma>0)$ can create value in waiting and affects investment timing. ${ }^{80}$

\footnotetext{
${ }^{78}$ Evans \& Quigley (2000) examine this issue in relation to the enforcement of contracts under competition law.

79 This follows from equation (6), section 2.4, with the inclusion of uncertainty.

80 The present discussion focuses on the option value of waiting before making an investment; however, Alleman \& Rappoport (2002, p. 394) explain that real options can take a variety of forms including the option to abandon an asset, shutdown and restart an asset, delay or default on a project, expand the scale of an investment, amongst
} 
Pindyck (2004, 2005a, 2007) argues that under ISR the access prices to unbundled local loop in the United States are inefficiently low as they do not take into account the option for the incumbent to defer the investment. Hausman, Pakes, \& Rosston (1997), Hausman (1998), and Hausman \& Sidak (2005, p. 188) support Pindyck's assessment of regulatory pricing in the United States. ${ }^{81}$ As will be discussed in chapter 5 , regulatory practice in New Zealand also excludes the value of real options. This policy can be represented by setting the access price $p_{t}^{a}$ such that:

$$
\sum_{t=0}^{\infty} \frac{\pi_{t}\left(p_{t}^{a}\right)}{(1+\rho)^{t}} \equiv I
$$

However, due to the irreversibility of the investment decision and the uncertainty in the basic market conditions, the investment threshold i $V^{*}>I$, which implies:

$$
V^{*}>\sum_{t=0}^{\infty} \frac{\pi_{t}\left(p_{t}^{a}\right)}{(1+\rho)^{t}} \equiv I
$$

Therefore, it is optional for the incumbent to wait and not invest immediately. As long as this condition holds then there will not be investment. Furthermore, notwithstanding the assumption that the incumbent owns the monopoly asset, low regulated price and non-price terms create a free option for firms seeking access. This also adversely affects dynamic efficiency as it reduces the incentives to bypass if bypass were efficient. ${ }^{82}$ Again, due to the uncertainty in basic market conditions, an access seeker's option to bypass the incumbent's local loop may have significant value. However, the access seeker is less likely to exercise an option to invest in bypass assets if the access price to the incumbent's local loop is low. Alleman \& Rappoport (2002), Hausman (1998), Pindyck (2004, 2005a, 2007), Hausman, Pakes, \& Rosston (1997), Hausman (1998), Hausman \& Sidak

others. All these options have value where costs are sunk and there is uncertainty, and highlight the value in maintaining flexibility.

82 Hausman (2000). 
(2005, p. 188), and Hori \& Mizuno (2004, 2006) stress that the failure to allow for the value of deferring an investment lessens the incentive to invest.

Reducing the incentive to invest can have significant implications for consumer welfare. Hausman, et al. (1997) observe the delay in the investment in mobile phone services in the United States had a significantly detrimental effect on consumer welfare, due to the absence of mobile telephony services. ${ }^{83}$ Evans, Quigley, \& Zhang (2003) model the trade-off between dynamic and static efficiency as access prices move closer to marginal cost, and show that there is second-best price above marginal cost and below monopoly at which consumer welfare is maximised. They conclude that setting prices too low undermines the incentives for investment in innovation and may have a substantial negative impact on consumer welfare.

It might be argued that excluding the opportunity cost of waiting enhances the incentive to invest. This may be the case if the opportunity cost of waiting is solely due to factors which are endogenous to the regulatory process. That is, say, a regulator reduces the incentive for rivals to invest and therefore compete, or reduces the commitment to a consistent regulatory pricing policy which provides certainty. However, in telecommunications uncertainty is not solely attributable to the regulatory process. There is also significant uncertainty in demand and supply conditions that are outside the control of any regulatory process, therefore there is significant value in deferring an investment.

As noted, a monopoly has not only the power to determine prices but also the timing of investments. Grenadair (2002) and Novy-Marx (2007) show that in a market with uncertain basic conditions, increasing the number of competing firms enhances efficiency. ${ }^{84}$ As Grenadair and Novy-Marx do not model market

83 Hausman, et al. (1997) show that new telecommunications services can create large gains in consumer welfare. They estimate that consumer welfare gains in the United States at that time for voice messaging services of $\$ 1.27$ billion a year and for cellular telephone services of $\$ 50$ billion a year. Brynjolfsson, et al. (2003) estimate that the increased product variety of online bookstores enhanced consumer welfare by $\$ 731$ million to $\$ 1.03$ billion in the year 2000.

84 Grenadair (2002) and Novy-Marx (2007) both argue that increasing the number of rivals enhances efficiency; however, they differ in the extent to which they believe efficiency is enhanced. Grenadair argues that as the number of rivals becomes large, the value of a firm's option to defer investment becomes negligible. In contrast, Novy-Marx 
entry, the implication of this result for regulation is not that more firms in a market enhance efficiency. Sutton (2007) stresses that it is conduct, not the number of firms, that affects efficiency. The implication for regulation in a dynamic market is that it is required to consider jointly the effect of a policy on pricing decisions and timing of investment. However, there is not a one-to-one relationship between price and timing.

In a static market where market conditions are constant and competition is limited, the idea of market power, where a reduction in competitive intensity allows a firm to set prices greater than marginal cost, suggests that it is optimal to set an upper-bound limit on price in markets. In effect, this policy attempts to emulate or mimic a competitive outcome. Prices above the competitive emulation suggest that a monopoly is exercising market power, whereas prices below this level suggest that the monopoly is not. Real options theory shows that, in a dynamic market, this upper-bound limit must also take into account investment incentives. However, Novy-Marx (2007) also shows that there is not an analogous concept to the upper-bound limit on price for the timing $T$ of an investment. He shows that where there is rivalry, sunk costs and uncertainty, firms minimise direct competition with their rivals by avoiding to invest at the same time and on the same scale as their rivals. That is, there is not a unique optimal time for firms to invest, and real option values appear in prices. Therefore, it is not clear how to define an optimal industry specific regulatory policy which attempts to mimic or emulate particular intensity in dynamic competition.

\subsubsection{Description of antitrust regulation}

Under ATR, an access seeker and incumbent negotiate the price and non-price terms of a contract that is subject to competition law. Competition law requires that the incumbent not exploit its market power and thus limit the process of competition. ATR considers the conduct of the incumbent in relation to a specific contract. The economic question is whether or not the incumbent would have negotiated the same contract had it not possessed market power due to the natural monopoly. 
With reference to the conjectural-variations equation (1), section 2.3, this is analogous to determining whether or not the contract would change if $\theta$ were reduced from a value signifying market power to a value signifying competition. If the view is that the contract would differ, then this indicates that the incumbent used its market power, whereas if the contract would remain the same, then it did not. One implication is that a determination of a misuse of market power does not depend on whether or not the incumbent earns excessive returns. The fact that an incumbent might earn excessive returns is simply a reflection of the fact that it has market power. If the incumbent did not have market power, it is given that it would not have earned excess returns. However, what is relevant is whether or not the incumbent would have negotiated the same contract.

The economic question also implies that it is not generally necessary to calculate $D E_{\text {o }}$ nor determine specific terms and conditions of an optimal contract looking forward (unlike with ISR). However, legal precedent has the potential to influence future contracts. An important example is the New Zealand courts' decision that the use of the efficient component pricing rule (ECPR) for determining interconnection prices is not anti-competitive. In a survey of access pricing, Vogelsang (2003, p. 834) notes the 'simple version' of ECPR states that the access price is sufficient to meet the incumbent's operational cost and the opportunity cost of the asset invested in to provide the access service, where the opportunity cost includes the profits that the incumbent would forgo from the loss of market share to the access seeker due to competition in the retail market. The efficient component price can be calculated by deducting the incremental cost the incumbent avoids by not supplying the retail service off the incumbent's retail price. However, even though ECPR may not be anti-competitive, it may not necessarily optimise (23) as it may allow the incumbent to earn monopoly returns. 
Vogelsang (2003, p. 835) sets out the conditions identified in the literature for ECPR to be welfare-optimal that include:

- The downstream services of the incumbent and entrant(s) are perfect substitutes.

- The entrants have no market power (Bertrand competition downstream).

- The downstream industry process at constant returns to scale.

- There is no bypass in the upstream market.

Using static models, Laffont \& Tirole (1994), and Laffont, et al. (1998a, 1998b) propose a variety of amendments to the 'simple' ECPR model to take into account a variety of situations where these conditions do not hold. In addition, Alleman \& Rappoport (2006) and Clark \& Easaw (2007) use real-options theory to extend the analysis to include uncertainty in demand, drawing the conclusion that opportunity cost includes the option for the incumbent to defer investment. If this opportunity cost is not considered in the investment decision then there would be suboptimal level of investment.

\subsection{Regulatory intervention and dynamic competition}

If the objective of regulation is to maximise $D E_{\mathrm{o}}$, then regulation cannot expect to define a policy that results in an outcome that is superior to a dynamically competitive market. As discussed in chapter 2, dynamic competition ${ }^{85}$ is characterised by rivalry in terms of price, as well as altered, improved or new products or production techniques; brand awareness and reputation; and the provision of information to consumers. ${ }^{86}$ Society benefits from this process of dynamic competition as it induces companies to be internally efficient, allocates

\footnotetext{
85 Dynamic competition is consistent with the legal standard of workable competition where "Workable competition means a market framework in which the pressures of other participants (or the existence of potential new entrants) is sufficient to ensure that each participant is constrained to act efficiently and in its planning to take account of those other participants as are known quantities. To that end, there must be an opportunity for each participant to achieve an equal footing with the efficient participant in the market by having equivalent access to the means of entry, sources of supply, outlets for product, information, expertise and finance"(Donald \& Heydon, 1978).

86 See Quigley (2004) for a discussion on the effect of regulation on the dynamic efficiency of the Canadian telecommunications market.
} 
resources to uses that consumers value, and makes investment decisions in order to gain a competitive advantage. ${ }^{87}$

Therefore, determining whether or not a market is dynamically competitive is necessary for determining whether or not to intervene with regulation. The process of dynamic competition indicates that it is necessary to extend the definition of market power beyond one that implies the conduct of setting price above marginal cost, as described by $\theta$ in equation (6), chapter 2. The exercise of market power needs to take into account the dynamic features of the market, particularly where there are irreversible investments and uncertainty in basic market conditions and the conduct of rivals.

One implication of a dynamic market, as Pindyck (2005b) points out, is that "uncertainty over future market conditions 'amplifies' the direct sunk cost of entering a market, and can thereby reduce the extent of entry and raise prices" (Pindyck, 2005b, p. 2). That is, with reference to the conjectural-variations framework discussed in chapter 2, uncertain market conditions mean the indicator $\theta$ in equation (1) may significantly overstate market power as much of the competition occurs before entry, taking the form of dynamic competition, rather than price competition post entry (Pindyck, 2005b, p. 23). Hence, a static indicator of market power focused on price may suggest that firms are exercising market power when the observed conduct is consistent with an efficient outcome of a dynamic market.

Furthermore, as discussed in section 3.3, the presence of irreversible investment and uncertainty may result in market structures that are profoundly different from those on which static models are predicated. Sutton (2007) argues that significant market concentration in one firm may be an indicator of vigorous, Bertrand competition rather than a source of market power.

The process of transformation from the telephony market structure (Figure 3) to the internet market structure (Figure 4) illustrates a process of technological

\footnotetext{
${ }^{87}$ Schumpeter (1942) describes how dynamic competition leads to technological progress by the process of "creative destruction". The economic value of technological progress to society is highlighted by Solow's (1957) conclusion that $87 \%$ of the economic growth in the United States in the first half of the twentieth century is explained by technological progress rather than by increases in capital and labour.
} 
bypass. The calling service offered over the local loop was replaced with internet services and this process is still developing. This raises the question regarding whether this process of replacement is due to the incumbent exerting market power or, alternatively, whether it is the outcome of a process of dynamic competition. This distinction is important for determining whether a regulatory intervention is required, particularly with respect to those contracts that are specific to the telephony market, such as one-way and two-way interconnection.

Suppose that the local loop is a natural monopoly, and by virtue of some technological integration between the local loop and the telephony technology, the incumbent is able to extend the local loop monopoly to telephony service. This suggests that the incumbent has the means to prevent the development of broadband internet access. One reason for the observed transformation in industry structure could be that it was the incumbent's profit-maximising strategy. The incumbent invested in broadband technologies as it expected to earn greater profits than it expected to earn from the existing telephony technologies. That is, the incumbent's optimised equation (24), where $I$ was the investment in broadband technologies, by choosing $T=0$. The scale of the growth of internet-based services suggests that consumers valued these services, therefore the incumbent may have been attracted to the prospect of increasing profits from the growing telecommunications market. However, even though $T=0$ may be the optimal solution for equation (24), it does not imply that it is the optimal solution for $D E_{0}$, equation (23).

Again suppose that the local loop is a natural monopoly. Now also suppose that the incumbent does not have the technological or institutional means for extending its market power to the telephony services. Internet services could technically bypass the telephony services. The fact that dialup-internet access was available is consistent with this proposition. It seems reasonable to expect that the incumbent would respond to the growth in competition from internet services, particularly if it was unanticipated, by modifying the price and nonprice terms of the contracts for telephony services, and investing in new technologies where they provide a competitive advantage. Therefore, even though the incumbent is assumed to have market power due to the local loop, the extent to which this is transferred to telephony services is tempered by the emergence of internet services. 
An additional plausible reason for the observed transformation in industry structure is that the incumbent did not have market power in the local loop, and the investment in broadband technology was a competitive response to rival firms. Plausible technologies that rivals may have invested in includes mobile technologies.

Laffont \& Tirole (1994, pp. 1690-1692, 2000, pp. 118-119), Armstrong (2002, pp. 316-321), and Armstrong, Doyle, \& Vickers (1996) consider the issue of partial bypass of the access network by an entrant; however, they focus on the optimal access price for telephony services determined by a regulator rather than the effect on bypass of the incumbent's local loop on negotiated access prices. Burnell, et al.(1996) provide an exception to this general approach by modeling negotiated one-way interconnection contracts with partial competitive bypass of the incumbent's local loops and all parties offered the same interconnection contract.

With respect to OW interconnection, Burnell, et al. (1996) analyse the negotiated OW interconnection contract as potential (and actual) bypass by entrants of the incumbent's local loop increases. That is, they associate particular network elements with particular services but relax the assumption that the local loop is necessarily a natural monopoly. They find the OW interconnection contracts converge on the cost of the local loop as the scope of the rivalry increases. The effect of the increased scope of the rivalry is illustrated by the graph in Figure 5 below.

Burnell, et al. (1996) assume that the total network cost is a function of network output, which can be read either as call minutes or calls. The incumbent is a conglomerate that owns the local-loop business unit and a retail business unit, where the retail business unit purchases OW interconnection from the local-loop business unit. There are also entrant retail businesses that may choose to bypass (part of) the incumbent's upstream network, where it is assumed that there is (potential) imperfect or monopolistic competition. The incumbent is required to offer its own retail business unit and the entrant business units the same interconnection contract. Thus the upstream local-loop business unit provides OW interconnection on the same terms to all toll bypass operators. 
Figure 5: Network total cost function of contracts under (potential) partial bypass

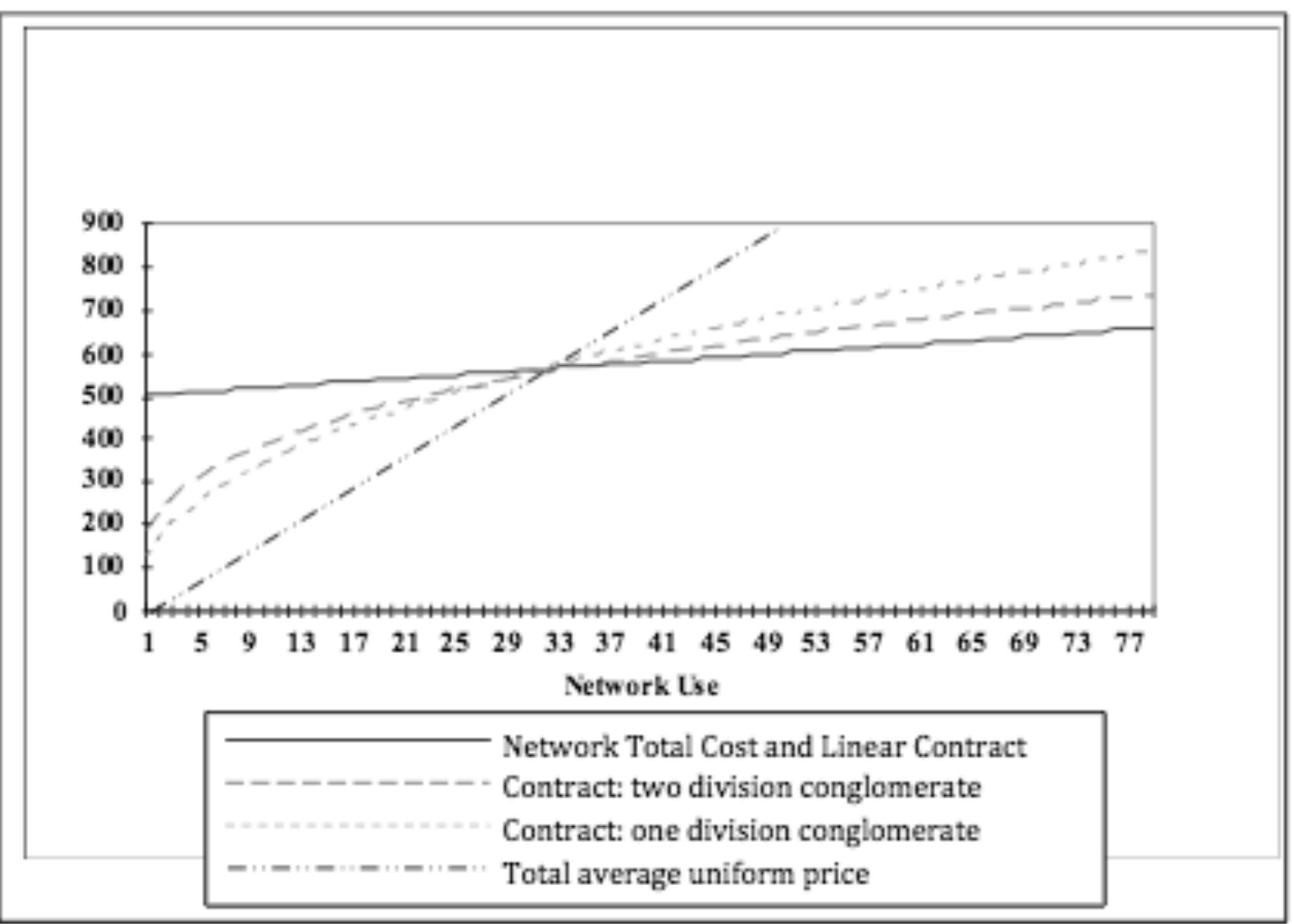

Source: Burnell, et al. (1996, p. 29 Figure 1)

The vertically integrated conglomerate network business unit chooses the OW interconnection contract that maximises the conglomerate's profit based on the extent of potential bypass of the local loop by the entrant, the joint profit of the conglomerate's retail and local-loop business units, and subject to the imperfect competition in the market for toll-call services. The two-division conglomerate keeps the upstream local-loop business and the retail business as separate divisions where the retail unit separately maximises its own profit subject to the OW interconnection contract. In the two-division conglomerate, the local-loop business takes into consideration the effect of the interconnection contract on retail profit as well as its profit, although the retail division acts independently. Figure 5 illustrates the outcome of these organisational structures against the cost of the network. Increased retail-competitive entry in this model results in the network contract approaching more closely the network cost structure. Thereby, competition is endogenous to market structure as technological change permits bypass. 


\subsection{Summary}

Dynamic demand and supply conditions in the telecommunications market have a significant effect on the conduct of market participants. If the objective of regulation is to maximise dynamic efficiency, then regulatory policy needs to take into account the uncertainty, particularly where a large irreversible investment has the potential to enhance efficiency. A highly concentrated market within static conditions suggests a firm with a significant degree of market power. Yet a highly concentrated market within dynamic conditions indicates a level of entry that may be optimal due to the 'amplification' of direct sunk costs which would result in intensive competition. Even if local loop is an enduring natural monopoly, the regulated access price still needs to allow for the dynamic market conditions. In this case, assuming that conditions are static will lead to under investment that is detrimental to dynamic efficiency.

A numerical example, based on the theory of two-part tariffs set out in appendix $\mathrm{B}$, is used to illustrate the effect of a firm's and consumers' incentives on the structure of a two-part tariff and market performance. The central observation is that market structure is not separable into an optimal access fee or an optimal call price that can be determined independently. The optimal access fee and call price are not independent of each other, and the structure of the optimal twopart tariff differs depending on whether the objective is to maximise a firm's profits or to maximise consumer surplus, subject to a constraint on the firm's profits.

The implication for regulatory policy is that determining whether or not there is a competition problem becomes increasingly context specific. If the process of regulation is to maximise dynamic efficiency, then regulation cannot expect to define policy that results in outcomes superior to a dynamic competitive market. However, less can be inferred from the conduct and performance of dynamic competition, based on static models of natural monopoly and perfect competition, when supply and demand conditions are uncertain. This implies that the analysis of perceived competition problems become increasingly context 
specific. Furthermore, determining an optimal structure for the market becomes more problematic. The imposition of a particular structure on the market is increasingly likely to be detrimental to dynamic efficiency because it is likely to limit the opportunities available to firms for the recovery of irreversible investments. 


\section{International experience}

The international experience of industry specific regulation (ISR) in the telecommunications market is varied. Countries opened their markets to competitive entry at different times and, unlike New Zealand, when they did they instituted some form on ISR of access to the incumbent's network. Contemporaneous with these regulatory changes, mobile and internet technologies developed leading to the expansion of and demand for new services. This chapter compares the effect of these changes on market performance between countries.

This chapter starts by summarising the key international regulatory developments, highlighting the regulatory features that were unique to New Zealand. This is followed by closer examination of the performance of the regulatory developments, first by direct comparison of prices and the date new services began in New Zealand and other OECD countries, and then by a review of the literature that used market data from different regulatory regimes ${ }^{88}$ to study the effect of regulatory policy on market performance.

\subsection{International comparison of regulatory developments}

By 2001, the telecommunications markets of most countries within the OECD had undergone regulatory reforms that involved opening markets to competition, and in some cases either total or partial privatisation of stateowned telecommunications operators. ${ }^{89}$ The market in New Zealand followed the international trend in regulatory reforms that involved opening markets to competition between profit maximising firms that were formerly closed to stateowned or controlled monopolies. However, a distinguishing and unique feature of the implementation of the regulatory reforms in New Zealand was the absence of ISR of access to wholesale services provided by the incumbent operator,

\footnotetext{
88 Regulatory regimes are either countries or the states of the United States.

89 See Boylaud \& Nicoletti (2001, p. 106 Table 1) for the dates when those countries in the OECD liberalised trunk, international calling, and mobile markets prior to 1998. Boylaud \& Nicoletti (2001, p. 110 Table 3) also give the ownership and privatisation dates of the incumbent telecommunications operators. See Laffont \& Tirole (2000, pp. 16-35 Section 1.3) for a general history of the regulatory reforms.
} 
particularly the absence of specific regulation of access to interconnection..$^{\circ}$ The price and non-price terms of interconnection with the incumbent network was governed solely by antitrust regulation (ATR).

Table 2: Telecommunications regulation, 1999

\begin{tabular}{|c|c|c|c|c|c|c|}
\hline & & & \multicolumn{2}{|c|}{ Interconnection } & \multicolumn{2}{|c|}{ Regulations } \\
\hline Country & $\begin{array}{l}\text { Regulatory } \\
\text { institutions }\end{array}$ & $\begin{array}{l}\text { Approval } \\
\text { of merger }\end{array}$ & $\begin{array}{c}\text { Authorisation } \\
\text { of charges of } \\
\text { operators with } \\
\text { significant } \\
\text { market power }\end{array}$ & $\begin{array}{l}\text { Dispute } \\
\text { resolution }\end{array}$ & Pricing & $\begin{array}{l}\text { Service } \\
\text { quality }\end{array}$ \\
\hline Australia & $\begin{array}{l}\text { Independent regulator } \\
\text { Competition authority }\end{array}$ & $\mathrm{X}$ & $\mathrm{X}$ & $\mathrm{X}$ & $\mathrm{X}$ & $\mathrm{X}$ \\
\hline Canada & $\begin{array}{l}\text { Independent regulator } \\
\text { Competition authority }\end{array}$ & $\begin{array}{l}\mathrm{X} \\
\mathrm{X}\end{array}$ & $\mathrm{X}$ & $\mathrm{X}$ & $\mathrm{X}$ & $\mathrm{X}$ \\
\hline Finland & $\begin{array}{l}\text { Independent regulator } \\
\text { Competition authority }\end{array}$ & $\mathrm{X}$ & $\mathrm{X}$ & $\mathrm{X}$ & $\mathrm{X}$ & $\mathrm{X}$ \\
\hline Ireland & $\begin{array}{l}\text { Independent regulator } \\
\text { Competition authority }\end{array}$ & $\mathrm{X}$ & $\mathrm{X}$ & $\mathrm{X}$ & & $\mathrm{X}$ \\
\hline New Zealand & $\begin{array}{l}\text { Ministry }{ }^{91} \\
\text { Competition authority } \\
\text { Other }\end{array}$ & $\mathrm{X}$ & $\begin{array}{c}\text { No } \\
\text { authorisation }\end{array}$ & $\mathrm{X}$ & $\mathrm{X}$ & $\mathrm{X}$ \\
\hline $\begin{array}{l}\text { United } \\
\text { Kingdom }\end{array}$ & $\begin{array}{l}\text { Independent regulator } \\
\text { Competition authority }\end{array}$ & $\begin{array}{l}X \\
X\end{array}$ & $\mathrm{X}$ & $\mathrm{X}$ & $\mathrm{X}$ & $\mathrm{X}$ \\
\hline United States & $\begin{array}{l}\text { Independent regulator } \\
\text { Competition authority } \\
\text { Other }\end{array}$ & $\begin{array}{l}X \\
X\end{array}$ & $\mathrm{X}$ & $\mathrm{X}$ & $\mathrm{X}$ & $\mathrm{X}$ \\
\hline
\end{tabular}

Source: OECD Secretariat, cited in the New Zealand Government Ministerial Inquiry into Telecommunication (2000, p. 16) final report. ${ }^{2}$

90 There was the regulation of a universal service obligation called the Kiwi Share Obligation as noted in section 1.2.

${ }^{91}$ The pricing and service quality regulation reported here are in relation to the monitoring of the quality of telecommunications services for residential customers, and a universal service obligation cap on the rental price for the standard residential telephone service. See in section 1.2 a description of the obligation.

92 The New Zealand Government Ministerial Inquiry into Telecommunications, (2000, p. 16) final report is a summary of Table A.2 in an OECD Economics Department Working Paper by Boylaud \& Nicoletti, (2000, pp. 50-52). The interpretation of this table in the present work is based on the Boylaud \& Nicoletti working paper. The 
The above comparison of regulatory regimes in place in 1999 highlights the fact that interconnection charges in New Zealand did not require authorisation by a regulatory institution, with any disputes addressed by the courts under antitrust laws. 93 In addition to New Zealand being unique with respect to the absence of regulation of access to the incumbent network, Boylaud \& Nicoletti (2000, 2001) highlight that the implementation of the regulatory reforms also differed between countries in the OECD. Differences included the dates that markets were opened to competition, the extent of competitive entry, the number of foreign entrants, the date of privatisation, and the extent of state control in the market.94

A noteworthy difference has developed between the United States' and the European Union's approaches to access regulation, particularly the unbundled access to the local loop. Renda (2010) notes that ex ante regulation of access to network elements, such as access to the unbundled local loop, was introduced in the United States with the 1996 Telecommunications Act, and in the European Union with the 1998 European Commission Access Notice95. Furthermore, this access regulation was based on essential facilities doctrine. ${ }^{96}$ However, in a

working paper without table A.2 was subsequently published as a journal article (Boylaud \& Nicoletti, 2001).

93 The New Zealand Government Ministerial Inquiry into Telecommunications (2000, p. 2) states that "As other countries have moved to privatise and deregulate, none have followed New Zealand's approach of almost exclusive reliance on general competition law (the Commerce Act). Without exception, they have opted for industry specific regulation."

A study by Boylaud \& Nicoletti (2000, pp. 50-52 Table A.2), which the Ministerial Inquiry relied on, shows that in 1999, with New Zealand, the Czech Republic, Iceland, Norway, Switzerland and Turkey did not require regulatory authorisation of interconnection contracts. In Iceland, Norway, Switzerland and Turkey the incumbent was $100 \%$ owned by the government, and in the Czech Republic it was $51 \%$ owned by the government (Boylaud \& Nicoletti, 2000, p. 30 Table 3), which may have enabled the government to regulate the interconnection prices.

94 See Boylaud \& Nicoletti (2001, pp. 106-112) for a summary as at and prior to 1998 by country of the regulation of entry and foreign investment, the market structure, and ownership and privatisation of incumbent operators.

95 See European Commission (1998). This was followed in 2000 by the regulation of unbundled access to the local loop (European Commission, 2000).

${ }_{96}$ Renda (2010, p. 24) quotes a $7^{\text {th }}$ Circuit Court decision which explains "a monopolist's refusal to deal [...] is governed by the so-called essential facilities doctrine. Such a refusal may be unlawful because a monopolist's control of an essential facility (sometimes call a 
series of decisions from 2002 to 2005 the United States industry specific regulator, the Federal Communications Commission (FCC), decided to forbear from imposing mandatory unbundling and price regulation on new and emerging cable access, fibre access, and wholesale broadband technologies and services, while maintaining the regulated access to legacy local-loop network. Renda comments that these decisions to deregulate access to networks that use new technologies "reportedly provided a tremendous stimulus to investment in the US"(2010, p. 25). The European Union has not followed a similar deregulatory trend. Renda argues the regulatory framework adopted by the European Union mandates rivals access not only to enduring bottlenecks but also access to network elements that "could not be conceived as essential facility" (2010, p. 29). Contemporaneously with the divergent approaches to access regulation between the United States and the European Union, New Zealand began to regulate access to wholesale broadband services in 2003 and unbundled access to the local loop in 2006.

\subsection{Development of internet and mobile services}

The development of the internet and mobile services has had a significant influence on industry structure and regulation. Both developments experienced significant technological and demand uncertainty, which has a direct bearing on the effect of regulation on dynamic efficiency.

The description of the technological and institutional evolution resulting in the emergent internet, which is presented in appendix A, notes that the evolution and development of the internet was not regulated by a government authority. There was no ISR of price and terms at which network operators and service providers accessed and interconnected with each other's network. The nascent internet developed as a non-commercial network for interconnecting university networks, which after 1991 was subsumed into the commercial, interconnecting networks that grew into the internet. During both the non-commercial and commercial phases of the development of the internet, academic institutions,

'bottleneck') can extend the monopoly power from one stage of production to another, and from one market to another." 
and then commercial network and service providers, negotiated access and interconnection contracts without the oversight of statutory ISR.97

In the unregulated environment, participants had the flexibility to make investment decisions and agree contracts. This flexibility was of value in a market with significant technological and demand uncertainty resulting in the arrival over time of new information about demand, and consumers' willingness to pay for new services. ${ }^{8}$ Examples of how this flexibility was exercised presented in appendix A, include the IP protocol that early developers of the internet chose given the other options available. One might speculate that an alternative protocol may have been in some sense superior; however, this does not lessen the observed benefit of the growth and range of services based on the IP protocol. ${ }^{99}$ Another example is the development of the peering and transit contracts which define the commercial terms under which network operators exchange user traffic between their networks. ${ }^{100}$ The choice of peering or transit contracts is made by mutual agreement between two network operators without any regulatory oversight. The fact that the internet enables a seamless communication between two consumers in different countries on separate networks, and the significant growth in demand for new, innovative services, demonstrates the efficacy of these contractual agreements. ${ }^{101}$

The other major development has been that of mobile services. Hausman, Pakes \& Rosston (1997) provide an indication of the benefits arising from the development of mobile telephony services. Noting that mobile services in the United States began in 1983, they estimate that the gain in consumer welfare in the United States from mobile telephony in 1994 was $\$ 50$ billion a year. ${ }^{102}$

\footnotetext{
${ }_{97}$ See appendix A.10 for further discussion.

${ }^{98}$ See sections 2.4 and 3.5.1 for further discussion.

99 See appendix A.7

${ }^{100}$ The timing of the introduction of mobile broadband services across the OECD countries is examined in more detail in the next section. For a description of mobile broadband technologies and the pricing of mobile broadband services see OECD (2009a).

${ }^{101}$ See appendix A for discussion on these features of the internet.

102 Hausman, et al. (1997) also claim that mobile telephony technology was available in the early 1970s; however, mobile services did not begin until 1983 due to regulatory
} 
Mobile telephony services have since evolved further so that they can now provide high-speed internet access (thus benefiting from the growth in the internet services), which is expected to result in further substantial gains in consumer welfare. ${ }^{103}$

\subsection{International comparison of industry performance}

The variation in the implementation of the regulatory reforms across OECD countries that opened state controlled markets to competition enabled Boylaud \& Nicoletti (2001) to estimate that the general effect of these reforms on the performance of the telecommunications markets. They conclude that allowing competitive entry to previously state-controlled markets led to productivity and quality improvements as well as price reductions in national calling, international calling, and mobile services. They also conclude that there was no clear evidence indicating that the ownership of the incumbent had an effect on performance (Boylaud \& Nicoletti, 2001, p. 134). Data limitations prevented the authors from analysing the efficacy of particular forms of regulation.

With respect to New Zealand, Boylaud \& Nicoletti's study suggests that the regulatory reforms and market structure resulted in prices that were $34 \%$ less than the OECD average across long-distance and mobile services (Boylaud \& Nicoletti, 2000 Table 11, page 41); productivity ${ }^{104}$ was $1 \%$ greater than the OECD average (Boylaud \& Nicoletti, 2000 Table 11, page 40); and quality was 366\% greater than the OECD average (Boylaud \& Nicoletti, 2000 Table 11, page 42). By comparison, for the United Kingdom, which had an industry specific regulator, Boylaud \& Nicoletti found that the regulatory reforms and market structure had resulted in prices that were $35 \%$ less than the OECD average across long-distance and mobile services (Boylaud \& Nicoletti, 2000, p. 41 Table 11); productivity was $3 \%$ greater than the OECD average (Boylaud \& Nicoletti, 2000, p. 40 Table 11); and quality was $471 \%$ greater than the OECD average

indecision and the subsequent licensing procedure used by the FCC. Their conclusion is that this lengthy regulatory delay caused very large losses in consumer welfare.

103 See the OECD (2009a) study of the developments of mobile broadband for a description of mobile broadband, the mobile broadband technology options and data comparing the OECD countries. See appendix $\mathrm{C}$ for the dates when mobile broadband services were adopted by each country in the OECD. 
(Boylaud \& Nicoletti, 2000, p. 42 Table 11). For Australia, Boylaud \& Nicoletti found that the regulatory reforms and market structure had resulted in prices that were $46 \%$ less than the OECD average across long-distance and mobile services (Boylaud \& Nicoletti, 2000, p. 41 Table 11); productivity was 39\% greater than the OECD average (Boylaud \& Nicoletti, 2000, p. 40 Table 11); and quality was 335\% greater than the OECD average (Boylaud \& Nicoletti, 2000, p. 42 Table 11).

These results are generally consistent with De Boer \& Evans' (1996) finding that the opening of the New Zealand telecommunications market to competition in 1989 resulted in substantial gains in consumer surplus between 1987 and 1993 , mainly due to reductions in price. In addition, De Boer \& Evans estimate that productivity improvements reduced cost at an annual compound average of $5.6 \%$.

These gains in industry performance are due to the process of regulatory reform where markets that were once closed were opened to competition. Both Boylaud \& Nicoletti (2001) and De Boer \& Evans (1996) conclude that these reforms led to a substantial reduction in prices, thus increasing consumer surplus. The change in utility that a consumer derives from a change in prices is due to the combined effect of changes in the access fee and call price on utility. This was particularly relevant when assessing the affect of the regulatory reforms on the New Zealand market where there was rebalancing of access and calling prices, where the access price was increased and call prices fell in preparation for opening the market to competition. Evans (1996) examines the effect of this rebalancing on consumer surplus and shows that the detriment, due to an increase in access fees, was less than the benefits of reduced calling prices for residential customers after the New Zealand telecommunications market was opened up to competition.

Instead of comparing the utility that consumers derive when presented with a particular tariff, a method for comparing price differences between countries or price changes over time, which is applied in practice, is to calculate an average or a representative consumer's total outlay on telecommunications services based on a usage basket. De Boer \& Evans (1996) compare the effect of the price changes between 1987 and 1993 using consumers' usage as at 1987. Boylaud \& Nicoletti's (2001) analysis of price differences between OECD countries is based 
on usage baskets defined and reported frequently by the OECD for making cross country comparisons. ${ }^{105}$ Policy makers and regulators extend this approach to reporting price differences between countries in the form of ranking New Zealand's tariffs. ${ }^{106}$

Table 3 ranks the prices for telecommunications services available in New Zealand and Australia by sector of the telecommunications market.

Table 3: Performance of New Zealand telecommunications prices based on OECD ranking

\begin{tabular}{|c|c|c|c|c|}
\hline \multirow[t]{2}{*}{ Telecommunications Sector Usage Basket } & \multirow{2}{*}{$\begin{array}{c}\text { Nov } 1998^{107} \\
\text { Ranking }\end{array}$} & \multicolumn{3}{|c|}{ August 2008 108} \\
\hline & & $\begin{array}{c}\text { Low } \\
\text { usage }^{109}\end{array}$ & $\begin{array}{l}\text { Medium } \\
\text { usage }^{110}\end{array}$ & $\begin{array}{l}\text { High } \\
\text { usage }\end{array}$ \\
\hline New Zealand Residential Telephone Services & $14^{\text {th }}$ out of 29 & $20^{\text {th }}$ & $20^{\text {th }}$ & $18^{\text {th }}$ \\
\hline New Zealand Business Telephone Services & $15^{\text {th }}$ out of 29 & $20^{\text {th }}$ & $17^{\text {th }}$ & \\
\hline New Zealand Mobile Services & $9^{\text {th }}$ out of 24 & $10^{\text {th }}$ & $9^{\text {th }}$ & $14^{\text {th }}$ \\
\hline Australia Residential Telephone Services & $17^{\text {th }}$ out of 29 & $17^{\text {th }}$ & $15^{\text {th }}$ & $14^{\text {th }}$ \\
\hline Australia Business Telephone Services & $19^{\text {th }}$ out of 29 & $26^{\text {th }}$ & $26^{\text {th }}$ & \\
\hline Australia Mobile Services & $5^{\text {th }}$ out of 24 & $11^{\text {th }}$ & $17^{\text {th }}$ & $9^{\text {th }}$ \\
\hline
\end{tabular}

OECD countries are ordered and ranked according to the consumers' outlay based on the tariffs available in the country with the assumption that consumers' usage within the sector is the same as the OECD usage basket. The above table

105 The OECD reports its usage baskets every two years in the OECD Communications Outlook reports. For example, see OECD (2009b, p. 269).

106 For examples, see the Commerce Commission (2008, 2009), Ministry of Economic Development $(2004,2005)$ and Ministry of Commerce $(1998,1999,2000)$ reports on the performance of the New Zealand telecommunications market.

107 Cited in Ministry of Commerce (1998, pp. 14,15).

108 OECD (2009b, pp. 270-277).

109 For the Business Telephone Service line, the Low usage column reports the OECD (2009b, p. 274, Figure 7.7) ranking for the small office and home office business category.

110 For the Business Telephone Service line, the Medium usage column reports the OECD (2009b, p. 274, Figure 7.8) ranking for the small and medium-sized enterprises business category. 
gives New Zealand's ranking for the residential fixed-line baskets, business fixed-line baskets, and mobile baskets in 1998 and 2008.

The country with the tariff resulting in the lowest outlay is ranked $1^{\text {st. }}$. This table gives the ranking of New Zealand tariffs out of the OECD countries included in the benchmark. One problem with comparing New Zealand's ranking between 1998 and 2008 is that the OECD introduced new baskets and countries were added between these two dates. If an interpretation is to be made, the table suggests New Zealand's ranking for residential and business telephone services declined slightly and the ranking for mobile services stayed approximately constant between 1998 and 2008. The same rankings have been provided for Australia because Australia is frequently used as a reference point when comparing New Zealand's economic performance generally. This indicates that Australia's ranking was generally constant for residential telephone services, although perhaps declined for business telephone services and mobile services. Comparing New Zealand with Australia in 2008, the ranking for residential telephone services is lower in New Zealand than Australia; the ranking for business telephone services is higher; and the ranking of mobile services is broadly comparable.

However, Boylaud \& Nicoletti (2000, 2001) caution when interpreting the OECD pricing benchmark. These benchmarks are based on usage baskets for a particular representative usage basket that does not take into account differences in income between countries, different consumer preferences, and the substitutes available within countries. Furthermore, inter-temporal comparison of rankings is hindered by the fact that consumer preferences and usage changes with time. ${ }^{111}$

Two-part tariffs and non-linear tariffs determine consumers' outlay on telecommunications services. The implication is that comparing the price of, say, calling in one country with the price of calling in another country, or the outlay on a given usage basket in one country with outlay on the usage in another may

${ }^{111}$ The OECD (2009b, pp. 268-269) notes “... that in certain countries the prices may appear more competitive in one basket than in another. This is commonly the result of offers tailored to specific national calling patterns that may mimic the composition of certain basket more closely than others." 
not provide a valid comparison of the efficiency of tariffs between countries. Such a comparison requires knowledge of input costs, consumer preferences, consumer income, and substitute services and prices to be the same. Assuming that input costs and consumer preferences do not differ across countries, or that the effect of any difference on price can be explained and accounted for, then differences in income and the availability of substitutes still have a significant effect on consumer demand and the optimal tariff for an individual service. Mao, et al.'s (2008) and Chen, et al.'s (2008) analyses, discussed above, illustrate this point in relation to fixed-to-mobile access substitution and call substitution. They show that the availability of fixed-line services and the average income per capita significantly influences the average demand for mobile services. The theory of two-part tariffs put forward in appendix B explains that the optimal two-part tariff depends on the effect of income on consumers' participation and consumption decisions, and income distribution across a population. If the intention is to compare the performance of tariffs between countries, rather than comparing outlay based on a common set of usage baskets, then the structure of the tariffs, in addition to the level of tariffs, needs to be taken into consideration.

Taken on its own, the rankings presented in Table 3 suggest a corresponding ranking of the relative allocative efficiency between countries. Those countries with a higher ranking - i.e. lower prices and therefore lower outlay for the usage basket - imply consumers benefit from lower prices, thereby resulting in a greater allocative efficiency. However, these rankings do not take into consideration differences in the input costs between countries. Using an engineering model of a telephony network, Alger \& Leung's (1999) comparison of the average cost of supply indicates that there are substantial differences in average unit costs between five countries due to differences in customer density. They estimate that average unit costs for Australia, New Zealand, and Sweden, respectively, are about $10-14 \%, 15-20 \%$, and $23-27 \%$ greater, and the United Kingdom 19-22\% lower, than the United States average. Boylaud \& Nicoletti (2000, pp. 17, 35) take this and other exogenous factors into account that represent income levels, population density, input costs, price structures, quality, and intensity of capital by including the percentage of digital lines, the ratio of fixed investment over total employment, the ratio of fixed investment over mainlines, as well as other indicators. 
Firms in the telecommunications market attempt to gain and maintain a competitive advantage by investing in new technologies that either give a cost advantage or enable the supply of an innovative service. The benefits that society derives from new services can be very large. Comparing the efficiency gains from these investments in innovative services is not captured in prices or even a more comprehensive measure of allocative efficiency between countries. Comparing the price of services between countries does not provide an indication of the performance of a country's market and the associated regulations. Additional information about the timing of the introduction of innovative services gives an indication of the dynamic efficiency of the market. This is because the dynamic efficiency of a market determines the timing of investments, particularly irreversible investments in innovations where there is demand and technological uncertainty. ${ }^{112}$

This is illustrated by the timing of the investment in broadband access. Grimes, Ren, \& Stevens' (2009) analysis of the effect of broadband on the productivity of firms in New Zealand concludes that productivity increased with the availability of broadband, and that there was no observable increase with the speed of the broadband. Therefore, any delay in access to broadband had a detrimental effect on the economic benefits due to improvements in firm productivity.

Figure 6, below, presents the timing of the investment in the fixed-line digital subscriber line (DSL) family of technologies and the family of mobile technologies across OECD countries.

${ }^{112}$ Section 3.5.1. 
Figure 6: Launch of fixed-line and mobile broadband services ${ }^{113}$

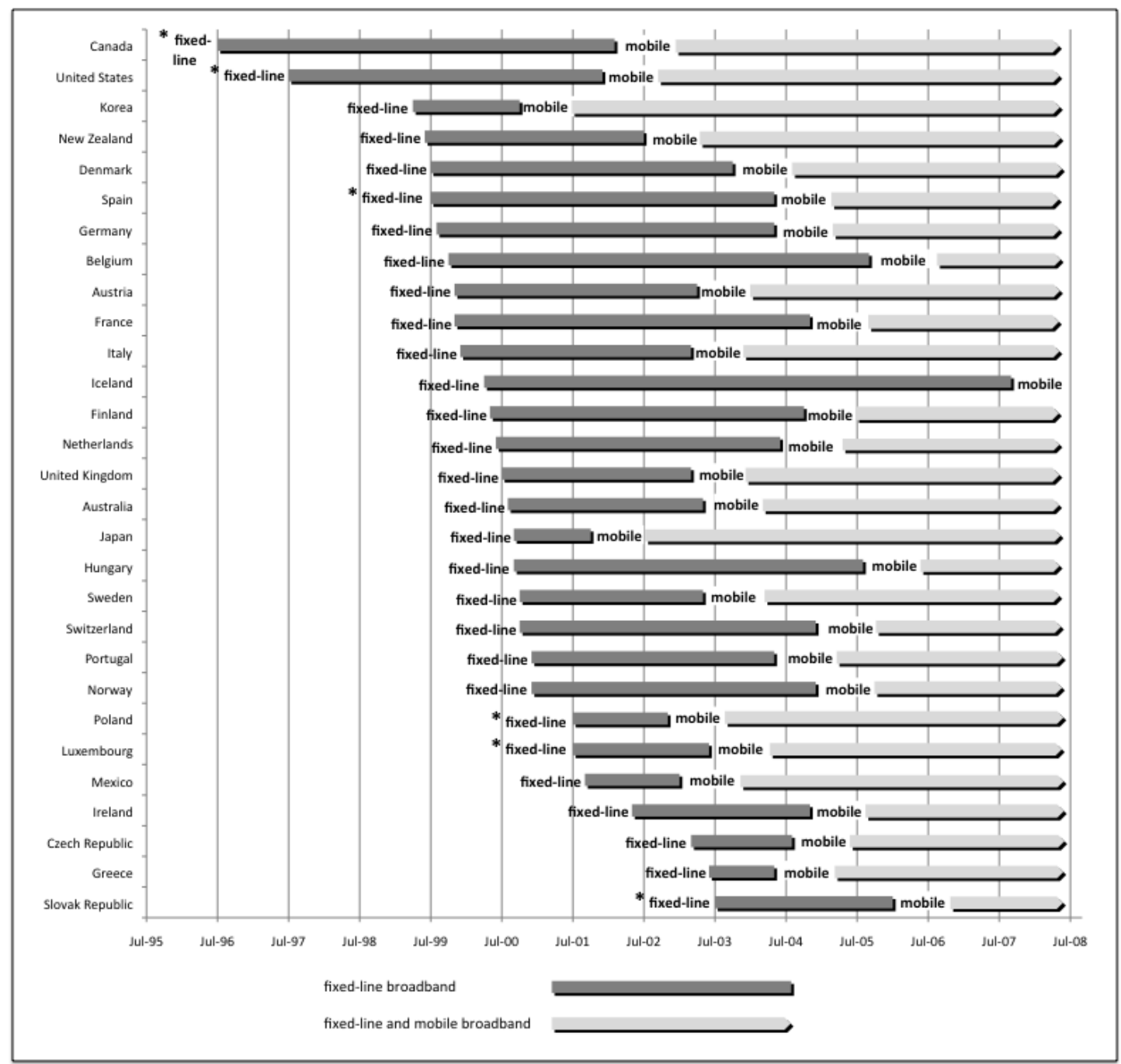

113 The dates in the table are provided in appendix C. See OECD (2009b, p. 136 Table 4.15) for the dates that commercial fixed-line broadband services based on digital subscriber line (DSL) fixed-line broadband began, and OECD (2009a, pp. 23-25 Table 1) for the dates that mobile broadband services began. The OECD (2009b, p. 136 Table 4.15) gives the year but not the month that commercial DSL broadband began in Canada, Luxembourg, Poland, Slovak Republic, Spain, and the United States. For these countries, Figure 2 shows the month of July of the year reported by the OECD as the start date, with the label '* fixed-line' to indicate this point. Showing the month of July does not affect the conclusions drawn from this diagram. Any month in year that DSL broadband was launched in these countries could be used and the same conclusions would be drawn. The OECD (2009b, p. 136 Table 4.15) gives the month and year that commercial DSL broadband began for all the other OECD countries, and OECD (2009a, pp. 23-25 Table 1) gives the month and year that mobile broadband services began in all OECD countries except for Turkey. The OECD $(2009 \mathrm{~b}, \mathrm{p} .136$ Table 4.15$)$ reports that Turkey began commercial DSL broadband in February 2001, and OECD (2009a, pp. 11, 42, endnote 23) indicates that Turkey did not have a commercial mobile broadband service. 
The graph shows that the launch of fixed- and mobile-broadband technologies spans approximately 10 years. Starting at the left-hand end of the dark-grey bar, the 'fixed-line' label indicates the arrival of commercial DSL fixed-line broadband in the country. At the right-hand end of the dark-grey bar, the 'mobile' label indicates the arrival of commercial mobile broadband services. The dark-grey bar is the period over which fixed-line broadband was the only mode of broadband available in the country. Both fixed-line and mobile modes of broadband were available starting from the right-hand end of the dark-grey bar, continuing through to the light-grey bar, and onwards.

If it is assumed the productivity gains that Grimes, et al. (2009) identified for New Zealand firms are applicable to all OECD countries, then this implies that those countries, including New Zealand, that launched broadband access technologies earlier benefited from significant productivity gains earlier and subsequently than those countries that introduced broadband later.

The graph also shows that fixed-line broadband arrived in all OECD countries before mobile broadband. This may have been a function of the timing of the availability of particular versions of a technology; however, the graph indicates that mobile broadband was launched in some countries before fixed-line broadband was launched in others. That is, it seems that there was no technological reason that mobile broadband could not have been launched before fixed-line DSL broadband.

An alternative explanation for the fact that mobile broadband followed DSL broadband as indicated by Figure 2 was that the ordering was determined by the inter-modal, dynamic competition between fixed and mobile services. That is, owners of fixed-line networks invested in broadband services in order to gain a competitive advantage over mobile networks, and that mobile network owners invested in mobile technologies in order to regain the competitive advantage that seems to have developed for the traditional telephony calling services. As discussed, Chen, et al. (2008) observe that fixed-to-mobile access and call substitution is a function of a country's average per capita income. ${ }^{114}$ Quigley \& Sanderson (2005) argue that the fixed-to-mobile call substitution is increasing

\footnotetext{
114 Section 3.4.
} 
in Canada, though constrained by regulated low fixed-line telephony prices. Rodini, et al. (2003) show that in the United States over 2000 and 2001, mobile service was a moderate substitute of fixed-line service, and that their expectation at that time, based on evolving calling patterns, was that fixed-line and mobile services would become greater substitutes over time.

As well as a process of dynamic competition, assuming that the same technologies were available to all countries included in Figure 2 at the same time, then it seems reasonable to suppose that the timing of the investment in broadband services between countries was due to country specific factors. New Zealand was unique, as ISR of access to the incumbent's network did not arrive until 2001. With the arrival of DSL broadband in June 1999, Figure 2 suggests that New Zealand was one of the earliest countries in the OECD to have a commercial fixed-line broadband service. ${ }^{115}$ It also suggests that the lack of ISR at that time did not delay the arrival of fixed-line broadband services. With the arrival of mobile broadband in July 2002, New Zealand was also one of the earliest countries in the OECD to have a commercial mobile broadband service. ${ }^{116}$ Even though this was after the advent of ISR in 2001, at that time ISR did not include the regulation of access to mobile networks. ${ }^{117}$

\subsection{International experience of the effect of regulation on efficiency}

The literature has examined the international experience of access regulation, particularly the effect of local-loop unbundling, on the investment, price and demand for telecommunication services. This literature is grouped here into those who consider the effect of access regulation on the allocative efficiency represented by uptake of services or the price, and those who consider the effect of access regulation on investment, where investment is an indicator of dynamic efficiency.

115 Canada, United States and Korea launched commercial DSL broadband services before New Zealand.

116 Korea, Japan, United States and Canada launched commercial mobile broadband services before New Zealand.

117 Interconnection with mobile networks was regulated in August 2010 (Minister of Communications, 2010). 
With respect to the effect of regulated access on allocative efficiency, Economides, Seim, \& Viard (2008) evaluate the effect on consumer welfare of competitive entry over the period 1999 to 2003, due to unbundled local loops in New York State. The authors conclude that consumers gained $6.2 \%$ on their monthly account from this competition. Another example is the Berkman Center's (2009, p. 12) pricing study of 59 OECD operators' broadband services in 2008, which concludes that the lowest broadband access prices and highest access speeds are almost all offered by firms in markets where, in addition to an incumbent telephone company and a cable company, there are market entrants who use regulated unbundled local loop or bitstream services. Furthermore, the Berkman Center claims that firms in the United States and Canada offer broadband services with the lowest speeds and highest prices, where the market is structured around inter-platform competition between one incumbent owning the telephone service and one incumbent owning a cable TV system. They also conclude that unbundling the local loop provides a positive contribution to the uptake of broadband services.

Further support for the proposition that unbundling is more significant than platform competition in explaining broadband penetration is provided by the OECD (2007a). However, in response, Boyle, Howell, \& Zhang (2008), correcting errors in the specification of the OECD model, conclude that the contribution of unbundling to the level of national broadband uptake is statistically insignificant. Distaso, Lupi, \& Manenti’s (2006) econometric analysis, using quarterly data between 2000 and 2004 from 14 European countries, is equivocal on whether or not local-loop unbundling contributes to broadband uptake. ${ }^{118}$ They find that inter-platform competition seems to be one of the main drivers of broadband uptake, whereas competition based on unbundled local loop does not seem to play a similar roll. ${ }^{119}$ However, they also

\footnotetext{
${ }^{118}$ Wallsten's (2006) econometric analysis of broadband uptake across 30 OECD countries from 1999 to 2003 also finds that local-loop unbundling has no robustly significant impact on broadband penetration.
}

119 Cava-Ferreruela \& Alabau-Munoz's (2006) econometric analysis, pooling data from 2000 to 2002 across 30 OECD countries, also concludes that inter-platform competition accelerates the deployment of broadband noting, however, that there are geographic areas that are unlikely to be served by broadband services. 
note that the econometric analysis supports the proposition that lower unbundled prices are associated with broadband uptake.

This conclusion highlights a tension between lower access prices and the development of inter-platform competition. Crandall, Ingraham, \& Singer (2004), using United States data at the state level from 2001 to 2002, show competing facilities-based line growth relative to growth in unbundled localloop lines was higher in states where the cost of unbundled local loop was greater than the cost of facilities-based investment. ${ }^{120}$ An econometric study of more than 70 fixed-line operators in 20 countries over 10 years by Grajek \& Roller (2009), observes that even though an increase in the intensity of access regulation increases the investment by entrants on technologies that rely on regulated access to the unbundled local loop, it is not greater than the loss due to reduction in the incumbents' investment. ${ }^{121}$ Therefore, the effect of an increase in access-regulation intensity is to reduce total investment in the market. In addition, by treating the level of regulation as endogenous, Grajek \& Roller observe that higher levels of investment by the incumbent encourages the provision of regulated access. ${ }^{122}$

Grajek \& Roller (2009) analyse the effect of regulation on investment and the effect of the incumbents' investment on the intensity of access regulation. However, they expressly do not draw any conclusions regarding the effect of regulatory decisions on welfare and price. Their results support the proposition developed in the theoretical literature ${ }^{123}$ that increasing the intensity of

${ }^{120}$ This result is supported by Wallsten \& Hausladen (2009), using data from 27 European countries from 2002 through to 2007. They find the number of local-loop lines unbundled by entrants is negatively correlated with the number of broadband connections over fibre, cable and wireless local loop.

${ }^{121}$ Ingraham \& Sidak (2003) find evidence to support the proposition that mandatory unbundling of the local loop reduced the incentives of the incumbent local exchange operators in the United States to invest in their own network.

122 De Boer, Enright, \& Evans (2000), comparing the performance of internet service providers (ISP) between Australia and New Zealand in 1999, find that relative ISP costs of the two countries were in accord with the argument that telecommunications infrastructure competition in Australia was weaker than in New Zealand. They attribute the weaker competition to different regulatory regimes. At that time in Australia, the terms of access were governed by ISR, whereas in New Zealand, there was no ISR.

123 See chapter 3 for a discussion of theoretical literature on the effect of regulation on investment. 
regulation either by lowering access prices or regulatory opportunism is detrimental to dynamic efficiency, particularly in a dynamic market such as telecommunications.

Lowering access prices will enhance consumer welfare in the short term if it leads to lower retail prices. Höffler (2007) finds that inter-platform competition between DSL and cable TV networks had a significant positive effect on broadband penetration in western Europe. However, Höffler calculates that the "welfare gains from the increase of penetration due to infrastructure competition seem not to be sufficiently large to over compensate for the very high investments into the basically redundant alternative cable infrastructure" (2007, p. 411). That is, infrastructure-based competition is not welfare enhancing.

Höffler's (2007) analysis does not consider whether or not inter-platform competition enhances dynamic efficiency in the context of timing and innovation. He only considers the cost and benefits of inter-platform competition with respect to static, allocative efficiency. In a static market, where firms invest large sunk costs leading to monopolistic competition, the standard result is an over investment in competing assets that is not welfare enhancing (Salop, 1979). The present value of the expected total surplus into the future is an important determinant of dynamic efficiency; however, it is not the only determinant. As discussed in section 3.5, an additional determinant of dynamic efficiency is the present value of the flexibility to make decisions in response to new information. Höffler does not consider the economic value of flexibility that inter-platform competition provides. The other papers considered in this section do not take into account the economic value of the flexibility to respond to new information in the future. The implicit assumption seems to be that the penetration or the price of broadband is the main determinant of dynamic efficiency, as it is positively correlated with future gains in consumer welfare. Therefore, accelerating this uptake enhances consumer welfare.

\subsection{Summary}

The lack of ISR did not lessen competition or reduce performance in the telecommunications market in New Zealand. The performance of the New Zealand telecommunications market after it was opened to competitive entry in 1989, and before the advent of ISR in 2001, was not significantly different from 
other countries that had ISR when their markets were opened to competitive entry. Between opening the market to competitive entry in 1989 and the arrival of ISR in 2001, Boylaud \& Nicoletti (2001) find that long-distance and mobile prices, productivity, and quality were generally consistent with comparable OECD countries that had ISR.

New Zealand was amongst the first group of countries in the OECD to launch DSL broadband internet access. Figure 6 indicates that only Canada, the United States, and Korea launched before it. The literature indicates that there was substantial welfare gains for New Zealand from having broadband access available, and that the incremental gains become less substantial with improvements in the quality of broadband access. The introduction of broadband internet access also led to the transformation of industry structure illustrated by Figure 4 .

The timing and the size of investment is an indicator of dynamic efficiency, as firms value present and future options when making investment decisions. The flexibility to make decisions in the future is valuable in the telecommunications markets where there is significant uncertainty. As discussed in chapter 2 , this uncertainty is due to technological progress leading to growth in the range and capability of new technologies - particularly the growth in the internet - and demand. With the emergence of commercial arrangements in an unregulated environment, these new technologies and contracts that differ significantly from those employed by the traditional telephony service, have led to an increase in the range of services and in demand. In such a changing commerical environment, the flexibility to choose between investing or not, and the form of the commercial arrangements, is significant and has significant value. 


\section{New Zealand experience}

Dynamic and uncertain demand and supply conditions have a significant effect on the conduct of firms, particularly where decisions involve irreversible investments in innovative services. Regulatory policy also has an effect on these investment decisions. If the regulated price of access to a natural monopoly asset does not allow for the value of deferring the investment, then the monopoly's expected revenue may not be sufficient to compensate for the opportunity cost of deferring the investment, resulting in no investment. Also, if the regulator lacks commitment to incorporating the value of real options over the life of the monopoly asset, then this will have a detrimental effect on investment. The regulator may acknowledge the opportunity cost of the investment before it is made, but there is a possibility that it will not commit to recover this cost once the investment is sunk.

Dynamic and uncertain demand and supply conditions also mean the conduct of rivals in a competitive market is unpredictable and market structure is uncertain. In a dynamic market, firms not only compete on price and product but also on the timing of investment. They seek to make and time investments when competition is minimal. With respect to market structure, a highly concentrated, static market suggests that firms exist with a significant degree of market power, whereas a highly concentrated, dynamic market can be consonant with intensive competition.

The implication of uncertainty for regulatory policy is that determining whether or not there is a competition problem becomes increasingly context specific and cannot be inferred from static models. Also, determining the optimal market structure looking forward becomes increasingly problematic. The imposition of a particular structure on the market is increasingly likely to be detrimental to dynamic efficiency, as it is likely to limit the opportunities available to firms for the recovery of irreversible investments.

The New Zealand experience is of interest because from the deregulation of the market in 1989 through to the arrival of industry specific regulation (ISR) in 2001, access to the incumbent's wholesale services was governed solely by antitrust regulation (ATR). This chapter traces the development of regulation by 
examining the conduct of regulation before, in the lead up to, and after the advent of ISR. Of particular interest is constancy of the decisions under ATR and ISR over a period of significant change, and how they assessed competition. A striking difference between ATR and ISR is that ATR defined competitive conduct and assessed past conduct, whereas ISR had a view of market structure that was expected to promote competition. Even though the courts had determined certain contracts were not anticompetitive, the government's concept of a competitive market structure influenced contracts prior to the arrival of ISR. Then partly in reaction to contracts that developed in a dynamic market, this arguably led to the establishment of an ISR institution, and subsequently the government's view of a competitive market structure led to the introduction of further regulations. This chapter examines each of these phases of the development of ISR. This is followed by an analysis of the effect of ISR on entry and the process of dynamic competition over the period of 1989 to 2008.

\subsection{Defining competition under ATR}

In a landmark decision in 1994, the Judicial Committee of the Privy Council (Privy Council) established case law defining anti-competitive conduct under the Commerce Act 1986, s 36. ${ }^{124}$ A dispute between Clear and Telecom had emerged during the negotiation of an interconnection contract. ${ }^{125}$ Clear claimed that

\footnotetext{
124 The Judicial Committee of the Privy Council was New Zealand's highest court of appeal. It ended hearing appeals in relation to all decisions of New Zealand courts made after 31 December 2003, when it was replaced by the Supreme Court of New Zealand.

125 In October 1990, Clear Communications Ltd (Clear) registered as a network operator pursuant to the Telecommunications Act 1987. It signed toll-by pass and local access interconnection agreements with Telecom on March 1991 ("Telecom Corporation of New Zealand Ltd v Clear Communications Ltd," 1994, p. 392), and commenced commercial operation on April 1991 (Ministry of Commerce, 1997, Section 7.1).
}

Clear required interconnection to Telecom's network in order to provide calling with ubiquitous coverage. Local access interconnection allowed consumers on Clear's access network to call consumers on Telecom's access network. Furthermore, in the case of toll by-pass, interconnection allowed consumers on Telecom's access network to place toll calls over Clear's toll-call networks. Therefore, Telecom had two roles: one as the provider on an essential input to Clear's downstream services, and another as Clear's competitor.

During the process of negotiating the interconnection contract, a dispute emerged that led to litigation in 1991. ("Telecom Corporation of New Zealand Ltd v Clear Communications Ltd," 1994, pp. 392-395). Clear claimed that Telecom's terms were in breach of s 36 of the Commerce Act 1986. Clear argued that the terms of the contract were an exploitation of Telecom's dominance. The Court of Appeal accepted Clear's 
Telecom exploited its market power in the local-access telephony market and set interconnection prices that were anticompetitive in the downstream market for long-distance toll-calls. ${ }^{126}$

The Privy Council defined anti-competitive conduct as conduct that could not be profitable for a hypothetical firm that was the same in all respects as the incumbent, except that it does not have market power. ${ }^{127}$ This test is referred to as the counterfactual test, as it relies on defining a hypothetical firm that is the same as the firm with market power in all respects except that it does not have market power. ${ }^{128}$ The Privy Council also decided that wholesale access prices based on the Efficient Component Pricing Rule (ECPR) was not an anticompetitive use of market power. ${ }^{129}$

The counterfactual test defines market power and (anti) competitive conduct in static terms. Drawing on the conjectural-variations framework in section 2.3, equation (1) measures market power as an index $\theta$ along a continuum from a firm without market power in perfectly competitive $\theta=0$ to a firm with market power that is a monopoly $\theta>1$. The test states that conduct is not anticompetitive if it is profitable irrespective of the value of $\theta$. However, if the

argument. In response, Telecom appealed to the Judicial Committee of the Privy Council ("Telecom Corporation of New Zealand Ltd v Clear Communications Ltd," 1994).

${ }^{126}$ For discussion on telephony interconnection see section 3.1.

127 The Privy Council's view was "it cannot be said that a person in a dominant market position 'uses' that position for the purposes of s 36 unless he acts in a way which a person not in a dominant position but otherwise in the same circumstances would have acted" ("Telecom Corporation of New Zealand Ltd v Clear Communications Ltd," 1994, p. 403).

${ }_{128}$ The New Zealand Supreme Court decision on Commerce Commission v Telecom New Zealand reaffirmed this definition of anticompetitive conduct. The New Zealand Supreme Court replaced the Privy Council as New Zealand's highest court in 2004 (Courts of New Zealand, 2010).

129 Noting that the Privy Council decision refers to the Efficient Component Pricing Rule as the Baumol-Willig Rule (after the names of the authors of each rule), the Privy Council found that "... the Baumol-Willig Rule did not breach s 36 since it did not involve the use by Telecom of its dominant position" ("Telecom Corporation of New Zealand Ltd v Clear Communications Ltd," 1994, p. 408). 
conduct is not profitable for a low value of $\theta$, then it is considered to be an anticompetitive use of market power.

The test does not state that the absolute level of interconnection prices changes in the $\theta$. By definition the absence of market power will lower the value of $\theta$ which will lower the interconnection price. Lower interconnection prices would lead to lower retail prices for long-distance toll calls, if Telecom notionally treats the price charged to Clear as the price it charges itself for terminating calls on its own network. ${ }^{130}$ Therefore, it is the margin between the retail and interconnection price that is relevant.

Telecom argued that its interconnection price was the retail price less the incremental cost that Telecom saved by not carrying the toll call, and that this price was not anticompetitive. This price is the standard definition of the ECPR. ${ }^{131}$ The Privy Council's articulation of the ECPR is "in a fully contestable market, someone selling to a competitor the facilities necessary to provide a service that the seller could otherwise provide that would demand a price equal to the revenues that would have been obtained if the seller had provided the service - in short the price equals the opportunity cost." ${ }^{132}$

The Privy Council considered whether or not the continued inclusion of rents within the opportunity cost contradicted the proposition under the counterfactual test. The Privy Council's view was that it was not apparent, based on the available evidence, whether or not Telecom was earning economic rents from its local-access network. However, even if Telecom did earn rents, it was largely an irrelevant consideration. It would only be relevant if the

${ }^{130}$ This is referred to as the principle of comparative parity ("Telecom Corporation of New Zealand Ltd v Clear Communications Ltd," 1994, p. 396).

${ }^{131}$ See section 3.5.3 for further discussion regarding the ECPR.

132 ("Telecom Corporation of New Zealand Ltd v Clear Communications Ltd," 1994, p. 386). Also, the Privy Council decision refers to the ECPR as the Baumol-Willig Rule, which are names of the authors ("Telecom Corporation of New Zealand Ltd v Clear Communications Ltd," 1994, pp. 386,395-397). 
interconnection price were so high as to foreclose entry, and Clear did not make this claim. ${ }^{133}$

The Privy Council's reasoning was that the ECPR ensured that both operators would compete on equal terms in the market for calls. The ECPR provided Clear with a signal regarding the incremental cost to Telecom for those service elements that Clear would compete on. If Clear was (not) more efficient, then it could (not) compete. In a static sense, this would lead to an allocatively efficient outcome.

Furthermore, if the price of interconnection included rents, the Privy Council identified either one of two solutions, which depended on whether or not the rents were economic rents. If the rents were not economic rents, and reflected option value of investment timing, then the presence of rents would attract competition in the retail market for access to the PSTN, which the Privy Council identified as taking place. ${ }^{134}$ If the rents were enduring economic rents or, as the Privy Council described, if competition in the local access market was limited or

133 ("Telecom Corporation of New Zealand Ltd v Clear Communications Ltd," 1994, p. 407).

${ }^{134}$ ATR relies on commercial negotiation to settle interconnection contracts. Burnell, et al. (1996) use a static model to show that commercially negotiated interconnection contracts converge on network costs to the extent of competitive bypass of the access network.

Burnell, et al. (1996) assume that the entrant's cost to build at the margin not only influences the incumbent's pricing of retail access fee but also influences the incumbent's optimal interconnection pricing strategy. An attempt to exploit a dominant position by increasing interconnection prices increases the incentive on the entrant to bypass the incumbent's network. It would do this to compete for retail customers at the margin, in order to bypass the interconnection contract and thereby reduce the average marginal cost to itself of terminating calls. Another effect of access bypass is that it allows the entrant to earn interconnection revenue.

Further, Burnell, et al. (1996) compare two tariff structures for interconnection: a twopart tariff and a uniform price per unit time. As the two-part tariff more closely matches the decreasing average cost structure of a network than a uniform price, the two-part tariff reduces the incumbent's risk to unexpected variations in demand and provides the entrant with the efficient cost signal for it to decide whether to by-pass the network or interconnect. Traditionally however, commercially negotiated interconnection prices are uniform prices per unit time. 
likely to be lessened, then the Commerce Commission had the power under Part IV of the Commerce Act 1986 to regulate price. ${ }^{135}$

Certainty of legal process and the establishment of case law would maintain dynamic efficiency. By not increasing uncertainty, the Privy Council decision would not change the option value of deferring investment and thus would maintain dynamic efficiency. If the Privy Council decision increased uncertainty, then it would adversely affect dynamic efficiency.

In response to the Privy Council's decision, the government stated that it opposed the use of the ECPR "because it had the potential to lessen competition." ${ }^{136}$ The rationale for this divergence with the Privy Council's view can be found in a report prepared by the Ministry of Commerce \& The Treasury, (1995, paras. 110,111 \& 124-126). The report proposed that there might be "dynamic benefits of competition" 137 from pricing interconnection below the ECPR. It is argued that pricing below the ECPR price would encourage entry, including potentially productively inefficient operators, who would compete resulting in an efficient outcome. Decreasing the price for interconnection may result in increased entry and thus a reduction in retail prices.

Rather than focus on the competitive conduct considered by the Privy Council, the government posed a policy intended to influence entry into the downstream toll-call market. It presented a view of industry structure and its effect on efficiency that influenced the finally agreed prices. The Ministry of Economic Development notes: "The terms finally agreed between the companies [Telecom and Clear] set access prices at levels below those implied by the Baumol-Willig Rule." ${ }^{138}$ Even though there was no instituted ISR of access, there was tacit ISR of access, with the government taking views of policy that were diverging from ATR.

135 ("Telecom Corporation of New Zealand Ltd v Clear Communications Ltd," 1994, p. 407).

${ }^{136}$ Ministry of Economic Development (2001, p. 6).

${ }_{137}$ Ministry of Commerce \& The Treasury (1995, paras. 9, 110 and 124).

${ }_{138}$ Ibid. 


\subsection{Adaptation of contracts in a dynamic market under ATR}

Telecom and Clear entered into an interconnection agreement in 1996 that was to expire in 2000. ${ }^{139}$ Significant unexpected changes in supply and demand conditions followed, which led to changes to interconnection contracts in 1999. These contractual changes, which included the introduction of new interconnection services, are collectively known as the ' 0867 package' for reasons discussed below. The 0867 package was tested in the courts to determine whether or not Telecom had exercised an anti-competitive use of market power under s 36 of the Commerce Act 1986. The Commerce Commission claimed that Telecom contravened s 36 by making an unlawful use of a dominant position in a market when it introduced the 0867 package in 1999. ${ }^{140}$ At the end of the legal process in 2010, the New Zealand Supreme Court decided that Telecom had not made anti-competitive use of market power in implementing the 0867 package. The Supreme Court decision also reaffirmed the 1994 Privy Council decision that the counterfactual test was appropriate for identifying anti-competitive conduct under s 36 of the Commerce Act 1986.141

A feature of the 0867 package is that it was a contemporaneous response to rapid and unexpected changes in market conditions. Another feature of the 0867 initiative is that it arguably precipitated the advent of ISR of access to the incumbent's network. ${ }^{142}$ Even though the courts ultimately decided the conduct was not anticompetitive, by introducing ISR, the government's actions indicate that it believed different policy settings would enhance market efficiency.

The local access interconnection agreement that Clear and Telecom entered into in 1996 enabled them to hand over local calls that originated on their networks

\footnotetext{
139 Ministry of Commerce (1998, p. 20).

140 ("The Commerce Commission v Telecom Corporation of New Zealand Ltd," 2009, para.1).

141 The 0867 case was the first time the recently established Supreme Court had considered competitive conduct under the Commerce Act s 36.

142 The New Zealand Government Ministerial Inquiry into Telecommunications (2000, p. 97, sect. 10.1) noted that market participants generally expressed dissatisfaction with Telecom's actions in relation to the introduction of the 0867 package. It also noted that a contributing factor in the 0867 dispute at that time had been the terms of the TelecomClear interconnection agreement. The Inquiry recommended the regulation of interconnection.
} 
and terminated on the other carrier's local access network, as Figure 3

illustrates. Telecom paid 2 cents per minute to Clear for Clear to terminate a call on its network. ${ }^{143}$ Clear paid Telecom more for Telecom to terminate a call on its network. Telecom claimed the difference included a contribution to the cost of providing the Kiwi Share Obligation (KSO). ${ }^{144}$

This interconnection agreement did not anticipate the subsequent growth in dial-up internet traffic. ${ }^{145}$ The contract was based on the calling characteristics traditionally associated with consumers making voice calls, particularly the characteristic that on average the calls that consumers made and received would be in balance. This expectation combined with the difference between Telecom's and Clear's termination rate implied that Clear was expected to make netpayments to Telecom for local-access interconnection. ${ }^{146}$

Before the introduction of commercial broadband services in 1999, consumers accessed the internet by subscribing to a dial-up internet access service offered by internet service providers (ISP). ISPs rented access lines to the PSTN from Telecom or Clear. ISPs connected these access lines to a bank of modems that were in turn connected to the internet backbone by a data network with elements either leased or owned by the ISPs. As well as providing dial-up access to the internet, ISPs supplied homepage and email services, which are now not necessarily bundled in with internet access and are available from service providers on the internet.

The growth in demand for dial-up internet access was rapid and unforeseen when Telecom and Clear entered into the agreement in 1996. ${ }^{147}$ In 1992, the number of internet host addresses was negligible; by 1995 the number had

\footnotetext{
143 Evans (2007 para. 9).

144 ("The Commerce Commission v Telecom Corporation of New Zealand Ltd," 2008 para. 20).

145 ("The Commerce Commission v Telecom Corporation of New Zealand Ltd," 2009 para. $11 \& 26)$.

146 ("The Commerce Commission v Telecom Corporation of New Zealand Ltd," 2009 para. 10).

147 ("The Commerce Commission v Telecom Corporation of New Zealand Ltd," 2009 para. $11 \& 26)$.
} 
increased to approximately 15,000, in 1996 to 53,000, in 1997 to 84,000, and in 1998 it increased to $169,000 .{ }^{148}$ Between March 1998 and 1999 the proportion of total traffic volume on the local call network that was internet traffic almost doubled to $31 \% .{ }^{149}$

This rapid growth in demand was also accompanied by a change in the characteristics of calls. In 1999, the duration of a voice call within a local call area was on average three minutes, whereas the duration of an internet dial-up call was on average 22 minutes. ${ }^{150}$ Another change was the shift in the time of the call volume peak. The call volume for voice calls peaked at approximately 7.oopm on weekdays, whereas for dial-up internet calls peaked at approximately 9.0opm. A further difference was related to the balance between calls made and received. On average, residential consumers made and received the same number of voice calls, thus the volume of voice calls to and from a residential consumer was in balance. In contrast, dial-up internet call volume was out of balance as residential consumers always called their ISP.

The significant increase in demand for dial-up internet access and the fact that dial-up internet calls were out of balance resulted in Clear receiving net payments from Telecom. By July 1999, Telecom's interconnection termination payments had reached $\$ 700,000$ per week, and the liability was expected to increase to $\$ 70$ million per year. ${ }^{151}$ As $99 \%$ of residential customers were connected to Telecom's telephone network, nearly all the calls to the internet originated on Telecom's network. Telecom's termination payments to Clear increased with the number of consumers using ISPs connected to Clear's network. There was no similar balancing growth in calls from Clear's network back to Telecom's network, as Clear had virtually no residential customers.

\footnotetext{
${ }^{148} \mathrm{An}$ internet host address is the internet address of a service provider or more specifically a computer connected to the internet. See appendix A.7 for a discussion on internet hosts.

149 ("The Commerce Commission v Telecom Corporation of New Zealand Ltd," 2008 para. $60 \& 61)$.

150 ("The Commerce Commission v Telecom Corporation of New Zealand Ltd," 2008 para. $57 \& 59)$.

${ }^{151}$ Evans (2007, para.14).
} 
Prior to the introduction of the 0867 package, Clear had a strong incentive to exploit the arbitrage opportunity provided by the unexpected growth in internet calls and the 1996 interconnection agreement. It did this by growing the volume of dial-up internet calls terminating on its network. The 2 cent per minute payment that Clear received was greater than Clear's marginal cost for terminating a call on its network. Clear used the margin between 2 cents per minute and marginal cost to fund further growth in termination traffic by subsidising ISPs connected to its network. This subsidy enabled ISPs on Clear's network to offer free dial-up internet access to consumers. ${ }^{152}$ In 2000, several free ISPs emerged in the market although most ceased their free service within a year. ${ }^{153}$ Revenue received by some free ISPs via this source is reported to have been as much as approximately $\$ 500,000$ per month. ${ }^{154}$ In addition to the losses incurred due to increasing termination payments, Telecom anticipated that under the status quo an additional \$205 million investment would be required to PSTN over the following three years in order to meet forecast growth in dialup internet traffic. ${ }^{155}$

Telecom did not recover the increased capital and termination costs from residential consumers due to the free local calls provided by the KSO. Telecom did not charge residential consumers for these growing costs as it treated residential customers' dial-up internet calls to a local phone number the same as a voice call to a local phone number.

In response to the growth in termination payments and the potential growth in capital expenditure, Telecom implemented the 0867 package in 1999.156 Telecom also introduced a service called Internet Dial-up Access (IDA) to manage internet dial-up calls. Consumers dialled their ISPs via a specific number range,

152 Karel (2003, p. 23).

153 Karel (2003, pp. 18-20).

154 Karel (2003, p. 65) cites pers. comm.

155 ("The Commerce Commission v Telecom Corporation of New Zealand Ltd," 2008 para. 71).

156 In addition to the 0867 package, Telecom paid the ISP Ihug up to $\$ 16$ million for it to connect exclusively to Telecom's network, allowing Telecom to avoid termination payments to Clear for Ihug traffic (L. Evans, 2007 para.13). 
starting with the four digits 0867 , which identified calls as dial-up internet calls, enabling Telecom to separate these calls from voice calls on its network. ${ }^{157}$

Telecom considered that 0867 calls fell outside the interconnection agreement agreed in $1996 .{ }^{15^{8}}$ Telecom proposed that there be no charge for terminating this traffic on another network.

Telecom also considered that dial-up internet calls fell outside the KSO. A retail charge was introduced to complement IDA. Telecom did not charge consumers for internet dial-up calls made either to ISPs using the 0867 service or Xtra (a business unit of Telecom). Telecom charged consumers for calls to ISPs using local telephone numbers, either on Telecom's or another network provider's network. This was called the Internet Dial-up Charge (IDC). Consumers making internet calls to a local number (not a 0867 number) were charged 2 cents per minute after the first 10 hours of internet calls in a month. The combination of IDC and IDA is the 0867 package. ${ }^{159}$

The 0867 package aligned the retail price for internet calls with the interconnection termination rate, thereby eliminating the arbitrage. Residential consumers were not charged for internet calls to 0867 numbers, and there was no charge for terminating this traffic on another network. Residential consumers making internet calls to a local telephone number were charged 2 cents per minute after the first 10 hours of calling in a month, and Telecom was charged 2 cents per minute for calls terminating at local access number on Clear's network.

157 Calls made to the 0867 number range were directed to modems located in the local exchange nearest to the consumer making the call. The IDA service separated internet and voice call traffic on the network close to the retail customer. This enabled internet traffic to be managed separately from voice traffic. Technically, this meant that internet traffic could be diverted on an IP network and thus carried more efficiently than over the public switched telephone network. It also meant that the 0876 traffic would fall outside the interconnection agreements.

${ }_{158}$ ("The Commerce Commission v Telecom Corporation of New Zealand Ltd," 2008, para 71$)$.

159 ("The Commerce Commission v Telecom Corporation of New Zealand Ltd," 2008, para 71$)$. 
In 1999, Telecom sought the approval of the government to introduce the 0867 package. The government agreed to the introduction subject to conditions designed to protect the interests of residential consumers: ${ }^{160}$

- Calls to 0867 numbers must be free to residential customers.

- Telecom must ensure residential calls to 0867 numbers are of no worse quality than ordinary residential calls to the internet.

- Telecom must monitor standards to ensure quality is maintained.

- Telecom must not implement the IDC before 1 November 1999.

- $\quad 0867$ calls to commercial organisations using 0867 numbers to a carrier network interface are to be free.

Following a change of government in November 1999, Telecom agreed to temporarily suspend IDC, pending the completion of a government inquiry into the telecommunications industry. The government inquiry into the telecommunications industry led to the arrival of ISR in 2001. ${ }^{161}$ IDC was not reinstated.

In addition to the advent of ISR, the Commerce Commission pursued litigation, claiming that Telecom contravened s 36 of the Commerce Act 1986 by making an unlawful use of a dominant position in a market when it introduced the 0867 package. ${ }^{162}$ The High Court of New Zealand concluded in 2008 that the introduction of the 0867 package did not contravene s 36 of the Act. ${ }^{163}$ The Commerce Commission appealed this decision, which the Court of Appeal of

160 ("The Commerce Commission v Telecom Corporation of New Zealand Ltd," 2008, para. 72).

161 ("The Commerce Commission v Telecom Corporation of New Zealand Ltd," 2008, para.73).

162 ("The Commerce Commission v Telecom Corporation of New Zealand Ltd," 2009, para.1).

163 ("The Commerce Commission v Telecom Corporation of New Zealand Ltd," 2008, para. 114). 
New Zealand dismissed in 2009. ${ }^{164}$ In 2010, the Supreme Court of New Zealand dismissed a further appeal by the Commerce Commission. ${ }^{165}$

The High Court of New Zealand (High Court) did not accept that the 0867 package was not injurious to competition. ${ }^{166}$ It found that the termination payments, and the resultant subsidies to ISPs, leading to low, even zero, prices to consumers were not the result of competition, but were the result of the KSO and the operation of the 1996 interconnection agreement in an era of escalating internet use. The High Court found that the introduction of the 0867 package could have led to increased dynamic efficiency, due to the removal of the incentive to grow inefficient dial-up internet traffic. ${ }^{167}$ In response to the claim that the 0867 package had sent a signal to the market that Telecom would use its dominance to unilaterally rewrite contracts, the High Court indicated that Telecom's response could not reasonably be regarded as an indicator of the way that it would act in the future. ${ }^{168}$

Having dismissed the appeal on the grounds that the Commerce Commission failed to show that Telecom's conduct could not be rational in a competitive market, ${ }^{169}$ the Court of Appeal raised a concern with the counterfactual test:

The reality of the case is that it is about terminating charges which are markedly above cost and the willingness of Telecom, under threat of regulation, to share its monopoly rents with Clear. Any realistic counterfactual must take monopoly rents as a given. It is difficult to see

\footnotetext{
164 ("The Commerce Commission v Telecom Corporation of New Zealand Ltd," 2009, para.99).

165 ("The Commerce Commission v Telecom Corporation of New Zealand Ltd," 2010, para 50).

166 ("The Commerce Commission v Telecom Corporation of New Zealand Ltd," 2008, para. 108).

167 ("The Commerce Commission v Telecom Corporation of New Zealand Ltd," 2008, para. 112).

168 ("The Commerce Commission v Telecom Corporation of New Zealand Ltd," 2008, para. 111).

169 ("The Commerce Commission v Telecom Corporation of New Zealand Ltd," 2009, para. 98).
} 
how there can be any plausible counterfactual about the distribution of monopoly rents where non-dominance has to be assumed: in the absence of dominance there can be no monopoly rents. ${ }^{170}$

The conjectural-variations framework discussed in section 2.3 indicates that market power cannot be separated from economic rents, as this statement suggests. The counterfactual test assesses whether or not a monopoly with market power could rationally engage in the disputed conduct. Economic rents are dependent on market power, therefore the hypothetical absence of market power under the counterfactual test must imply that economic rents are absent. ${ }^{171}$ It follows that the counterfactual test determines whether the conduct could have been rational if the firm did not have economic rents. If it is shown that the monopoly's conduct was not rational without economic rents present then market power was a factor in the conduct, otherwise economic rents are an irrelevant consideration.

The Supreme Court also dismissed the Commerce Commission's final appeal on the grounds that the Commission failed to show that a firm like Telecom but without market power could not have rationally introduced the 0867 packages. ${ }^{172}$ In addition, the Supreme Court decision reaffirmed the counterfactual test as appropriate for determining whether or not a firm with market power has acted anti competitively. ${ }^{173}$

In contrast to the constancy of ATR, the institution of ISR has shown a greater willingness to change and adapt to changing market conditions. That is, there has been a persistent view regarding the structure that the competitive market should take. Following the Privy Council decision on Telecom v Clear, the government presented a view that interconnection prices should be less than the

\footnotetext{
170 ("The Commerce Commission v Telecom Corporation of New Zealand Ltd," 2009, para. 100).

${ }^{171}$ The reverse is not necessarily true. That is, a firm with market power either does or does not earn economic rents.

172 ("The Commerce Commission v Telecom Corporation of New Zealand Ltd," 2010, para. 49).

173 ("The Commerce Commission v Telecom Corporation of New Zealand Ltd," 2010, paras. 31-36).
} 
ECPR. The 0867 package was a catalyst to the introduction of the industry specific regulator. In contrast, the courts determined that both the TelecomClear interconnection agreement and the 0867 package were not anticompetitive.

The New Zealand Government instituted the industry specific regulator within the Commerce Commission in 2001. The role of the regulator is to determine the terms of access to regulated services such as interconnection between network operators and the resale of the incumbent's (Telecom's) retail services. The regulator also investigates whether to regulate access to new services.

\subsection{Adaptation of contracts to a dynamic market under ISR}

In 2003, New Zealand's telecommunications industry regulator investigated whether or not to regulate access to unbundled local loop (ULL), unbundled bitstream access (UBA), and unbundled partial circuits (UPC). ${ }^{174}$ Access to ULL allows entrants to offer consumers broadband internet access service in competition with the incumbent by installing electronic equipment in the incumbent's exchanges and connecting it to the copper wires that lead to consumers' premises. Access to UBS allows entrants to offer consumers broadband internet access services, without installing their electronic equipment in the incumbent's local exchanges, by providing access to unbundled elements of the incumbent's broadband service. Access to UPC allows entrants to offer business data services by using unbundled elements of the incumbent's point-topoint data services.

The regulator was required to recommend to the government whether or not to regulate access to ULL and UBS based on whether or not regulation would promote competition in telecommunications markets for the long-term benefit of end users. 175 The regulator assessed the state of competition in wholesale markets in which ULL, UBS and UPC could be supplied. Where the market was found to be competitive, the regulator's view was that regulation could not improve efficiency. ${ }^{176}$ Where competition was limited, the analysis considered

\footnotetext{
174 Commerce Commission (2003).

175 Telecommunications Act 2001 (s 18).

${ }^{176}$ Commerce Commission (2003, para. 305).
} 
whether or not the benefits of regulation exceeded the costs. ${ }^{177}$ Static, partial equilibrium models were used to quantify the benefits and costs of regulation. The main benefit of regulation was the reduction in the retail price for broadband access.

The regulator recommended the government regulate UBS, and not regulate UPC and ULL, subject to Telecom agreeing to certain conditions. Regarding UPC, the regulator stated that "cost-based pricing of at least those components of the service reliant on legacy assets is the efficient form of pricing that should be applied." ${ }^{178}$ Telecom complied with this condition and the government did not regulate UPC. ${ }^{179}$

Regarding ULL, when accepting the regulator's recommendations, the Minister of Communications (2004) indicated that he:

... will watch developments very closely and will be taking particular note at how quickly and successfully Telecom moves to promptly facilitate the delivery of higher-speed, more competitive broadband for New Zealand.

On the same day, ${ }^{180}$ Telecom (2004b) announced it had set a target of connecting 250,000 residential broadband customers by the end of 2005 and that "... about a third of the 2005 target would be delivered by competitors ...".

By December 2005 Telecom had 279,123 residential broadband connections, of which $22.7 \%$ were wholesale connections. Telecom met the target for residential broadband connections (250,000 connections), but it had failed to meet the target for the proportion of connections (33\%) that would be with its wholesale customers. ${ }^{181}$

\footnotetext{
177 Commerce Commission (2003, pp. 77,78).

${ }_{178}$ Commerce Commission (2004).

179 Minister of Communications (2004).

18019 May 2004.

${ }^{181}$ Commerce Commission (2006).
} 
In May 2006, the government announced a plan to introduce new regulations. ${ }^{182}$ Although not specifically expressed in these terms, an interpretation of the intended purpose of the new regulations was to enhance dynamic efficiency. The government compared the performance of the New Zealand telecommunications sector and regulatory policies with those of other OECD countries and came to the view that New Zealand's performance would be enhanced by following the regulatory policy adopted by other OECD countries. The government stated that the policies were to ensure that the telecommunications sector becomes more competitive, with particular emphasis that the availability and quality of broadband services was a key enabler of economic growth. ${ }^{183}$

The new regulations included the unbundling of Telecom's local loop and enhancing the quality of the regulated UBS. In addition, the May 2006 announcement questioned whether "additional measures are warranted ... such as the structural separation of Telecom's retail and lines operations." 184 The government did not introduce structural separation, but introduced operational separation of Telecom's retail and local-loop operations. ${ }^{185}$ These new regulations were instituted in December 2006 by an amendment to the Telecommunications Act 2001. ${ }^{186}$

The new regulations were intended to facilitate competition by improving access to the local loop. The government's view was that there was a lack of effective competition. ${ }^{187}$ The natural monopoly of the local loop was enduring and restricted the development of competition. ${ }^{188}$ There was the view that

\footnotetext{
182 Minister of Communications (2006a).

183 Minister of Communications (2006b, paras. 1-8).

184 Minister of Communications (2006a). interest.

186 New Zealand Parliament (2006).

187 Minister of Communications (2006b, para. 34).

188 Minister of Communications (2006b, para. 35).
}

185 Structural separation includes separating the ownership of retail and local-loop operations' assets. Under operational separation, Telecom maintains ownership of these assets, the local-loop operation is not to discriminate between Telecom's retail operations and external wholesale customers, and Telecom's retail and local-loop operations' commercial decisions are generally expected to be made in their own 
"[v]ertically integrated incumbents have the incentives and ability to place access-seekers at a competitive disadvantage by supplying wholesale services on less favourable terms and conditions than those made available to their own retail arm." 189 This view was supported by comments made by stakeholders regarding the conduct of Telecom. ${ }^{190}$ This view was also supported by Telecom's conduct following the decision in 2003 to not regulate ULL.

When accepting the regulator's recommendation not to regulate ULL, the government had expected the decision "would lead to a co-operative development of an effective wholesale market, and provide incentives for Telecom to quickly deploy its Next Generation Network (NGN)."191 The investment in residential NGN infrastructure had not developed as quickly as the government expected. ${ }^{192}$ In addition, while recognising that Telecom's ability to deliver the wholesale target depended on competitors delivering effectively, the government's view was that the failure to meet the target was due to Telecom's failure to promptly resolve UBS supply agreements. ${ }^{193}$

In sum, the government had an expectation that the competitive conduct would follow from the implementation of a particular market structure. However, as discussed in chapters 2 and 3 , the structure of a dynamic market follows from the competitive conduct of the firms, and that structure can evolve and change unpredictably with the conduct of the firms.

\subsection{Entry and exit as an indicator of market performance}

The deregulation of the telecommunications market in 1989 opened the market to competitive entry. This section traces the subsequent process of entry, mergers and acquisitions. The regulator's annual process for determining the funding of the TSO conveniently supplies the list of network operators over the

\footnotetext{
189 Minister of Communications (2006b, para. 36).

190 Minister of Communications (2006b, para. 37).

${ }^{191}$ Minister of Communications (2006b, para. 40). The Next Generation Network is a communications network based on the internet protocol that enables firms to offer services such as voice, video conferencing, and video streaming at a quality better than available from best-efforts grade of internet service.
}

192 Minister of Communications (2006b, para. 40).

193 Minister of Communications (2006b, para. 41). 
period from 2007 to 2008 that have an interconnection agreement with Telecom in order to provide telephony services. ${ }^{194}$ Table 4 lists the telecommunications service providers in operation over 2007 and 2008, ranked by their share of industry revenue, with the date when the network operator or their predecessor first entered into the New Zealand market.

Of the 10 entrants or their predecessors, nine entered the market before the start of ISR in 2001, when competition was governed solely by ATR. The table also indicates that there has been a significant number of mergers and acquisitions following entry. This entry and merger activity indicates that the operation of the market before 2001 was sufficiently efficient for these transactions to take place, allowing firms to take advantage of expected gains. Table 4 also indicates that the number of new entrants after 2001 (two firms) was significantly less than before 2001 (11 firms).

194 Commerce Commission (2008a, p. 29). 
Table 4: Market entry of firms with telephony service and interconnection agreement during 2007 and 2008

\begin{tabular}{|c|c|c|c|c|}
\hline $\begin{array}{l}\text { Telecommunications } \\
\text { Service Providers }\end{array}$ & $\begin{array}{l}\text { Share of } \\
\text { TSO Liable } \\
\text { Industry } \\
\text { Revenue } 195\end{array}$ & $\begin{array}{l}\text { Predecessors } \\
\text { and Former } \\
\text { Names }\end{array}$ & $\begin{array}{l}\text { Market } \\
\text { Entry }\end{array}$ & Brief Description and History \\
\hline Telecom New Zealand & $67 \cdot 368 \%$ & $\begin{array}{l}\text { New Zealand Post } \\
\text { Office }\end{array}$ & March 1987 & Formed by separating from New Zealand Post Office. \\
\hline \multirow[t]{2}{*}{$\begin{array}{l}\text { Vodafone } \\
\text { New Zealand }\end{array}$} & $26.074 \%$ & $\begin{array}{l}\text { BellSouth New } \\
\text { Zealand }\end{array}$ & July 1993 & $\begin{array}{l}\text { BellSouth launched a mobile phone service in Auckland and then built a } \\
\text { national network (Ministry of Commerce, 1997, s. 7.3). Vodafone } \\
\text { acquired BellSouth in November } 1998 \text { (Vodafone, 2009). }\end{array}$ \\
\hline & & Ihug & August 1994 & $\begin{array}{l}\text { Launched as an internet service provider (Twose, 2008). Vodafone } \\
\text { acquired Ihug in } 2006 \text { (Vodafone, 2009). }\end{array}$ \\
\hline \multirow[t]{3}{*}{ TelstraClear } & $5 \cdot 791 \%$ & $\begin{array}{l}\text { Clear } \\
\text { Communications }\end{array}$ & April 1991 & $\begin{array}{l}\text { Clear commenced by offering domestic and international toll-call } \\
\text { services (Ministry of Commerce, 1997, s. 7.1). } \\
\text { TelstraSaturn and Clear merged in December } 2001 \text { (TelstraClear, 2001). }\end{array}$ \\
\hline & & $\begin{array}{l}\text { Telstra New } \\
\text { Zealand }\end{array}$ & 1996 & $\begin{array}{l}\text { Telstra relaunched its New Zealand operation providing virtual private } \\
\text { networks, national and international calls, ISDN services and local } \\
\text { access (Ministry of Commerce, 1997, Section 7.3). Telstra New Zealand } \\
\text { and Saturn announced a merger in February 2000 to form TelstraSaturn } \\
\text { (Ministry of Economic Development, 2001, s. 2). }\end{array}$ \\
\hline & & $\begin{array}{l}\text { Saturn } \\
\text { Communications }\end{array}$ & May 1998 & $\begin{array}{l}\text { Saturn Communications launched the first residential local wire network } \\
\text { in competition with the incumbent Telecom. The network was launched } \\
\text { in the Hutt Valley, then subsequently expanded to all of (cont.) }\end{array}$ \\
\hline
\end{tabular}

195 Commerce Commission (2008a, p. 29). 


\begin{tabular}{|c|c|c|c|c|}
\hline $\begin{array}{l}\text { Telecommunications } \\
\text { Service Providers }\end{array}$ & $\begin{array}{l}\text { Share of } \\
\text { TSO Liable } \\
\text { Industry } \\
\text { Revenue }\end{array}$ & $\begin{array}{l}\text { Predecessors } \\
\text { and Former } \\
\text { Names }\end{array}$ & $\begin{array}{c}\text { Market } \\
\text { Entry }\end{array}$ & Brief Description and History \\
\hline & & & & $\begin{array}{l}\text { Wellington, the Kapiti Coast and Christchurch (Ministry of Commerce, } \\
\text { 1998, p. 9). Telstra New Zealand and Saturn announced a merger in } \\
\text { February 2000 to form TelstraSaturn (Ministry of Economic } \\
\text { Development, 2001, s. 2). }\end{array}$ \\
\hline WorldxChange & $0.287 \%$ & & 1995 & $\begin{array}{l}\text { Commenced business as an international and national toll provider } \\
\text { (WorldxChange Ltd, 2000). }\end{array}$ \\
\hline CallPlus & $0.172 \%$ & & 1997 & $\begin{array}{l}\text { Commenced business as a national service provider offering national and } \\
\text { international toll bypass (Free Internet Access Ltd, CallPlus Ltd, \& Attica } \\
\text { Communications Ltd, 2000). }\end{array}$ \\
\hline Compass & $0.138 \%$ & & 1995 & $\begin{array}{l}\text { Compass began by providing fax broadcast services to business } \\
\text { customers (Compass, 2009). }\end{array}$ \\
\hline Orcon & $0.110 \%$ & & 1997 & $\begin{array}{l}\text { Entered into the ISP market in 1997. Prior to this date it provided } \\
\text { computer support (Kordia Media Release, 2007). }\end{array}$ \\
\hline Woosh & $0.050 \%$ & Walker Wireless & 1999 & $\begin{array}{l}\text { Launched in } 1999 \text { offering fixed wireless broadband services (Woosh, } \\
\text { 2009). }\end{array}$ \\
\hline TeamTalk & $0.007 \%$ & & 1995 & $\begin{array}{l}\text { Launched early in } 1995 \text { offering a trunked mobile radio-based service, in } \\
\text { competition with Telecom's established Fleetlink mobile radio service } \\
\text { (Ministry of Commerce, 1997, Section 7.4). }\end{array}$ \\
\hline Airnet & $0.002 \%$ & & 2002 & $\begin{array}{l}\text { Launched in } 2002 \text { offering fixed wireless broadband services to } \\
\text { businesses in the Hawke's Bay region. }\end{array}$ \\
\hline 2degrees & $0.001 \%$ & $\begin{array}{l}\mathrm{NZ} \\
\text { Communications, } \\
\text { and Econet }\end{array}$ & $\begin{array}{l}\text { August } \\
2009\end{array}$ & $\begin{array}{l}\text { 2degrees launched its mobile service in August } 2009 \text { (2degrees mobile, } \\
\text { 2009a). The development of 2degrees' network started in February } 2001 \\
\text { (2degrees mobile, 2009b). }\end{array}$ \\
\hline
\end{tabular}


This does not provide a complete picture of the market entry and exit, particularly amongst ISPs. Karel $(2003$, pp. 16,17) observes that at the start of 1996 there were 30 ISPs in New Zealand, most of which served regional markets. With the increase in price-based competition, some of the operators exited the market or were acquired to form larger ISPs that could take advantage of the economies of scale. ISPs continue to provide internet services in the retail market by leasing access to infrastructure in the wholesale market, with some bundling telephony services that utilise the incumbent's regulated retail telephony services under ISR.

Table 5: Market entry date of wholesale operators in operation in 2009

\begin{tabular}{|l|c|l|}
\hline \multicolumn{1}{|c|}{$\begin{array}{c}\text { Wholesale } \\
\text { Opetwork } \\
\text { Operator }\end{array}$} & $\begin{array}{c}\text { Market } \\
\text { Entry }\end{array}$ & \multicolumn{1}{c|}{ Comments } \\
\hline CityLink & 1995 & $\begin{array}{l}\text { Citylink (2009) privately owns and } \\
\text { operates a regional fibre network in } \\
\text { Christchurch, Wellington and Auckland. }\end{array}$ \\
\hline Enable Networks & 2007 & $\begin{array}{l}\text { Owned by the Christchurch City Council, it } \\
\text { operates a regional fibre network in } \\
\text { Christchurch (Enable Networks, 2009). }\end{array}$ \\
\hline FX Network & 2005 & $\begin{array}{l}\text { FX Network (2008) is a subsidiary of a } \\
\text { firm that operates network in various } \\
\text { countries. It operates a national fibre } \\
\text { transmission network. }\end{array}$ \\
\hline Kordia & $\begin{array}{l}\text { Until 2003, it was the transmission arm of } \\
\text { Television New Zealand, until being } \\
\text { established as a State Owned Enterprise } \\
\text { with an independent board. It operates } \\
\text { wireless access and backhaul networks } \\
\text { throughout New Zealand (Kordia, 2009). }\end{array}$ \\
\hline $\begin{array}{l}\text { Vector } \\
\text { Communications }\end{array}$ & $\begin{array}{l}\text { Vector (2004) is a publicly listed company } \\
\text { with a consumer trust as the majority } \\
\text { shareholder. It operates a regional fibre } \\
\text { network in Auckland. }\end{array}$ \\
\hline
\end{tabular}

In addition, regional and national communications network providers entered into the market, investing in transmission and distribution infrastructure, offering wholesale network services to retail service providers. These firms are listed in Table 5, with a market entry date where it could be found. There are an 
additional eight regional fibre network operators and one wireless regional network operator, which are not included in Table 5, as entry dates could not be found. ${ }^{196}$ These firms, offering only wholesale services, do not appear in Table 4 as they do not have an interconnection agreement with Telecom, thus they are not required to contribute to funding the TSO. They make services available to firms providing retail services, including those listed in Table 4, as well as to firms that only offer internet access and data services.

Tables 4 and 5 suggest that there was an ongoing process of entry by competitors since the market was opened to competition through to the 2009. Comparing Tables 4 and 5 also indicates a change in the pattern of entry. Before 2001, entry was dominated by firms offering telephony services. After 2001, entry was dominated by firms specialising in the wholesale or retail market, and internet services.

The introduction of ISR in 2001 was contemporaneous with the introduction of broadband internet access. The pattern of entry described above suggests that either the advent of ISR acted as a disincentive for firms to invest in technologies required to provide telephony services and interconnect with Telecom's network, and/or the arrival of broadband and the internet made new investment in telephony services redundant for most entrants.

It seems reasonable to expect that the growth in wholesale transmission capacity was due to the growth in demand for internet services. As observed in appendix A.3 the volume-weighted mean annual growth rate of internet traffic between 2002 and 2008 was $68 \%$ on average. Entrants supplied network capacity in response to this growth in demand. Such a significant growth in demand might also have been expected to result in an increase in the number of firms offering telephony services. The fact that there were 11 entrants before 2001 and two after 2000 suggests that there is no inherent barrier for firms to offer telephony

\footnotetext{
${ }^{196}$ Amuri.net operates wireless access networks in the North Canterbury region; Counties Power operates a fibre network in the Counties-Manukau region; Digital Nation operates a fibre network in the Manawatu-Wanganui region; InverNET in conjunction with Venture Southland operate a fibre optic network in Invercargill; Northernpower operates a fibre network in Whangarei; SmartLinx3 operates fibre and wireless access networks in Upper Hutt, Lower Hutt and Porirua; thelink operates fibre access and backhaul networks in the Nelson and Marlborough regions; Velocity Network operates fibre access networks in Hamilton; and WIC operates wireless access networks in Dunedin (The National Broadband Map, 2009).
} 
services. This might suggest that it is generally more profitable to offer network services in the wholesale market than to offer retail telephony services and have an interconnection agreement with the incumbent.

In addition, the introduction of regulation of access to the incumbent's retail telephony services, under ISR, would have meant that entrants could avoid investing in telephony equipment. As well as regulating interconnection, ISR also required the incumbent to make its retail access to the telephone network available to competitors at the retail price less a discount. The discount is equal to the cost the incumbent avoids by supplying the service in the wholesale instead of the retail markets.

The significant increase in demand for internet services, combined with the fact that telephony services are available over the internet or the incumbent's telephony service can be resold, are plausible reasons for new entrants not investing in telephony equipment. If the reason for the reduction in investment in telephony equipment was due to the option to resell the incumbent's services then this may have lessened the extent of dynamic competition, and thus dynamic efficiency, as the extent of innovation in these service would have been limited to the incumbent's retail services. If the reason for the reduction in investment in telephony infrastructure was due the growth in demand for internet services, then it would suggest that the advent of ISR of interconnection with the incumbent's network was made redundant by technological progress.

\subsection{Non-price competition in the access market}

Firms engage in competitive rivalry based on service differentiation resulting from investing in successive waves of new technology. This enables them to offer an ever-increasing range of better-quality services. Consumers benefit from this rivalry as firms seek out a competitive advantage.

The process of dynamic competition in mobile broadband that was initiated prior to the arrival of ISR has continued unabated. However, the government's comments in 2006 regarding the quality of fixed-line broadband suggest that this was not sufficient to spur the investment necessary to meet the government's expectation regarding the desired quality of broadband access.

Figure 6, section 4.3, shows that DSL broadband was launched in New Zealand in June 1999, before the arrival of ISR in 2001. It shows that mobile broadband was launched in New Zealand in June 2002. It also shows that fixed-line and 
mobile broadband were launched in New Zealand before most other countries in the OECD.

Figure 6 illustrates the dynamic relationship between fixed-line and mobile broadband internet access. Fixed-line broadband was launched in all OECD countries before mobile broadband. This may have been a function of the timing of the availability of technology; however, the graph indicates that mobile broadband was launched in some countries before fixed-line broadband was launched in others. It seems that there was no technological reason that mobile broadband could not have been launched in some countries before fixed-line DSL broadband. An alternative explanation for the fact that mobile broadband followed DSL broadband is that the ordering was determined by dynamic competition between fixed and mobile services. ${ }^{197}$ The observed ordering suggests that mobile operators did not see the need to invest in mobile broadband services until fixed-line operators invested in broadband services, perhaps due to having a competitive advantage such as mobility. The launch of DSL broadband bettered this advantage thus inducing a response from mobile operators.

The absence of ISR in 1999 did not seem to have a detrimental effect on the decision to invest in fixed-line broadband internet access. Assuming that the technologies were universally available at the same time, it seems reasonable to suppose that the timing of the investment in broadband services between countries was due to country specific factors.

Rivalry in the New Zealand mobile market commenced the year that Telecom was formed in 1987, with the launch of the first mobile telephony services in New Zealand. ${ }^{198}$ Telecom had the monopoly for mobile telephony until 1993 when BellSouth entered into the mobile market using a digital technology. ${ }^{199}$ Entering into the market with a later, more modern technology allowed BellSouth to offer a broader range of services, particularly the short message

197 Quigley \& Sanderson (2005) discuss the implications of regulating wireline telephone services on dynamic efficiency, particularly on the adoption of new mobile technologies by consumers in Canada. Comparing Canada with other countries, they found that fixedline and mobile services were in the same market, and that the low regulated wireline prices were slowing take up of new mobile services.

198 Telecom (2004a para. 87).

199 Telecom (2004a para. 88). 
service (SMS), which Telecom could not offer. Telecom differentiated its service with greater geographic coverage. ${ }^{200}$

In 1998, Vodafone purchased BellSouth's mobile network. ${ }^{201}$ Vodafone invested in network and increased its geographic coverage thereby eroding Telecom's advantage. Telecom followed by investing in a new mobile network technology called CDMA in 2001. As well as enabling Telecom to match Vodafone's SMS, CDMA provided a basic form of wireless internet access and other services that Vodafone could not offer. ${ }^{202}$ Vodafone in turn responded by investing in new services, and Telecom again replied. The following diagram illustrates this competitive interaction between the two firms. Each firm invested in newer technology, enabling it to offer an ever-greater range of services of increasing quality in order to gain a competitive advantage.

Technological rivalry between the firms extended to the fixed-line network, as the list of wholesale access providers in Table 2 indicates, as well as between fixed and mobile networks. The growth in demand for internet services provided firms with an opportunity to offer better-quality internet access. Before 1999, residential consumers gained access to the internet by a dial-up connection. Consumers connected their computer to a modem that was connected to the telephone network, programming their modems to dial their internet service provider's telephone number, which in turn connected them to the internet.

\footnotetext{
200 Telecom (2004a para. 88).

201 Telecom (2004a para. 92).

202 Telecom (2004a para. 93).
} 
Figure 7: Technology rivalry between mobile operators

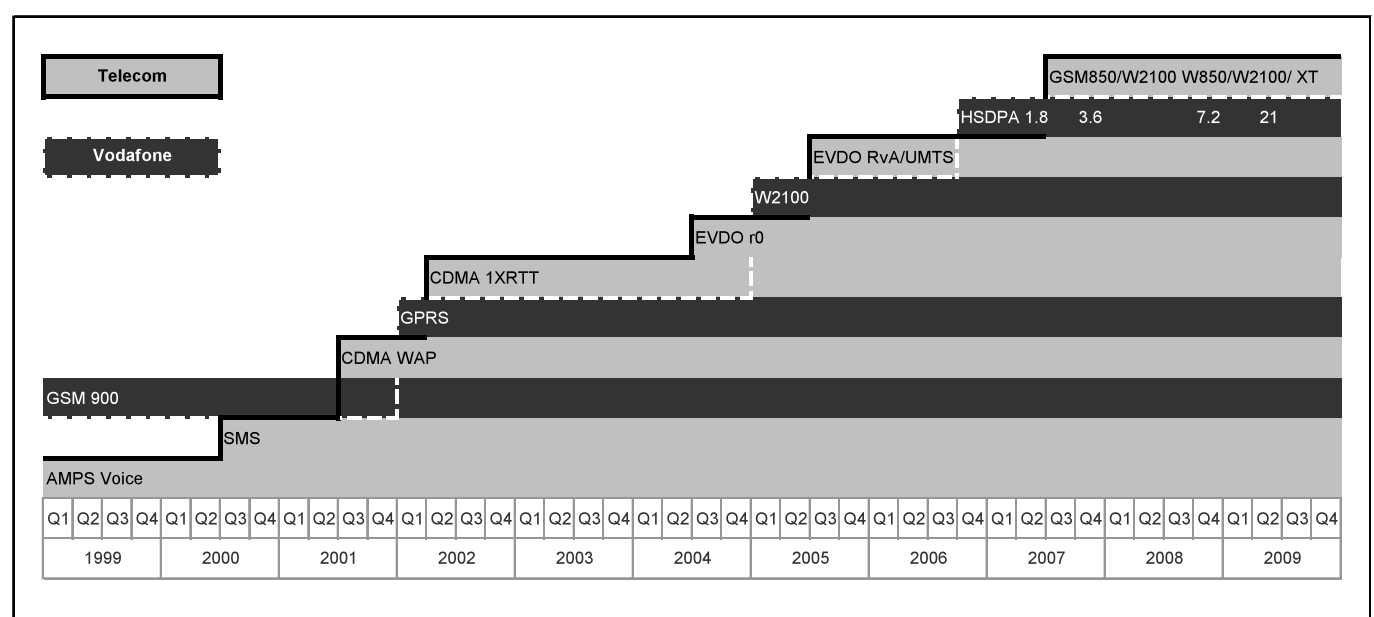

Source: Telecom (2009 para. 27)

Telecom launched its broadband internet access service in June 1999, which provided a better-quality service than dial-up internet access. Saturn Communication followed closely by launching a competing broadband service in Wellington in August 1999, and then a year later a broadband service in Christchurch. ${ }^{203}$ In addition, starting in 2001, Telecom and then Vodafone offered mobile broadband services that connect laptop computers and other devices to the internet. The quality of a mobile broadband connection is not as good as a fixed-line connection; however, mobility itself provides it with a significantly different and competitive feature.

\subsection{General price trends}

Overall, prices for telecommunications services have been decreasing in real terms. This is illustrated by the following graph, which compares price indices for access and calling with the Consumer Price Index (CPI). The bold vertical line indicates a structural break in the series due to a change in the composition of the baskets used to calculate the indices. 
Figure 8: Comparison of telecommunications and CPI indices ${ }^{204}$

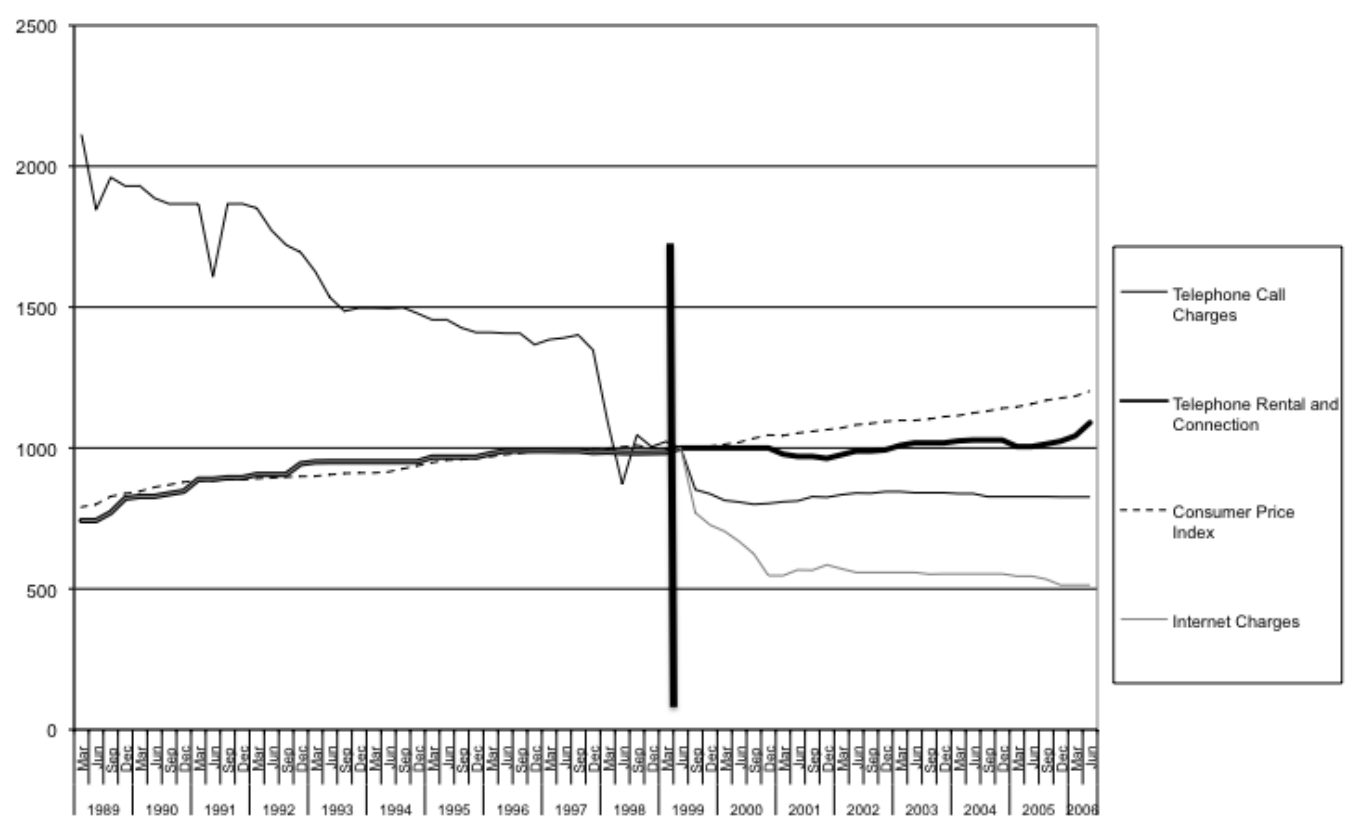

Source: Statistics New Zealand

These price changes represent the change in the average price of a call and the access fee; however, they do not represent the changes in the structure of access and calling. A feature of the pricing of telecommunications services is that consumers have a menu of non-linear tariffs to choose from. The analysis of two-part tariffs presented in appendix B, and illustrated by way of example in section 3.4, highlights that the structure as well as the level of prices determines the optimal tariff. Even though the above graph indicates that prices in general have been decreasing due to competition, it does not fully represent the benefits that competition brings to the structure of retail prices. The graph only presents the change in the average access fee and call price; however, it does not represent the change in the marginal price due to competition, which generally involves caps on the price of a national toll-call or calling packages that allow consumers to make an unlimited number of national calls for a fixed-monthly

204 The Telephone Call Charge series and Telephone Rental and Connection series represent price changes faced by households for both fixed-line telephony and cellphone services for the dates set out here. Cellphone call charges, which include the monthly access fee, were introduced at the June 1999 quarter. Prior to this date, telephone call charges were charges for national and international calling, and from the June 1999 quarter onwards, this series represents changes in cellphone call charges, and national and international calling rates. Internet charges represent both monthly (dial-up) access and usage fees. 
fee. The change in the marginal price also extends the growth of free calling services available on the internet, which are not captured in this graph.

\subsection{Summary}

There was substantial market entry before and after the advent of ISR supporting the conclusion, made in chapter 4 on the international experience, that the absence of ISR did not have an adverse effect on competition. A change did occur in the pattern of entry that coincided with the arrival of ISR and broadband internet access. Table 4 indicates that of those firms with interconnection agreements with the incumbent during 2007 and 2008, 11 entered the market before the advent of ISR in 2001, whereas two entered the market after. This suggests that there has been a significant reduction in network-based service providers investing in technologies that support telephony services. In contrast, Table 5 indicates that from 2001 there have been four entrants providing telecommunications infrastructure in the wholesale market, with the possibility of many more entrants. It is proposed that this growth in network capacity was in response to the growth in demand for internet services.

The growth in demand for internet services has also had a significant effect on investment in new mobile technologies. Figure 7 shows that the two competing mobile operators invested in successive mobile technologies, providing consumers with new, better-quality services for accessing the internet. This pattern of investment is consistent with the process of dynamic competition developed in chapter 2. One noticeable feature of the pattern of investment is that the timing of the new investments does not coincide. This is consistent with Novy-Marx's (2007) conclusion, discussed in section 2.4, that rivals will avoid investing at the same time under dynamic market conditions. 


\section{Conclusion}

The history of the telecommunications market in New Zealand presents a natural experiment on the conduct of regulation in a dynamically evolving market and its effect on market performance. The regulatory feature that made the telecommunications market in New Zealand unique compared with other countries is that there was no industry specific regulation (ISR) of access to the incumbent's network for a substantial period of time following the opening of the market to competitive entry. The telecommunications market was opened to competitive entry in 1989, and ISR of access to the incumbent's network was introduced in 2001. During the period without ISR, the commercial agreement of price and non-price terms of wholesale access to the incumbent's network was governed by antitrust regulation (ATR), under general competition law and enforced by the courts. Contemporaneous with these regulatory changes was significant technological change and growth in demand for arguably unforeseen, innovative internet and mobile services. These changes led to a substantial change in industry structure.

The lack of ISR did not lessen competition or performance in the telecommunications market in New Zealand. The performance of the New Zealand telecommunications market after it was opened to competitive entry in 1989, and before the advent of ISR in 2001, was not significantly different from other countries that had ISR when their markets were opened to competitive entry. Between opening the market to competitive entry in 1989 and the arrival of ISR in 2001, long-distance and mobile prices, productivity, and quality were generally consistent with comparable OECD countries that had ISR. New Zealand was amongst the first group of countries in the OECD to launch digital subscriber line (DSL) broadband internet access. Only Canada, the United States, and Korea launched before it. There were substantial welfare gains for New Zealand due to the availability of broadband. The introduction of broadband internet access also led to the transformation of industry structure.

Moreover, there was substantial market entry before and after the advent of ISR, indicating that the absence of ISR did not have an adverse effect on the process of dynamic competition. A change did occur in the pattern of entry, which coincided with the arrival of ISR and broadband internet access. Of those firms 
with interconnection agreements with the incumbent during 2007 and 2008, 11 entered the market before the advent of ISR in 2001, whereas two entered the market after. From 2001 there have been four entrants providing telecommunications infrastructure in the wholesale market, with the possibility of many more entrants. This suggests that there has been a significant reduction in network-based service providers investing in technologies that support telephony services.

In addition, the introduction of the regulation of access to the incumbent's retail telephony services, under ISR, would have meant that entrants could avoid investing in telephony equipment. As well as regulating interconnection, ISR required the incumbent to make its retail access to the telephone network available to competitors at the retail price less a discount. The discount is equal to the cost the incumbent avoids by supplying the service in the wholesale rather than the retail markets.

It seems reasonable to expect that the growth in wholesale transmission capacity was due to the growth in demand for internet services. As observed in appendix A.3, the volume-weighted mean annual growth rate of internet traffic between 2002 and 2008 was $68 \%$ on average. Entrants supplied network capacity in response to this growth in demand. Such significant growth in demand might also have been expected to result in an increase in the number of firms offering telephony services. The fact that there were 11 entrants before 2001 and two from 2001 suggests that there were no inherent barriers for firms to offer telephony services. This might indicate that it is generally more profitable to offer network services in the wholesale market than to offer retail telephony services and have an interconnection agreement with the incumbent.

The significant increase in demand for internet services, combined with the fact that telephony services are available over the internet, or the incumbent's telephony service can be resold, are plausible reasons for new entrants not investing in telephony equipment. If the reason for the reduction in investment in telephony equipment was due to the option to resell the incumbent's services, then this may have lessened the extent of dynamic competition. This would reduced dynamic efficiency, as the extent of innovation in these services would have been limited to the incumbent's retail services. If the reason for the reduction in investment in telephony infrastructure was due the growth in demand for internet services, then it would suggest that the advent of ISR of 
interconnection with the incumbent's network was made redundant by technological progress.

Uptake of fixed-line and mobile broadband and telephony services in New Zealand was comparable to the demand in other OECD countries prior to the introduction of ISR. Prior to the advent of ISR the demand for internet dial-up and broadband access was comparable to the average across the OECD. Following the introduction of ISR, the total dial-up and broadband internet access penetration was greater than the OECD average, although the penetration of broadband internet access was marginally less than the OECD average. More recently there was acceleration in the uptake of broadband internet access, reducing the difference with the OECD average penetration. It is also shown that the penetration of fixed-line and mobile telephony was comparable to the OECD average before and after the advent of ISR.

\section{Demand and supply conditions in the telecommunications market are} dynamic. Economic theory shows that the dynamic supply and demand conditions mean competitive conduct cannot be reduced to static models of natural monopoly and perfect competition. As regulation is predicated on the concepts of natural monopoly and perfect competition, this implies that understanding the limits of these concepts is important. A justification for regulating access to elements of a telecommunications network is that certain elements exhibit characteristics of a natural monopoly. It is usual to start an analysis for determining an optimal access price to an access network by proposing that it is a natural monopoly. In the case of telecommunications, it is common to claim the local access network is a natural monopoly. It follows that if the incumbent vertically integrates the local access network with services it supplies to the downstream retail market, and competitors in the retail market require access to the local-access network, then regulation to access is seen as a means to promote welfare.

To logically reduce the performance of oligopolistic competition to a point within a range between the extremes of natural monopoly and perfect competition requires a stable market equilibrium. If supply and demand conditions are static, where supply and demand are linear in quantity, and supply and demand parameter values are not uncertain, there is no irreversible investment, and in a market where quantity is uncertain, then inferences can logically be drawn from the static models of natural monopoly and perfect 
competition. If these conditions do not hold, then inferences regarding market performance cannot logically be drawn from the static models of perfect competition and natural monopoly.

Under static supply and demand conditions, the process of oligopolistic competition reduces to rivals simply competing on price or quantity, as described by Bertrand or Cournot competition. Under dynamic supply and demand conditions, the timing of irreversible investments becomes a valuable option for competing rivals. Dynamic supply and demand conditions lead rivals to change their actions as time progresses, resulting in unanticipated and unforeseen competitive conduct, particularly if firms invest in order to avoid competition. This unforeseen competitive conduct is not due to random variations around an expected market equilibrium, as there is no stable equilibrium. Dynamic conditions lead to a process of disequilibrium, resulting in the development of new services.

Real options theory stresses that the timing of an investment has value when investments are significant and irreversible, there is uncertainty, or if there is an expected significant expansion in demand. It also shows that dynamic processes have a significant effect on the conduct of competition between rivals, in particular that rivals will avoid making competing investments at the same time in order to avoid direct competition. The result is that rivals will endeavour to invest either before or after each other. The evidence presented in this thesis regarding the timing of DSL and mobile broadband technologies is consistent with this conclusion. This implies that the effect of these investments on welfare cannot be reduced to price, nor can the performance of the market be assessed in terms of natural monopoly and perfect competition.

Determining an optimal structure for the market is also problematic. The imposition of a particular structure on the market is increasingly likely to be detrimental to dynamic efficiency because it is likely to limit the opportunities available to firms to recover the cost of irreversible investments. A highly concentrated market within static conditions suggests a firm with a significant degree of market power, yet a highly concentrated market within dynamic conditions indicates a level of entry that may be optimal due to the opportunity cost of investment timing.

The implication for regulatory policy is that determining whether or not there is a competition problem becomes increasingly context specific. If the process of 
regulation is to maximise dynamic efficiency, then regulation cannot expect to define policy that results in outcomes superior to a dynamic competitive market. However, less can be inferred about the conduct and performance of dynamic competition, based on static models of natural monopoly and perfect competition, when supply and demand conditions are uncertain. It follows that the analysis of perceived competition problems becomes increasingly context specific.

Demand and supply conditions in the telecommunications market are dynamic. This is illustrated by the transformation from the telephony industry structure to the internet industry structure. The transformation from traditional telephony services to the internet resulted in increased demand for a wider range of new services. Another feature of the transition to the internet that indicates that it was part of a broader dynamic process was that it was generally unanticipated. Commercial interconnection agreements signed in 1995 did not anticipate the significant growth of internet access, resulting in the subsequent introduction of new agreements to address arbitrage opportunities. The advent of broadband internet access made the regulation of interconnection redundant.

The features of the telecommunications market, identified in this thesis, that induce dynamic supply and demand conditions are: (i) network effects; (ii) rapid development in hardware; (iii) significant sunk cost required to develop software; and (iv) large, sunk costs to build the capability or capacity to supply services and, once built, low marginal cost to supply services.

Network effects are inherently dynamic, resulting in positive-feedback effects, the absence of equilibrium, or the presence of multiple equilibria. Much of the economic and social value associated with the internet is due to network effects. Consumers' and service providers' valuation of a physical or virtual network depends on the size of the consumer and service provider population connected to the network. Direct network effects result when users directly benefit from the presence of others on a communications network. Indirect network effects occur when a user's valuation of a good depends on the availability and number of complementary services which in turn depends on the number of users.

Supply conditions are neither static nor linear due to ongoing technological progress in the quality and performance of hardware, the significant irreversible investment needed to develop the software required for new services, and significant irreversible investment in capacity to provide consumers with access 
to the telecommunications service. Moore's Law, which captures the ongoing technological development of the integrated circuit, highlights that the quality of a key input to telecommunications services has improved and is expected to continue to improve. This creates value in deferring an irreversible investment, which may have significant implications for the optimal timing of investment. It also creates the potential for the development of new services that can exploit the technological improvement.

There is also progress in the software. Although there is ongoing progress in the quality and performance of hardware, if the hardware is commonly available then the competitive advantage is to be gained in the software or intellectual property that a firm can add. The development of software depends on making irreversible investment in high-cost intellectual property as firms seek a competitive advantage.

A feature of these investments is that they are incremental. This not only includes the sunk cost of developing intellectual property but also extends to the irreversible investment in capacity required to meet a consumer's decision to participate in telephony or broadband access service. In the case of a fixed-line telephony or broadband service, this investment may take the form of installing a cable between the consumer's premises and an exchange with electronic equipment. In the case of mobile services, this includes augmenting capacity to accommodate growth in demand for new services.

Unanticipated changes in the expected supply and demand conditions, which progress over time, are not the same as a process where there are unanticipated changes in the supply and demand conditions but there is no change to the expected supply and demand conditions. These dynamic conditions do not imply that actual supply and demand for services will fluctuate around an expectation of services offered to consumers, quantities demanded, and technologies used to build these services. If the dynamics resulted in random fluctuations around an expectation, then the literature indicates that the dynamic process could be reduced to the static models of natural monopoly and perfect competition.

Markets are uncertain, and it is not surprising that commercial and regulatory decisions fail to anticipate unexpected changes. However, the important distinction is that the risks commercial and regulatory decision makers face in the telecommunications market are not random fluctuations in demand or supply around a stable equilibrium. The central feature of the 
telecommunications industry, which is described in detail in this thesis, is that the demand and supply conditions are not stable and static, but are dynamic. There are unanticipated changes in expectations, as time progresses, due to the introduction of previously unforeseen services, and in particular services related to the development of the internet.

The extent of the market dynamics results in uncertainty not only in terms of quantity demanded but also the uncertainty in the service itself. The difference between telecommunications services and other network industries, such as water or electricity reticulation, is that even though there may be uncertainty in the quantity demand for water of electricity, there is not the same uncertainty in water or electricity itself as there is in telecommunications. In telecommunications there have been and will continue to be unforeseen developments, resulting in no single 'telecommunications service' that is comparable to electricity or water.

The optimal two-part tariff access fee and call price are not separate services. A model of consumer participation as a normal-good, based on the theory of two-part tariffs developed in the thesis, is used to explain several features of the telecommunications market. The novelty of this model is the explicit consideration of participation as a normal-good, and its implication for the construct of the utility function. Desirable two-part tariffs must jointly consider access and usage since consumer utility is not separable in these dimensions, and vary with characteristics such as income. In addition, participation does not imply consumers substitute one service for another, but also includes the situation where consumers adopt an additional telecommunications service.

Consumers' participation decisions result in a discontinuity in demand, thus contributing to market dynamics. Consumers' choice to subscribe or not subscribe is determined by comparing their utility at two separate arguments of the utility function. In the particular case of calling and the access fee is greater than zero, if an individual is indifferent to subscribing and not, then the decision to subscribe results in a discontinuous increase in the demand for calls and the consumers' marginal utility of income.

The model also illustrates that the optimal two-part tariff access fee and call price are not separate services. The access fee and call price are not separable due to fact the access fee has a direct effect on the income available to consume services. Empirical evidence on the demand for mobile services is consistent 
with the proposition that participation is a normal-good. If the income of consumers who do not participate is increased, then at some point they will participate in the market for mobile services.

Also, the access fee and call price are not separable because the structure, as well as the level of the optimal access fee and call price, depends on whether the objective is to maximise profit, or to maximise profit subject to a constraint on profits. If access and calling are treated as if they are separate services, then some might argue that the Ramsey-Boiteux pricing principle is optimal, in which the level but not the structure of the access fee or call price would depend on whether the objective is to maximise profit or welfare. A numerical example, based on the theory of participation using the Stone-Geary utility function, illustrates the effect of different objectives on the optimal access fee and call price. It indicates that the profit maximising two-part tariff recovers a greater proportion of the common costs in the call price than a consumer surplus maximising two-part tariff.

ISR has not enhanced dynamic efficiency. It is assumed that the objective of regulation is to maximise dynamic efficiency, thus a role for regulation is to preserve the process of competition. The stated purpose of ATR and ISR in New Zealand is to promote competition for the long-term benefit of consumers. Harm to the process of competition due to a firm exerting market power is anticompetitive and may reduce dynamic efficiency. An expectation of competitive conduct is required to determine whether observed or anticipated conduct is anticompetitive or limits the process of competition. In the present, a view of competitive conduct can be formed given the current information about supply and demand, and the conduct of firms. If supply and demand conditions are static, then the current view of competitive conduct should not change with the passage of time. Current expectations of competitive conduct in the future will be the same as the view of competitive conduct now. If supply and demand conditions are dynamic, then reasonable expectations can not be formed of competitive conduct in the future.

Under ISR, regulatory policy is forward looking and attempts to influence competitive conduct. In 1989, the government threatened regulatory intervention if the incumbent hindered competition, notwithstanding that ATR was in place. In 1995, the government's view of competition differed from the Privy Council's view, resulting in an interconnection price that was less than the 
price required by the Privy Council decision. In 2001, the government instituted ISR of interconnection. Following the regulation of interconnection there was a reduction in investment in telephony equipment. This reduction may have been due to the regulation of access to the incumbent's retail services or the growth in internet services. If due to the former reason, then regulation may reduce incentives to invest in telephony technology, if the latter then technological process has made telephony technology redundant. In 2006, the government introduced regulation of access to the unbundled elements of the incumbent's local loop.

This ongoing evolution of industry regulation is due to a persistent view that the assets owned by the incumbent are a natural monopoly. In a static market, the conduct of competitors is expected to stay the same with the passage of time. In a dynamic market, there may be unanticipated changes in the competitive conduct with the passage of time, as firms launch innovative services utilising unforeseen technologies. Up until the advent of broadband internet access, the government's view of competitive conduct centred on calling and the interconnection agreement. Following the introduction of broadband internet access, the natural monopoly was still the local loop; however, the focus of regulation shifted to the unbundled local-loop, which allowed competitors to install their own equipment on these lines and bitstream services. These changes in regulatory policy show that expectations regarding competitive conduct changed in response to the changing supply and demand conditions, particularly as new services developed.

In a dynamic market, uncertainty is determined by supply and demand factors, and these factors are outside of the control of an industry specific regulator. A regulator can not expect to lessen the uncertainty inherent in these factors. However, a regulatory policy that adapts to changing market conditions suggests that an investor's risks may be heightened due to the commitment problem. This would increase the opportunity cost of deferring investment, thus reducing the likelihood of investments being made. A regulator may reduce uncertainty for the regulated firm by providing entrants with a free option to access existing infrastructure, thereby reducing the threat of competing investment. However, any such reduction in the intensity of dynamic competition may also reduce 
dynamic efficiency, as it reduces the incentives for investments in new technologies that may have reduced production costs or increased the range of services available.

ATR is likely to enhance dynamic efficiency. A determination of anticompetitive conduct by the courts in a static market addresses the enduring effect that such conduct has on dynamic efficiency. Conversely, a determination of anticompetitive conduct in a dynamic market addresses the incentives for firms to repeat the conduct in the future as supply and demand conditions change. The assessment of anticompetitive conduct under ATR is consistent with the limits of the concepts of natural monopoly and perfect competition in a dynamic market. In a static market, anticompetitive conduct will have an enduring effect on the market, and thus any harm to dynamic efficiency is enduring. There is no need for the firm to repeat the conduct as the market is static.

In a dynamic market, the potential for unanticipated change in competitive conduct with the progression of time means that the effect of anticompetitive conduct, at the present point in time, on the state of the market, at a future point in time, becomes less certain. This does not mean that a dynamic market mitigates the adverse consequences of such conduct. The risk of not prosecuting anticompetitive conduct as it occurs, even though the effects of the specific conduct might be short lived, is that the firm will repeat it in the future as supply and demand conditions change. Therefore, the threat of anticompetitive conduct by the dominant firm may deter competitive entry and investment, thus reducing the level of dynamic efficiency.

The courts form a view of competitive conduct based on the counterfactual test and the context of the disputed conduct. An expectation of competitive conduct is formed given the current information about demand, supply and the conduct of firms. The counterfactual test does not anticipate the state of competition at some future point in time. In 1994, the courts, using the counterfactual test, concluded that there was competition with only two rivals in a telephony market at a time when, although supply and demand conditions were changing, the internet was just emerging and its effect on the industry was generally unanticipated. A subsequent decision in 2010 was made about conduct during a period when the industry was undergoing significant change, and concluded that 
the market was competitive. This decision considered competitive conduct associated with the introduction of commercial interconnection contracts in response to significant growth in dial-up internet access and changing patterns of usage of the telephony network. As already observed, there has been entry into the telecommunications market before and after the advent of ISR. This suggests that ATR has provided sufficient protection to allow competitive entry and promote dynamic competition. 


\section{Appendix A: Evolution of the internet}

The structure of the telecommunications industry changed from the telephony network structure to the internet services structure illustrated by Figure 1, section 1.1. This change in industry structure evolved with the technological and contractual developments, leading to significant network effects, and ultimately growth in the internet and new services made available by the internet. These new services are dependent on the availability of the internet. The growth in the internet is dependent on the demand for these services. The growth of the internet and services are endogenous with network effects and dynamic competition.

This appendix starts with an account of the rapid growth of the internet and the value of the services available on the internet over a 10-year period. This is followed by a description of the technical features of the internet that has enabled the development of services that consumers value, and compares these features to the corresponding technical features of the public-switch telephone network. The contractual agreements for interconnecting networks carrying internet traffic have also had an important effect on the development of services and are discussed.

\section{A.1 Definition of service and network providers}

A network provider has a geographically distinct physical network that provides consumers with access to the internet. It was initially provided by a public switched telephone network, but over time it is being replaced by broadband networks. These have improved the quality of internet access. Access to the network is provided by a number of different technologies including the twisted copper pairs used by the fixed-line telephone network, wireless access (WiMax, $\mathrm{WiFi}$ ), and mobile cellular technologies. The definition of the network provider covers fixed-line telecommunications networks, mobile telecommunications networks, and internet service providers (ISP) that offer an access service.

Service providers provide internet-based services. The current range of services available on the internet is varied and large. To provide services, it is sufficient that service providers connect to the internet via a network provider's network. Service providers do not generally need to have contracts with the network provider that serves the consumer these services. There is a range of internationally accepted technical standards and a set of peer-to-peer and transit contracts which enable the delivery of the service ubiquitously to internet 
subscribers. A key feature of the internet is that service providers are largely independent of the access network that services consumers.

Examples of firms that perform both functions include the ISP or a telephone network. Some ISPs provide a network connecting a consumer to the internet as well as a homepage with news and information. A telephone network integrates a communications network with a voice-calling service.

\section{A.2 The range and growth of service providers}

The diverse range of services available to consumers and the growth in the scale of the internet are related by network effects. New telecommunications services, or services offered over the internet, can result in very large gains in consumer welfare. ${ }^{205}$ This has revealed latent demand for a range of services, including services that were previously unknown, which has attracted new participants who in turn create new commercial opportunities. The extent of the growth and the diversity of the new services available on the internet indicate that the gain in social welfare due to the internet is large.

The following description of internet activity relies on a combination of general international statistics, information about service providers based in the United States, as well as information about the New Zealand market. Two reasons for using international as well as New Zealand growth data are 1) that time series data on total international growth of the internet are available, but no comparable data has been found for New Zealand ${ }^{206}$, and 2) that the internet is international. It is estimated that in 2007 approximately $75 \%$ of internet traffic carried within New Zealand either originated or terminated overseas. ${ }^{207}$

Key services based on site popularity and providing a diverse range of services are: Google, Trade Me, Yahoo!, Facebook, YouTube, Wikipedia, Amazon.com

\footnotetext{
205 Hausman, et al. (1997) show that new telecommunications services can create very large gains in consumer welfare. They estimate a consumer welfare gains in the United States at that time for voice messaging services of $\$ 1.27$ billion a year and for cellular telephone of $\$ 50$ billion a year. Brynjolfsson, et al. (2003) estimate that the increased product variety of online bookstores enhanced consumer welfare by $\$ 731$ million to $\$ 1.03$ billion in the year 2000 .

${ }^{206}$ Internet NZ External Peering Group (2007, p. 14 paragraph 7.1.4) note a similar problem finding data about the New Zealand internet.

207 Internet NZ External Peering Group (2007).
} 
and Skype. ${ }^{208}$ Google is a web search engine that allows consumers to search web pages; YouTube offers an internet video search service that allows people to watch and share videos; Trade Me is a New Zealand-based internet auction website; Skype offers a telephone service to consumers connected to the internet; Facebook is a social networking site; Yahoo! is a web-portal; Wikipedia is an internet-community prepared encyclopaedia; and Amazon is an online retailer.

Only two of these service providers existed before 1998. Yahoo! and Amazon were founded in 1994. These were followed by Google in 1998, Trade Me in 1999, Wikipedia in 2001, Skype in 2002, Facebook in 2004, and YouTube in 2005. This is not a comprehensive list of major service providers that offer service in New Zealand, let alone those with a significant international presence, but it does provide an indication of the diversity, scale and speed of the growth of internet services in general.

These service providers grew rapidly to a significant size. Google Inc. entered the S\&P 100 in 2006, and earned revenue of US\$21.7 billion in 2008. Google acquired YouTube in 2006 for $\$$ US1.65 billion, with consumers retrieving daily 100 million video views and uploading 65,000 new videos by this time. In March 2009, Trade Me reported having 2.2 million active members out of the New Zealand population of 4.2 million. Fairfax purchased Trade Me for NZ\$700 million in 2006. eBay acquired Skype for US\$2.6 billion in 2005. Market research indicates that Skype carried 8\% of the world's international call minutes in 2008. Facebook had more than 175 million users in February 2009. Extrapolating a recent investment of US\$200 million for a 1.96\% stake in Facebook suggests a valuation for Facebook's preferred stock of US\$10 billion. Wikipedia attracted 684 million visitors in 2008. Amazon.com entered the S\&P 100 on 31 December 2008.

208 Refer to the annex to appendix A for supporting data and references. 
Figure 9 illustrates the marked increase in the rate of growth of aggregate revenue earned by internet firms from 2003 to 2006 compared with other sectors of the information technology and communications (ICT) industry.

Figure 9: Top 250 ICT firms' revenue trends by sector, 2000-2006 209

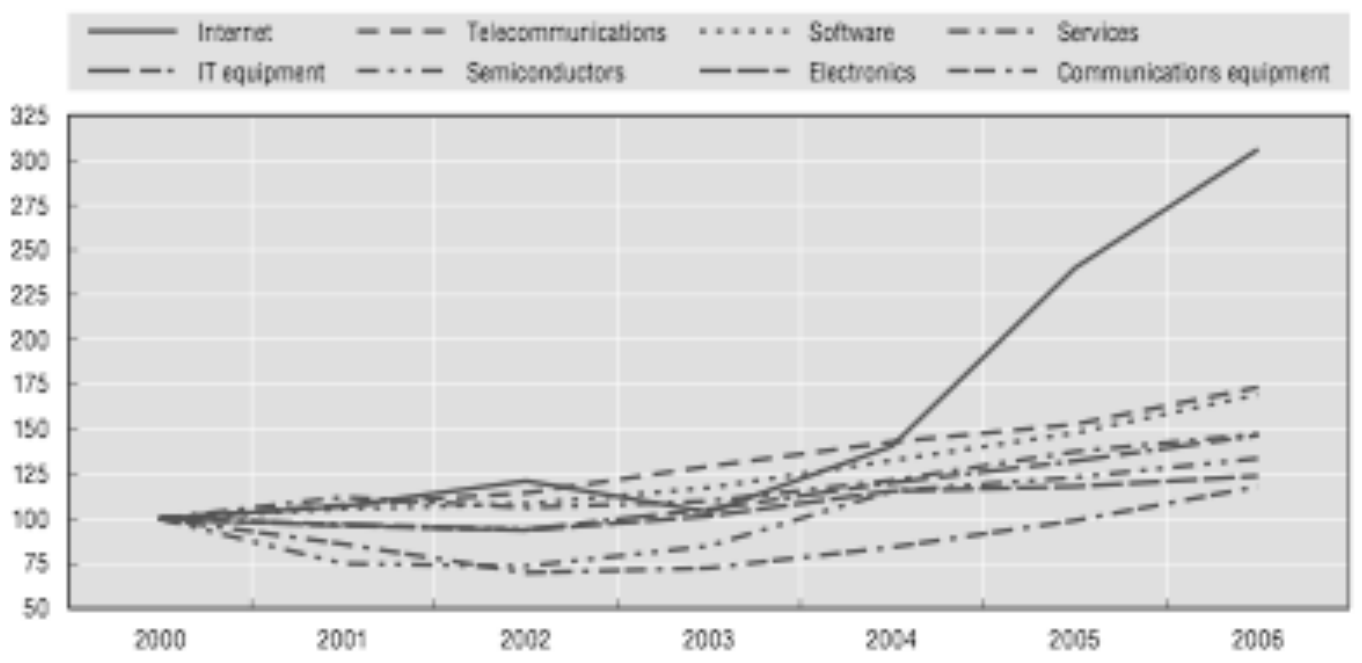

Source: OECD(2008c, p. 36, Figure 1.10)

The observed growth in new services such as social networking sites, web portals, internet search engines, web-based encyclopaedias, online retailing, and telephone calling, can be expected to have resulted in a substantial increase in consumer welfare. The range or the number of services per se are both of value, and the diversity of services means that an individual consumer is more likely to find a service or a group of services on the internet that they value sufficiently to incur the cost of gaining access to the internet.

Service providers have an international character as they operate from anywhere in the world. Only two, Trade Me and Yahoo! Xtra, of the top 10 sites listed in the Alexa internet survey are specific to New Zealand, although Google and others offer variants in their services with a degree of customisation to local markets such as New Zealand. The internet allows service providers to operate independently of each other and of the consumers' access networks. This significantly reduces the market entry cost for new service providers and the cost for existing service providers of making new services available to all the

209 USD current prices, index $2000=100$. 
consumers with access to the internet - hence the heralded internet start-ups that have offered services from a computer located in a garage or bedroom.

Consumers have the choice from several service providers for each type of service. Examples are: social networking sites that include Facebook, Bebo.com and Myspace; search engines include Google, Windows Live and Yahoo!; Web portals include Msn.com and Yahoo!; and telephone calling services include Skype and the traditional telecommunications operations. Among this shortlist, there is competition from which consumers would expect to benefit through a process of dynamic interaction.

\section{A.3 Growth of the internet}

The growth in the internet in the aggregate dimensions is indicated by the number of hosts connected to the internet, where a host is a machine connected to the internet with a domain name and IP address. In practice, a single physical machine may appear as many machines and each of these machines corresponds to a host. The following graph of the internet host count sourced from the Internet Systems Consortium website counts each host (Internet Systems Consortium, 2009b).

The Internet Systems Consortium (2009a) considers that this count is a reasonable estimate of the minimum size of the internet. Based on this data, the compound annual growth rate (CAGR) between 1998 and 2008 was 31\%, implying that the internet was doubling in size approximately every 2.5 years.

This internet host count measures the number of computers (or the equivalent) connected to the internet. The University of Minnesota Minnesota Internet Traffic Studies (MINTS) provides a measure of the growth in total internet traffic based on transmission rates in bits per second. MINTS estimates growth in internet traffic based on an analysis of published traffic studies. The most recent analysis indicates that on average the volume-weighted mean annual growth rate between 2002 and 2008 was 68\% (Minnesota Internet Traffic Studies, 2009). This suggests that the volume of internet traffic is doubling every 1.3 years. ${ }^{210}$

${ }^{210}$ The Global IP Traffic in 2008 is estimated to 43,518 PB per month. A PB is a Peta Bit which is $2^{50}$ Bits. 
Figure 10: Internet host count history

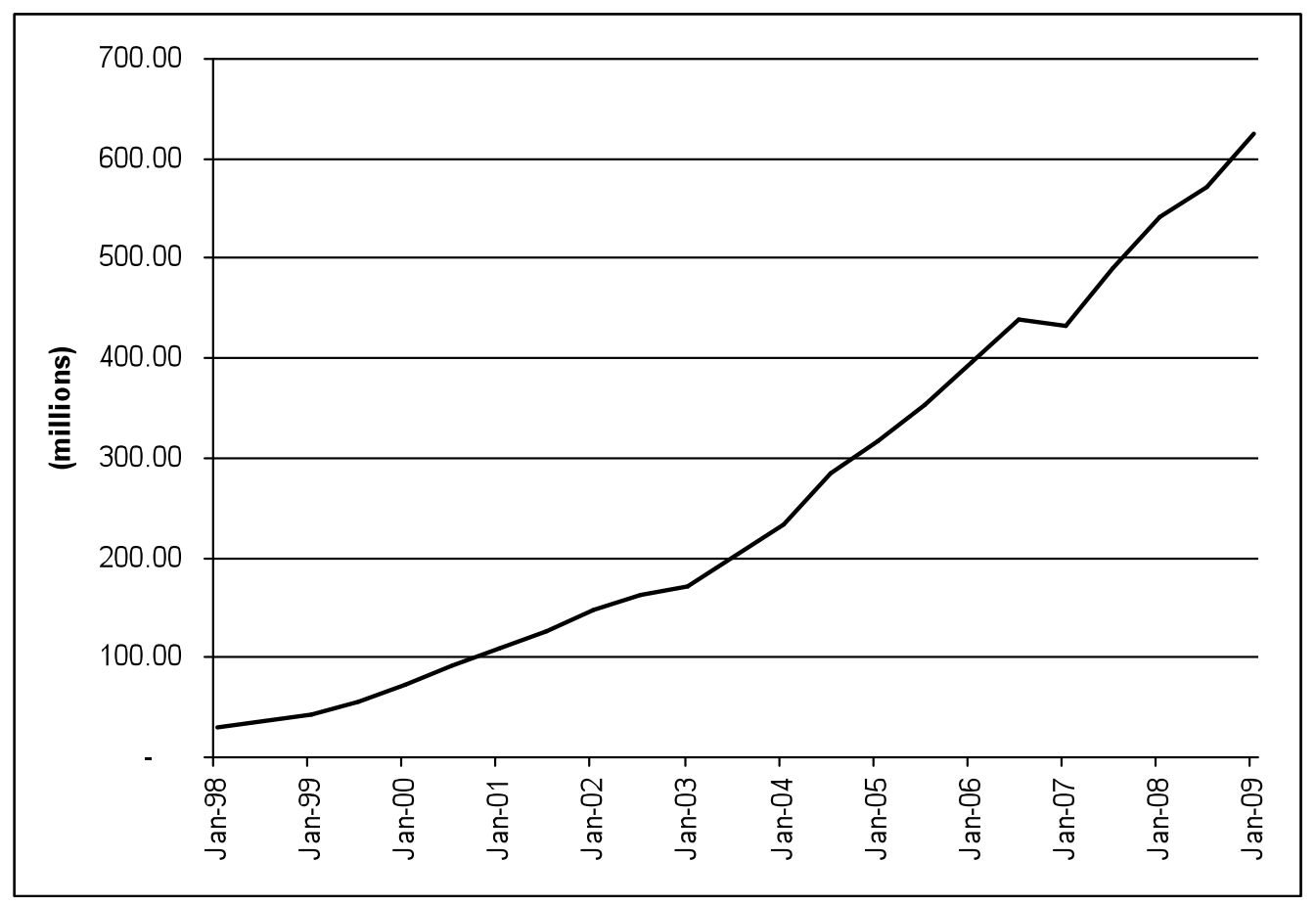

Source: Internet Systems Consortium (Internet Systems Consortium, 2009c)

The fact that traffic growth is significantly greater than the growth in hosts is suggestive of network effects. Network effects occur when a network participant's valuation of the network is a function of the number of participants on the network. To illustrate the general principle using a naïve example of simple direct network effects, if each network participant is equally likely to communicate with any other network participant and there is no resource constraint on the ability of participants to communicate, then it can be shown for a large number of participants that a $100 \%$ increase in the number of participants will result in a $200 \%$ increase in communication traffic. ${ }^{211}$ But for the internet, network effects are not as simple as this illustration. ${ }^{212}$

${ }^{211}$ The assumption that each participant is equally likely to communicate with another implies that the total volume of communication traffic is a function of the number of combinations of pairs of participants. The elasticity of the volume of communication traffic with respect to the number of network participants can be calculated with this implication in mind.

212 The fact the percentage growth in internet tariff is approximately double the growth in internet hosts does not mean that internet hosts are equally likely to communicate with each other. See section 2.1 for discussion on network effects. 


\section{A.4 Internet access demand growth}

In 1998, consumers in New Zealand, as in most other OECD countries, accessed the internet via dial-up modems connected to the fixed-line public switched telephone network. Commercial broadband internet access services based on DSL technology were launched in Canada in 1996 and the United States in 1997. New Zealand, along with nine other OECD countries, launched commercial DSL broadband services in 1999, with the remaining OECD countries launching commercial broadband services subsequently. By 2004, over $90 \%$ of the population of New Zealand were able to access broadband services (OECD, 2007b, p. 121, Table 4.11).

A number of studies using multivariate techniques have attempted to determine the effect of price, income, regulatory policies, and broadband availability on the growth of broadband access to the internet. ${ }^{213}$ None of these studies explicitly considers the change in or range of internet services, or the change in network effects as an influence on the uptake of broadband internet access, in particular.

The following graph illustrates the growth in internet subscribers in New Zealand in comparison with the whole OECD. Internet subscribers are grouped by those with broadband access (which includes cable modems and DSL technologies), and more generally fixed-line access (which is the sum of those with broadband access and dial-up internet access). The difference between the broadband and fixed-line access provides an indication of the number of subscribers with dial-up access.

213 See studies by OECD (2007a), Cava-Ferreruela \& Alabau-Munoz (2006), Boyle, Howell, \& Zhang (2008), Distaso, Lupi, \& Maneti (2006), and Sraer (2008). 
Figure 11: Internet access subscribers

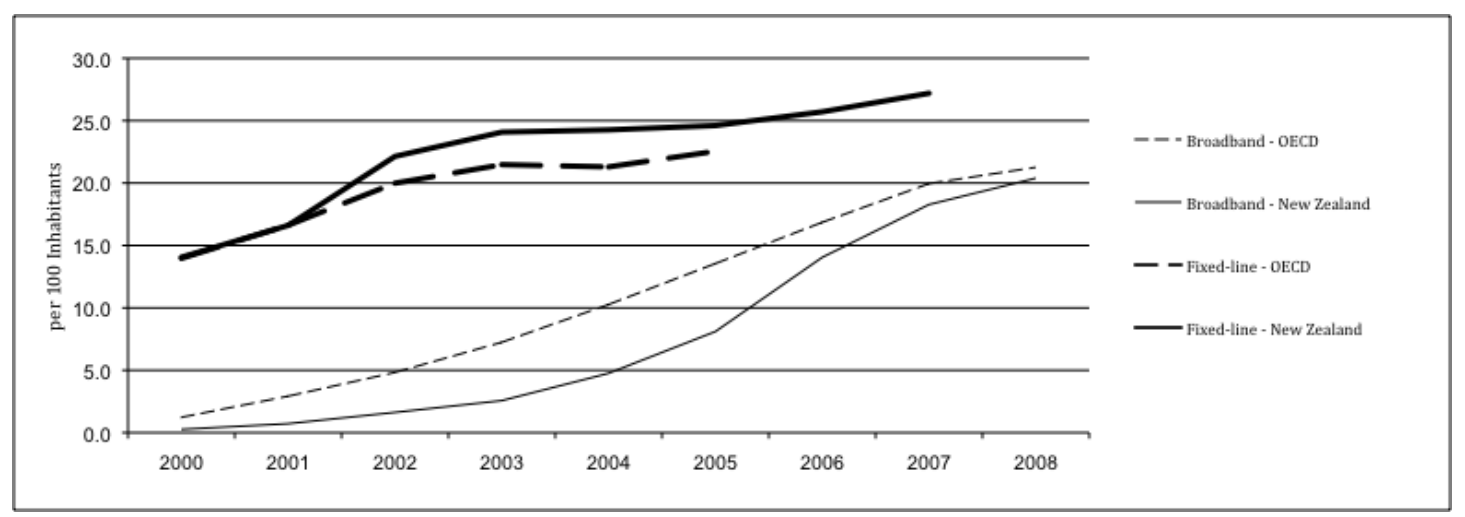

Source: Based on OECD (2007b p. 156, Table 5.1) and Commerce Commission (2008b)

The graph illustrates that in 2000 most consumers used dial-up internet access. Subsequently, the total growth rate of fixed-network internet access was less than the growth rate of broadband internet, indicating that most of the growth in broadband internet access is from consumers substituting from dial-up access. By 2008 most New Zealand consumers used broadband internet access.

The compound average growth rate (CARG) statistics in Table 6 show that the overall growth in uptake of internet access is less than the growth in broadband access. In 2000, internet access was dominated in New Zealand by dial-up connections, whereas by 2008 internet access was dominated by broadband connections.

Table 6: Fixed Network internet access growth rates

\begin{tabular}{|l|c|}
\hline & CAGR \\
\hline Fixed-line access - OECD from 2000 to 2005 & $10 \%$ \\
\hline Fixed-line access - New Zealand from 2000 to 2007 & $9 \%$ \\
\hline Broadband access - OECD from 2000 to 2008 & $40 \%$ \\
\hline Broadband access - New Zealand from 2000 to 2008 & $72 \%$ \\
\hline
\end{tabular}

\section{A.5 Fixed-line telephone and mobile access demand growth}

For traditional fixed-line telephone services, Figure 12 indicates that there is a small but noticeable reduction at a CAGR of $-1 \%$ for New Zealand and $-2 \%$ on average across the OECD. In contrast, the penetration of mobile services over the same period increased at a CARG of $13 \%$ in New Zealand and $19 \%$ on average across the OECD. As the graph illustrates, the net effect is that the 
penetration of mobile phones is approximately double that of fixed-line connections. It also indicates that consumers are not forgoing their fixed telephone access at the rate they take up mobile services.

Figure 12: Mobile and fixed telephone access path subscribers

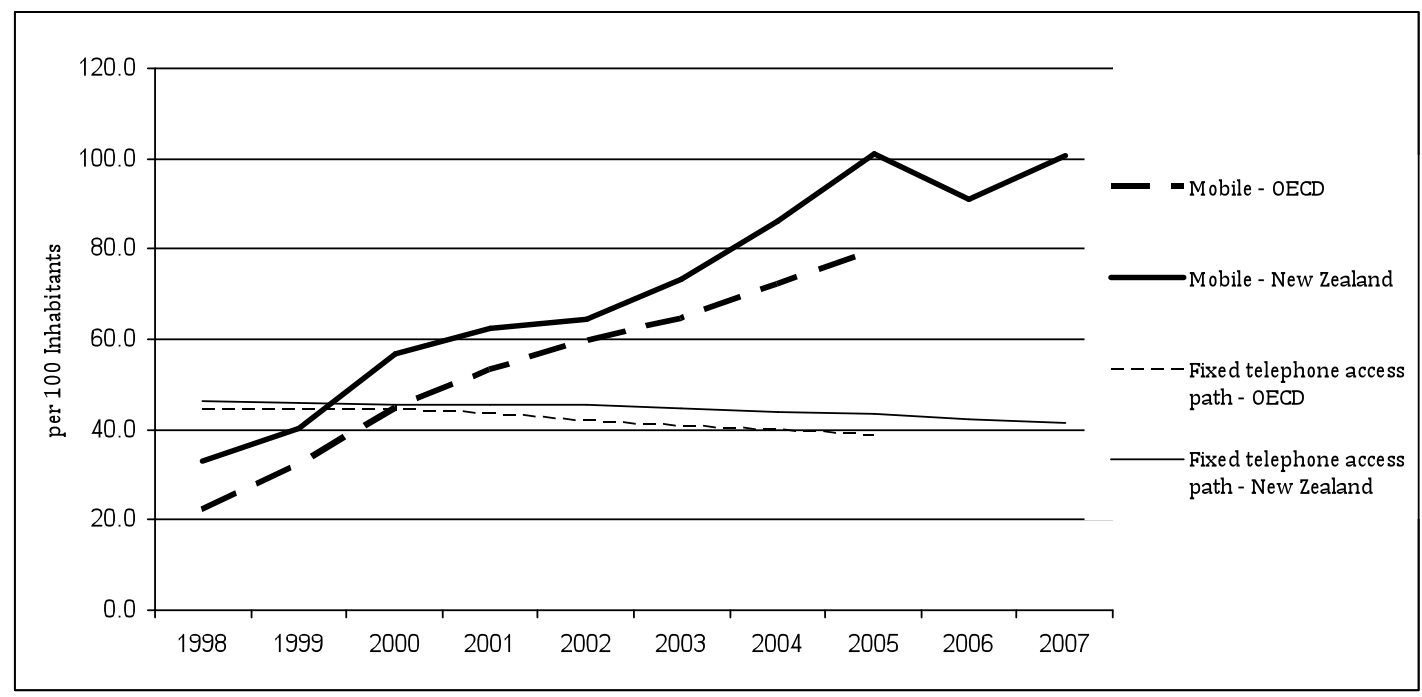

Source: Based on OECD Communications Outlook 2007 ( p. 156, Table 5.1) and (Commerce Commission, 2008b)

Table 7: Mobile and fixed telephone network access growth rates

\begin{tabular}{|l|c|}
\hline & CAGR \\
\hline Mobile Subscribers - OECD from 1998 to 2005 & $19 \%$ \\
\hline Mobile Subscribers -New Zealand from 2000 to 2007 & $13 \%$ \\
\hline $\begin{array}{l}\text { Fixed Telephone Access Path - OECD from 2000 to } \\
\text { 2008 }\end{array}$ & $-2 \%$ \\
\hline $\begin{array}{l}\text { Fixed Telephone Access Path - New Zealand from 2000 } \\
\text { to 2008 }\end{array}$ & $-1 \%$ \\
\hline
\end{tabular}

In 2008, mobile penetration was approximately double that of fixed-line connections because consumers generally install only one fixed telephone line in their homes. As a result, the number of residential dwellings has tended to determine the maximum number of residential telephone lines, in contrast to mobile phones which are not limited by this. Individuals are unlikely to share a mobile phone because the benefit of mobility requires that the mobile phone remain with the individual. Because on average there is more than one individual per dwelling, it follows that there is likely to be more than one mobile 
phone per dwelling. This may suggest that fixed telephone lines and mobile connections are not close substitutes. ${ }^{214}$

\section{A.6 Telecommunications company revenue}

In contrast to the significant growth in demand for internet services, revenue earned by Telecom New Zealand (Telecom), the incumbent telecommunications operator in New Zealand, remained constant. The following graph shows that the revenue per connection earned by Telecom through providing access to the fixed-telephone network, mobile services, and broadband internet access has been relatively constant over the past 10 years. This observation is generally consistent with the average across the OECD, as illustrated by the following graphs.

Figure 13: Change in Telecom's ratio of revenue to fixed Telecom connections, mobile subscribers, and broadband connections

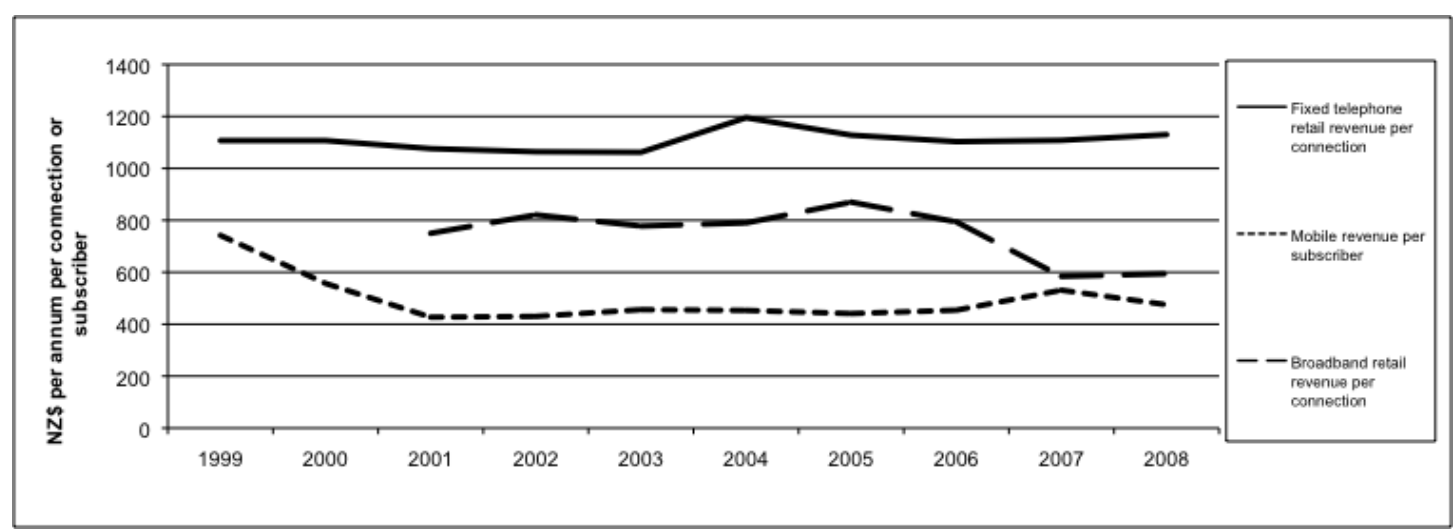

Source: Based on data reported in Telecom New Zealand Quarterly Reports and Annual Reports from 1999 to 2008. 
Figure 14: OECD telecommunications revenue per total communications access path

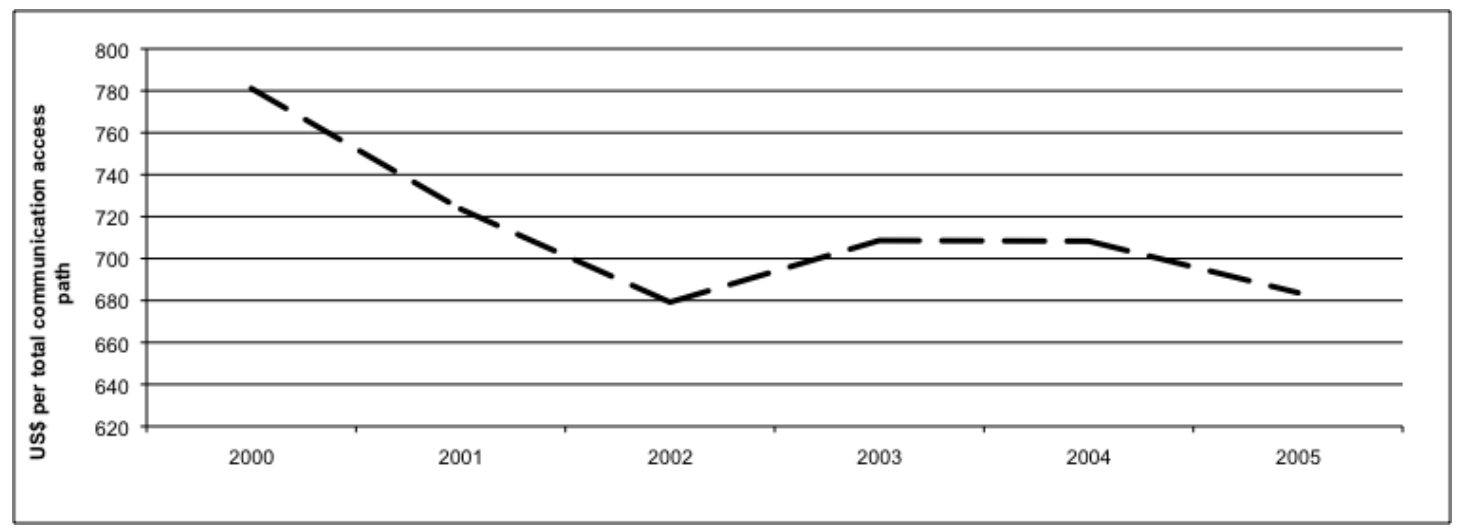

Source: OECD (2007b, p. 84, Table 3.3)

Comparing Figure 11 and Figure 13 suggests that Telecom earned increasing total revenue from consumers purchasing broadband services. However, Telecom did not earn any noticeable additional revenue per broadband connection since 2000, one year after the launch of its commercial broadband service. This suggests that the significant increase in demand for broadband internet access observed in Figure 11 is not due to a corresponding decrease in the access price, but that it is the result of consumers' increasing valuation of the internet-based services increasing over time.

\section{A.7 Technological conditions of supply}

A key factor in the change in industry structure is the change in technology. The public switched telephone network integrated the communications network with calling services, whereas the internet enabled the separation of the calling service from the communications network. This change significantly altered the general competitive process and cost structure of providing services and the communications network. The technical separation of the network from services has had significant implications for the provision of services. This is shown in the growth in the range and scale of service providers from 1998 to 2008.

The internet is a network of networks. ${ }^{215}$ It is designed to allow users who are connected to separate networks, but using the same application, to communicate

${ }^{215}$ See the Internet Engineering Task Force - Network Working Group (1989a, p. 7). The Internet Engineering Task Force publishes official specifications, guidelines and protocols for operating the internet as well as publications discussing issues in relation 
with each other as if they are communicating with users of the application on the same network. The approach taken to implement this principle is that information about the users' applications and data are kept and maintained by the users, and the communications interconnection between the networks is indifferent about the applications and the data being communicated.

This is analogous to a basic postal service with a single class of mail delivery. The sender and receiver of a letter are concerned with the act of sending and receiving a letter, the contents of the letter, and any actions to be taken following receipt of a letter. The postal service is not concerned with any of these factors. The postal service is concerned with getting the letter from the sender to the receiver, where the sender and receiver are not concerned with how the postal service collects, sorts, transports and delivers the letter.

This approach to designing the network function is referred to as the end-to-end principle. Originally proposed in 1984 (Saltzer, Reed, \& Clark), the end-to-end principle has fundamentally determined the technical architecture of the internet and economic incentives of those connecting to the internet.

Figure 15 illustrates a simplified topology of the internet. ${ }^{216}$ The internet is a network of hosts and routers that communicate with each other via links. A host is a computer that runs the applications and services which consumers value and demand. It is also a computer that consumers use to access services on other hosts via a communications network, which is made of routers and communications links. In contrast, the router does not run any applications; it directs communications between hosts.

Figure 15 relates to the internet industry structure represented in Figure 4, by noting that the hosts in Figure 15 correspond to the computer symbols in Figure 4 , and the routers and links correspond to the internet network illustrated by the "cloud" in Figure 4.

to the development of the internet. These publications are referred to as Request for Comments (RFC).

${ }^{216}$ This diagram does not include multiplexers, mirror sites, switches or other network elements. Although these other elements are important and frequently used, their inclusion is not required for the present discussion and would distract from the essential features under consideration. 
Figure 15: Schematic description of the internet

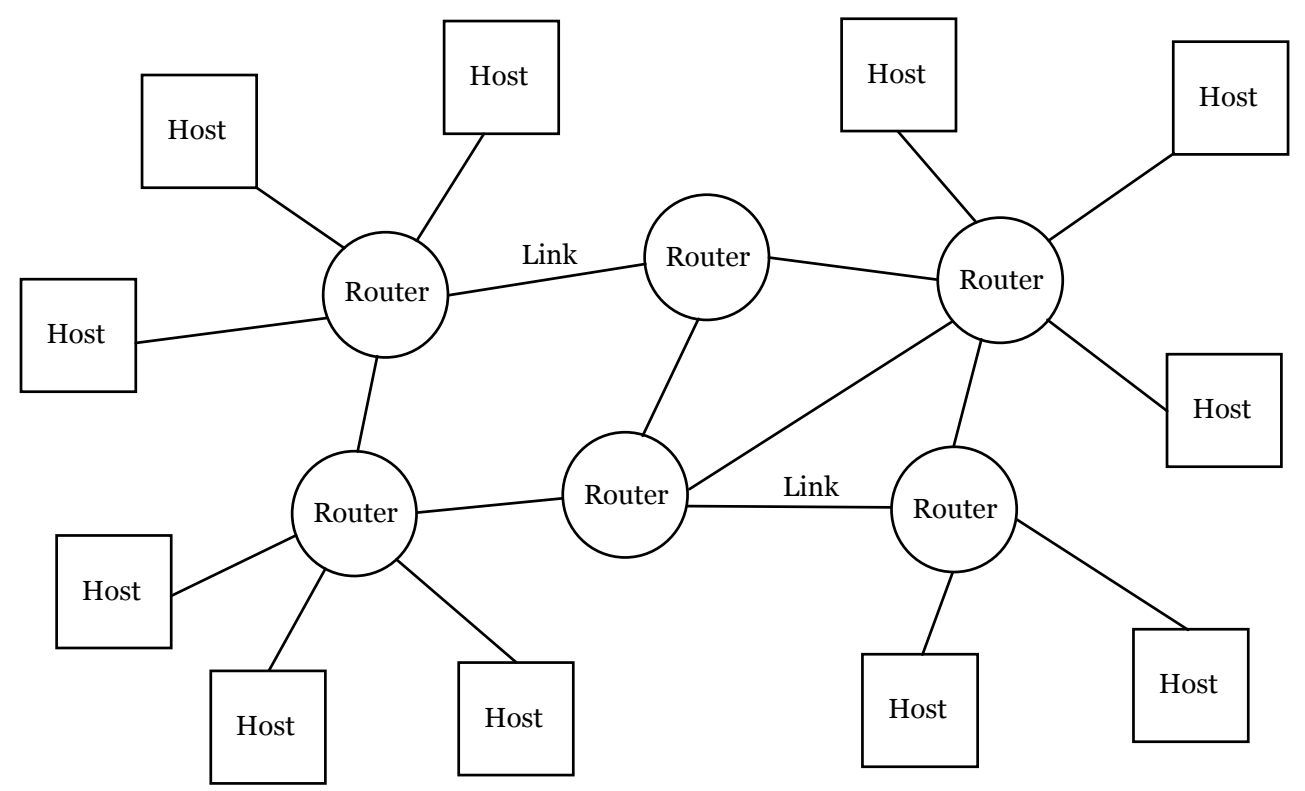

The applications and services that consumers value, which run on the hosts, create user data or request user data from other hosts. User data is transmitted from a host to its destination host by the process of encapsulation in which additional information is added to the data in layers. User data is encapsulated within four layers of information defined by the Internet Protocol Suite. ${ }^{217}$ The layers of the Internet Protocol Suite are:

1. Application Layer - adds information that indicates to the destination host the type of data and what it is for. The Application Layer information indicates whether the user data is text, audio or video; which applications are needed to view or listen to the data; whether the source host requires action to be taken by the user at the destination host; and it can test whether the integrity of data received has been corrupted during transmission;

2. Transportation Layer - converts the user data with additional Application Layer information into a stream of individual packets

\footnotetext{
217 Internet Engineering Task Force - Network Working Group (1989a, 1989b).
} 
suitable for transmission across the network and then reconstruction by the destination host. On receipt of the packets at the destination, this layer unpacks the packets; it can test whether the data has been corrupted during transmission; and it reconstructs the user data;

3. Internet Layer - adds the Internet Protocol (IP) address of the destination host and the next router en route to the destination; and

4. Link Layer - converts the IP packet into a format suitable for transmission over a next communications link.

The originating host of the user data encapsulates the user data with all four layers of information defined by the Internet Protocol Suite and then sends each pack to the first router. The first router and subsequent routers then inspect the packet for the destination host IP address, selects and sends the packet to the next router, resulting in the packet moving closer to the destination in hops. The final router in the chain forwards the packet to the destination host, which processes the packet based on the Transportation and Application Layers information.

The diagram above also shows that hosts are connected to each other via links and routers, and that the hosts are at the 'edge' of the communications network of routers and links. The fact that hosts are at the edge of the network graphically illustrates the implementation of the end-to-end principle.

Implementation of the end-to-end principle by the encapsulation process means that the routers and links do not inspect or act on the information contained in the user data, the Application Layer, or the Transportation Layer. All the information required by the routers and links to carry a packet between hosts is contained within the internet and Link Layers. Therefore, the communications network is functionally independent of the applications operating on the hosts and the applications are functionally independent of the IP communications network.

Returning to the comparison between the structure of the telephony calling market and the internet services market represented in Figure 1, the gap between the rectangle representing the internet services and the rectangle representing the internet access is in part due to functional separation between 
the services and the communications network described above. ${ }^{218}$ The gap also represents commercial separation between the available services and the internet access service. That is, internet access and the available services are not offered to consumers as a pure bundle.

This functional separation between the communications network and services has different implications for the supply of communications networks and the supply of the services. The rest of this appendix will focus on the basic market conditions in relation to the production of the communications network, starting with a discussion of the change in the performance and cost of the integrated circuit.

\section{A.8 Internet's technical performance and cost}

The integrated circuit is a fundamental, ubiquitous, building block of the internet. The growth in the internet is due to many interacting factors, but it does not depend on any one single input factor as much as it depends on the integrated circuit. Alternative network architectures, network protocols, communications media, hardware configurations, applications and services exist or have existed but are no longer in use. However, there is no alternative to the computational and data processing capabilities of the integrated circuit.

Extrapolating historic data indicating that the average cost per component decreased as the number of components on an integrated circuit increased, Moore (1965) predicted that the number of components on an integrated circuit would double every two years. Subsequently, a generalisation of this proposition emerged to the effect that the number of components on an integrated circuit will double approximately every 18 to 24 months, which is now commonly referred to as Moore's Law.

As Moore explained in his 1965 article, increasing the number of components on an integrated circuit would result in more powerful computers. The value of increasing the density of components is not just a decrease in average cost per

${ }^{218}$ Hatfield, Mitchell, \& Srinagesh (2005, p. 52) also note that the end-to-end principle with the Internet Protocol Suite has "far-reaching implications in terms of both the ability to support multimedia applications and in the control over the development of such applications." However, the authors do not relate this to how this is achieved in terms of its influence on industry structure or the resulting dynamic competition that emerges, which is addressed in the present work. 
component, but it is also an increase in the performance and capabilities of the integrated circuits.

The observed doubling of component density every 18 to 24 months is not a law of physics, technology or economics. It is a dynamic process that is the product of technical innovation, institutional arrangements, and market conditions (including, more recently, demand for the internet and services) that has resulted in a reasonably stable growth rate in the quality of integrated circuits. ${ }^{219}$ The fact that the historic trend may suggest a stable rate of change should not be taken to imply that it is amenable to a static approach to an analysis.

Two aspects of Moore's Law are of interest in relation to the internet. The first is whether or not there is an internet analogy of Moore's Law. As observed in section A.3, the CARG for hosts connected to the internet was $31 \%$ and for traffic was $68 \%$, which suggests the possibility of a Moore's Law for the internet. ${ }^{220}$ However, just as with Moore's Law for the integrated circuit, this does not mean that the underlying processes are stable or predictable. The underlying processes are a complex mix of evolving consumer preferences for a range of innovative new services with developing institutional arrangements.

The second aspect is the effect of increasing capabilities of integrated circuits on the capability of the internet. In this case, the rate at which the increasing performance of integrated circuits is incorporated into the internet, existing or new services is the outcome of demand and supply factors in the market for the internet and available services. As one of the input factors is integrated circuits,

${ }^{219}$ This is supported by Odlyzko's (2003, p. 4) observation that "'Moore's laws' are not laws of nature. Furthermore, even when there are extended periods of steady growth at a constant rate in a technology, that growth rate can periodically shift. For semiconductors, the traditional 'Moore's Law' has held remarkably well over more than three decades, but only if it was interpreted in a certain way." Eldering, Sylia, \& Eisenach (1999, p. 117) are more confident in predictions provided by Moore's Law, however they note: "What is most remarkable about Moore's Law is its ability to predict the outcome of the complex set of technological, institutional, and economic forces that determines what is actually bought and sold in the market.” The complex set of technological, institutional, and economic forces, which are changing over time would indicate a dynamic process. Schaller (1997, p. 55) emphasises that "The reinforcing effects of complementary software developments feeding back into PC hardware - and at the core, chip innovations - are significant". He describes these as "dynamically increasing returns".

${ }^{220}$ For example, Eldering, et al. (1999) ask "Is there a Moore's Law for Bandwidth?". Also, Coffman \& Odlyzko (2002b, p. 40) ask "is there a Moore's Law for data traffic?" in 2002 using data up until 2000, and find that the internet was growing at $100 \%$ per year, which superficially is greater than the current aggregate growth rate of $68 \%$. 
this suggests the general change in the performance of the integrated circuit as described by Moore's Law is a convenient reference point for measuring the change in this performance or cost of the internet.

\section{A.8.1 Implications of a relatively simple communications network}

The result of the end-to-end principle and the functional layering of the internet Protocol Suite is a communications network that is relatively simple compared with the traditional telephone network. As Blumenthal \& Clark (2001, p. 71) note, the resulting relatively simple network is easier to upgrade and the core does not need to change in order to accommodate new applications.

The traditional architecture of a switched telephone network integrates the applications into the core of the communications network. The economic consequence, as the Internet Engineering Task Force, Network Working Party explains, is as follows:

In the 1970 and 1980 s, the voice carriers competed by adding features which drove substantial increases in the complexity of the [public switched telephone network], especially in the Class 5 switching infrastructure. This complexity was typically software-based, not hardware driven, and therefore had cost curves worse than Moore's Law. In summary, poor margins on voice products today are due to [operational expenditure and capital expenditure] costs not dropping as we might expect from simple hardware-bound implementations. (2002, p. 6)

Applications such as calling, messaging, caller identification, call waiting indicator and others are embedded within the communications network, rather than at the edge of the network, in host and consumer computers and other access devices, as is the case of an IP communications network. This means that any changes to these services or any new service development is carried out by a telephone network operator, not by a large number of independent service providers as is the case with the internet. The result is that the cost of introducing new services to a traditional switched telephone network is less likely to decrease at the rate or more than the rate of Moore's Law, and that the network is not capitalising on benefits resulting from improvements in technology. 


\section{A.8.2 Best efforts communication network}

As Figure 15 illustrates, once a host breaks the user data into a stream of packets and sends the packets into the core of the IP communications network, there are many different routes that the packets can take across the network to reach the destination host. The routers manage this flow of packets around the network so that the packets reach their destination and maintain network stability by taking the least congested route. One of the technical marvels of the internet is that it is able to do this and thus share communication resources amongst a very large number of hosts communicating contemporaneously with many other hosts.

This means that the internet does not commit or dedicate capacity and resources for communication between two hosts. This is one of the consequences of the end-to-end principle. Communication capacity is provided on a best efforts basis using the available resources of links and routers between two hosts. In the case of a highly interconnected mesh of routers, packets can take a large number of different routes in order to avoid points of congestion.

In contrast, the switched telephone network dedicates a circuit of committed communication capacity over the network to connect calling parties for the duration of a call. This connection between calling parties is maintained for the duration of the call even during periods of silence. IP networks are defined as being connectionless, as there is no circuit-based connection. ${ }^{221}$

\section{A.9 Internet access technology dynamics}

As drawn in Figure 15, the link between a host and a router represents that access network. A single link does not provide the host with different routing options; however, there are still technical options available for providing access. It may seem that the technical capabilities of access to the internet will severely limit the internet services available to consumers. This is true up to a point, as the end-to-end principle with Internet Protocol Suite enables the service providers to functionally bypass services available on the access network. In the case of the traditional telephone switched network, the internet bypassed the calling service available on the switched network.

${ }^{221}$ Perhaps a better description of the internet is that all hosts are fully connected as they are all on the network at the same time and each host can identify the others on the network. 
Figure 11 indicates that, on average, for countries in the OECD, dial-up access to the internet dominated broadband access up until approximately 2004. Prior to 2004, most users accessed the internet by dialling ISPs over the telephone network. The telephone network had been technically optimised to carry voice calls, not internet traffic. Even so, the internet experienced some of its most significant growth rates prior to 2004. The technology that enabled this early growth of the internet was the dial-up modem and the hypertext browser, thus resulting in functional bypass of the switched telephone network and initiating investment in alternative broadband access technologies.

\section{A.9.1 Modems and internet access}

Modems for accessing computer networks over switched telephone networks emerged in the late 1960 s and early 1970 s with modems that could send and receive data at 300 bits per second. This remained the standard data rate for the next decade. By late 1998, dial-up modems became available that could send data at 33.6 kbits per second and receive data at 56.0 kbits per second. Eldering, et al. (1999, p. 120) estimate that dial-up modem data rates doubled every 1.9 years, as illustrated by the following graph up until 1998 .

Figure 16: Historical modem speeds 'Moore's Law' prediction

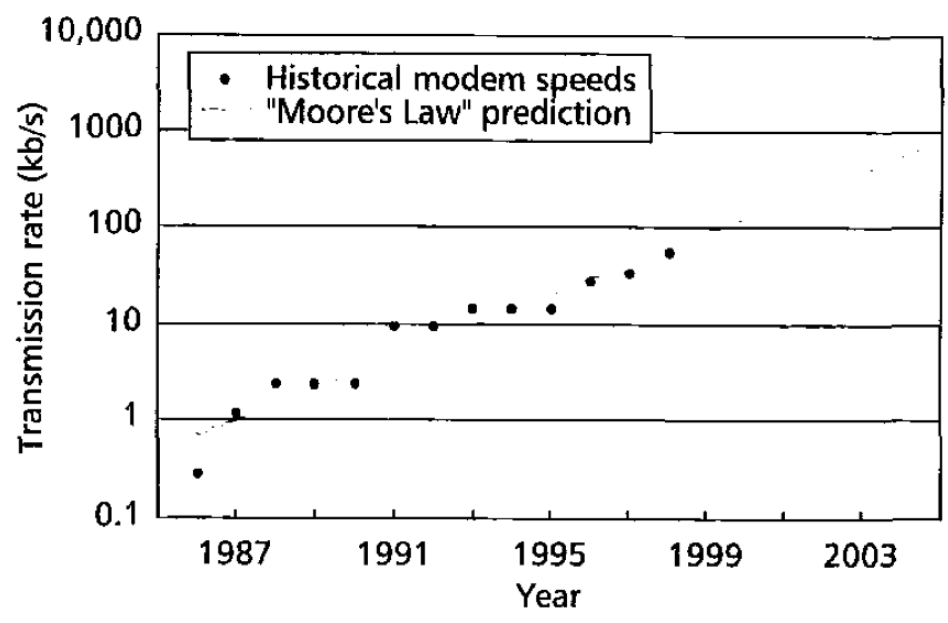

Source: Eldering, et al.(1999, p. 120 Figure 2)

Eldering, et al. (1999, p. 118) also observe that this increase in capabilities of the dial-up modem occurred without regulation. The only constraints in the United States were technical, ensuring that modems did not interfere with the operation of the telephone network.

Telecom New Zealand launched its commercial broadband service in 1999 based on Asynchronous Digital Subscriber Line (ADSL). This enabled data to be 
downloaded at a transmission rate typically below 5 Mbits per second ${ }^{222}$, compared with 56.0 kbits per second using dial-up technology over the copper lines connecting consumers' premises to the local exchange or equivalent network node. An additional feature of broadband access is that consumers remain connected to the internet, unlike dial-up access where consumers would normally have to initiate a connection by 'dialling up' an internet service provider.

Since 1999, the capability and variety of broadband technologies have increased substantially. By the end of 2008, Telecom New Zealand estimated it had installed the ADSL2+ version on $58 \%$ of its lines, enabling theoretical maximum download speed of 24 Mbits per second, with users typically experiencing download transmission rates of between 8 and 15 Mbits per second.223 These developments and the growing range of available access technologies are illustrated in the following table with the average data transmission speeds by access technology.

Table 8: OECD average advertised broadband speeds by technology, September $2008^{224}$

\begin{tabular}{|l|c|c|}
\hline & $\begin{array}{c}\text { Average upload speed } \\
\text { (kbits per second) }\end{array}$ & $\begin{array}{c}\text { Average download speed } \\
\text { (kbits per second) }\end{array}$ \\
\hline Total & 5,012 & 17,412 \\
\hline Wireless & 712 & 1,889 \\
\hline DSL & 699 & 9,623 \\
\hline Cable & 1,264 & 14,856 \\
\hline FTTx & 34,247 & 65,326 \\
\hline
\end{tabular}

Source: OECD(2008a)

222 The IDC \& Epitro Technologies (2008, pp. 8,9) report on broadband states that the ADSL standards allowed maximum download speeds capped at 8 Mbits per second, with typical rates below 5 Mbits per second.

223 Refer to IDC \& Epitiro \& Technologies (2008, p. 8).

224 The OECD (2008b) defines broadband as internet connectivity capable of download speeds of at least $256 \mathrm{kbits}$ per second. Wireless technologies include satellite, LMDS, MMDS, and WiMAX (fixed). DSL covers the digital subscriber line group of technologies including ADSL, VDSL, and SDSL among others. Cable is internet access using cable modems, and FTTx is fibre-to-the-premises (e.g. house, apartment). 
This table indicates that the OECD is monitoring four different technologies providing access to the internet across the OECD group of countries.

\section{A.9.2 Disruptive innovation and the Web browsers}

The discussion so far has considered how the underlying technologies influenced the industry structure of the internet. However, consumers do not value these technologies for themselves, but for the available information and services the technologies carry. One application that had a significant, disruptive, influence on internet access growth in making services and other applications more accessible is the Web browser.

It is common to not differentiate between the World Wide Web (the Web) and the internet. For many, the Web and the internet are synonymous. However, the Web is an application based on the Web browser, which operates over the internet. It allows consumers to access and share a very large number of documents, which are interlinked and contain text, pictures, video, audio and other applications. It increased the value of the internet for many consumers by making online content more accessible.

In 2002, Coffman \& Odlyzko (2002a, p. 42); (2002b, p. 72) claimed there were only two applications which consumers significantly valued: one was email, the other was the Web browser. They observed that it apparently took 18 months from the launch of the first release of the Mosaic visual browser around the middle of 1993 for Web traffic to dominate the internet. Furthermore, they speculate that a 100-fold increase in internet traffic over the two-year period of 1995 and 1996 can be attributed to more consumers being willing to use the internet as more graphics-rich content became available on the Web and the introduction of flat-rate internet access plans. This led to consumers tripling the time they spent online and accelerated the growth in internet access. No information has been found to suggest that a single application launched since 2002 had an effect of similar proportions on the growth of the internet.

\section{A.10 Internet peering and transit}

As the internet is a network of networks, a key input for the supply of internetbased services is the ability to interconnect between networks. The institutional arrangements governing interconnection are flexible and have been an important element in the dynamic development of the internet. The gap in Figure 1 between the rectangle representing the internet services and the rectangle representing the internet access is due to (i) the described functional 
separation between the services and the communications network, and (ii) the commercial separation between services and the internet access.

The vehicle that brought these factors together into a form that would eventually evolve into the internet was a non-commercial network 'NFSNET' developed by the National Science Foundation (NSF). NSFNET was a network that linked together universities across the United States. The first NFSNET goal was to link together supercomputer centres, and emerging regional and midlevel networks. ${ }^{225}$ The second goal was to expand the use of the network from scientists and researchers to a broad academic community for their general use. At the time, building a network for general-purpose use was novel, as networks had been built for a particular project or program of activity. In contrast, NSFNET was built to provide general-purpose connectivity.

The development of NSFNET commenced when it engaged a partnership of Merit Network, IBM, and MCI. By mid 1988, the partnership had commissioned an operational network connecting 13 sites across the United States, transmitting 152 million packets per month at a speed of 1.5 Mbps. Even at this early state, in its first year, the usage of NSFNET grew by 500\%. By late 1991 the network covered 16 sites, with a transmission speed of $45 \mathrm{Mbps} .^{226}$

During this period, pressure began to build to commercialise NSFNET as awareness of the benefits and potential for such a network grew, especially in the private sector. A constraint on the traffic that could traverse NSFNET was NSF's Acceptable Use Policy, which prohibited the transmission of purely commercial traffic. However, regional and other networks were attracting commercial customers. Plus, it was apparent that commercial traffic would improve the efficiency of networks given the networks' underlying economies of scale and scope. ${ }^{227}$

At this time, some commercial backbone operators circumvented NSFNET by establishing a Commercial Internet Exchange (CIX), which consisted of a router located in Santa Clara, California. ${ }^{228}$ CIX interconnected the commercial

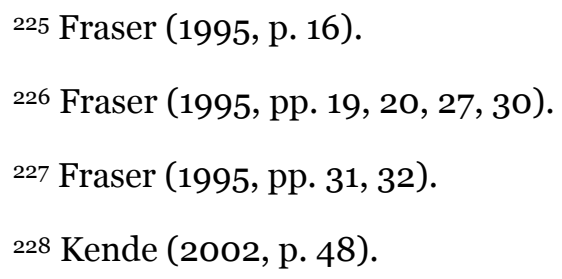


backbones, enabling them to exchange end-user traffic. In 1993, NSF ceased funding the NSFNET, leaving the management of the backbone to competing commercial networks. In order to facilitate development of competing backbone networks, NSF designed a system of Network Access Points (NAPs) across the United States, similar to the CIX, for interconnecting the commercial operators. These commercial networks and NAPs replaced NSFNET in 1995.

Although the NSF designed the system of NAPs, the NSF did not establish any terms for interconnection, nor did the Federal Communications Commission regulate interconnection among the commercial internet backbone operators. ${ }^{229}$ In 2008, the terms of interconnection among the internet network operators remained unregulated by the FCC.

Over time, network operators have developed two alternative types of interconnection for exchanging traffic. These two types of interconnection contracts emerged as the commercial internet developed in the early 1990 s and are still in use. Most internet traffic is carried and exchanged using these contracts. Network operators agree to either peer with each other or to transit traffic to another carrier's traffic.

\section{Peering 230}

In principle, peering involves two operators exchanging traffic that is destined for an end user on the other operator's network, and they agree to neither charge nor receive payment for terminating this traffic. An important implication of this arrangement is that no information is exchanged between network operators regarding usage or pricing of individual services connected to their network. Therefore, information about service usage does not traverse the internet, and is not passed onto individual consumers by the network operator, although the service provider may charge the consumer for services.

In the United States, peering requires the two operators to agree the geographic location where the two networks are to interconnect. In complex networks where there are multiple points of interconnection, the generally accepted practice is to engage in hot-potato routing. This involves each operator, with one of two end users (consumer or host) who are communicating, agreeing to hand

\footnotetext{
229 Kende (2002, p. 42).

230 Economides (2005, p. 379) and Kende (2002, p. 47).
} 
over traffic from the originating network to the terminating network at the point of interconnection closest to the end user originating the IP packet. This implies that a communication exchange between two end users, with each end user originating traffic on different networks, may traverse geographically separate handover points.

\section{Transit ${ }^{231}$}

The alternative to peering is transit. This involves a network operator agreeing to carry traffic for another network operator that originated the traffic, ultimately to a peering point of interconnection. ${ }^{232}$ The network operator originating the traffic will pay for transit, and therefore a wholesale customer of the network operator provides the transit service.

There is no accepted convention for deciding when two network providers should peer with each other or one offers the other transit. Kende (2002) distils the decision down to whether each operator judges that they will equally share in the benefits and the costs of interconnect. If the network operators believe that the benefits and costs are equal then they will agree to peer with each other, otherwise one operator will charge the other for transit. As observed in the United States, network operators engage in a mix of peering and transit agreements with different operators. ${ }^{233}$

\section{Development of the internet interconnection in New Zealand}

A report by Internet $\mathrm{NZ}^{234}(2007$, p. 7) states that prior to 2004, network operators, including the two largest - Telecom New Zealand and TelstraClear interconnected with each other at a multilateral peering exchange in Auckland and in Wellington, where traffic was exchanged without payment between network operators. Network operators funded the cost of carrying traffic to and

${ }^{231}$ Economides (2005, p. 379) and Kende (2002, p. 47).

${ }^{232}$ Under a peering agreement, if an operator receives traffic that is not for an end user connected to their network then the operator can disregard this traffic.

${ }^{233}$ See Kende (2002, p. 52) for a discussion on the commercial practicalities of peering and transit negotiations in the U.S. From an antitrust perspective, Besen, et al. (2001) indicate that these more complex peering and transit arrangements result in opportunities for competitive bypass and less chance for exclusion.

234 Internet NZ (2007, p. 5) states it is "a membership-based not-for-profit organisation and has the management responsibility for the administration of the .nz domain name registry, a critical component of the internet infrastructure in New Zealand." 
from these peering exchanges, including the cost of national transmission, from revenue earned from their customers.

In 2004, TelstraClear withdrew from the peering exchanges, and Telecom followed soon after. At the time the report was prepared by InternetNZ, TelstraClear and Telecom interconnected with each other and provided access for some other network operators by private bilateral transit arrangements. Some network operators continued to exchange traffic at the multilateral peering exchanges in Wellington and Auckland. Otherwise, traffic was exchanged at peering exchanges offshore. The report highlights issues regarding the efficiency of these particular arrangements with respect to the supply of local content, particularly video and audio-rich content, within New Zealand. It also highlights the flexibility in determining particular arrangements of peering and transit contracts within New Zealand. ${ }^{235}$

\section{A.11 Summary}

The transformation in market structure described by Figure 1 and Figure 4 was enabled by the internet protocol suite and the structure of peering and transit contracts. The end-to-end principle with the layering of the internet Protocol Suite meant that a wide variety of services could be added and removed from the internet without the need for changing the communications network. The peering and transit contracts meant that service providers did not need to have contracts with the network providers that their customers happened to connect. These features of the internet lowered the cost of entry for new services compared with introducing new services to the public switched telephone network.

\section{A.12 Annex: Selection of service providers}

There is a range of methods and sources for assessing the general demand or value that consumers place on websites. A variety of internet research companies provide this information using a variety of methods. As the data is publicly available, the two internet research companies selected are Alexa Internet and comScore. The data from these research companies are reported here and provide a general indication of the popularity of various websites both

\footnotetext{
235 An illustration of this flexibility is provided by some stakeholders in New Zealand indicating that in addition to the definition of peering and transit described above, paid peering is a possible form for an interconnection contract (InternetNZ External Peering Group, 2007, p. 9).
} 
here in New Zealand and overseas. Generally, the approach taken by these companies for ranking sites is to monitor a sample of consumers for the sites they visit and then adjust the raw data for any sample bias. The choice of these research companies here is not an indication of the validity of the reported data.

Table 9: Alexa internet traffic rankings

\begin{tabular}{|l|l|}
\hline NZ Top 1o Sites & Global Top 1o Sites \\
2 March 2009 & March 2009 \\
\hline 1. Google New Zealand & 1. Google \\
2. Google & 2. Yahoo! \\
3. Trade Me & 3. YouTube \\
4. Yahoo! & 4. Live.com search engine from \\
5. Windows Live & Microsoft \\
6. YouTube & 5. Facebook \\
7. Facebook & 6. Msn \\
8. Bebo.com & 7. Wikipedia \\
9. Wikipedia & 8. Blogger \\
10. Blogger.com & 9. Myspace \\
& 10. Yahoo.co.jp \\
\hline
\end{tabular}

Source: (Alexa Internet. Top Sites in New Zealand, 2009) and (Alexa Internet. Global Top Sites, 2009)

Table 10: comScore World Metrix Rankings

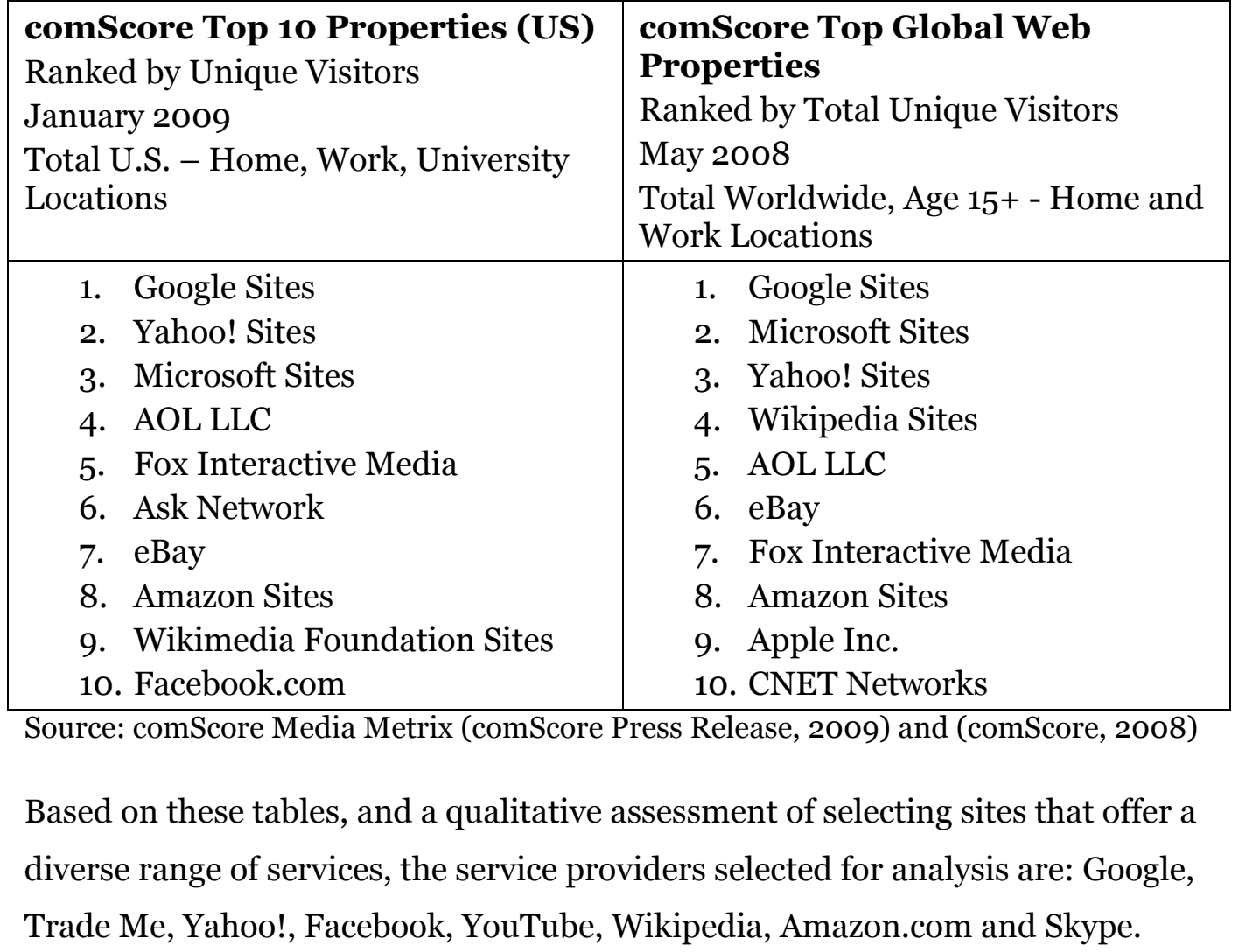


This is not a comprehensive list of major service providers that offer services in New Zealand, let alone those with a significant international presence. The service providers not included in this list but which appear in the rankings offer similar types of services to others in the list. For this limited selection of service providers, it will be shown there has been significant growth across a range of different services within the past 10 years. This will be followed by observations regarding the aggregate effect of the growth in services on the internet.

\section{Description and growth of each service provider}

\section{Google}

Google is a web search engine that allows consumers to search web pages.

Google provides consumers with numerous features and tools to assist with the search. Additional services offered by Google include Google News, Google Finance, Google Maps, Google Image Search, Google Video, Google Book Search, Google Blog Search, and Google Groups, amongst others.

Google was incorporated on 4 September 1998. In 2008, Google Inc. earned US $\$ 21.7$ billion revenue with income from operations of US $\$ 6.6$ billion (Google Inc., 2009). Google Inc. entered the S\&P $100^{236}$ on 17 December 2006 (Standard \& Poor's, 2006).

A general indication of the magnitude of the growth can be provided by way of comparison with Verizon Communications Inc and Sprint Nextel Corporation, a major telecommunications operator in the United States, and Apple Inc. For the 2008 financial year Verizon (2009) posted revenue of US\$97 billion and operating income of US\$17 billion. Sprint Nextel (2009, p. 30) posted revenue of US $\$ 35.6$ billion and an operating income loss of US $\$ 2.7$ billion. Apple Inc. (2008, p. 36) posted revenue of US $\$ 32$ billion and net income of US $\$ 5$ billion.

\section{YouTube}

YouTube offers an internet video search service which allows people to watch and share videos. By the time Google Inc. announced its acquisition of YouTube,

${ }^{236}$ Standard \& Poor's (2009, p. 3) state: “The S\&P 100 consists of 100 companies selected from the S\&P 500. To be included, the companies should be among the larger and more stable companies in the S\&P 500, and must have listed options. Sector balance is considered in the selection of companies for the S\&P 100. This index is widely used for derivatives, and is the index underlying the OEX options." Furthermore "The S\&P 500 focuses on the large-cap sector of the [U.S. equities] market; however, since it includes a significant portion of the total value of the market, it also represents the market." 
consumers were daily retrieving 100 million video views and uploading 65,000 new videos (Google Inc. Press Center, 2006).

The domain name 'www.youtube.com' was activated in February 2005 with its official launch in November 2005. In October 2006, Google Inc. announced that it had agreed to acquire YouTube for US\$1.65 billion, which was completed the following month (Google Inc. Press Center, 2006).

\section{Trade Me}

Trade Me is a New Zealand-based internet auction website. On 16 March 2009, Trade Me reported having 2.2 million active members and 1.2 million current listings (Trade Me, 2009). The total population of New Zealand at the end of June 2008 was 4.2 million.

Trade Me was founded in 1999 and acquired by Fairfax in April 2006 for NZ\$700 million (John Fairfax Holdings Limited Press Release, 2006).

An indication of the general magnitude of this growth can be gained by comparing this result with Telecom New Zealand's growth over a similar period. In 1998, a year before Trade Me was founded, Telecom (1998, p. 25) also reported having 1.8 million access lines and 476 thousand mobile connections in New Zealand. In 2008, Telecom (2008, pp. 12, 17) reported having 1.8 million access lines and 2.1 million mobile connections in New Zealand.

\section{Skype}

Skype offers a telephone service to consumers connected to the internet.

Consumers download and install the Skype software which allows them to make and receive calls. Calls between Skype consumers are free, whereas calls to a fixed or mobile telephone network incur a call charge.

Skype was founded in 2002. In September 2005, eBay Inc. announced that it had agreed to acquire Skype for US\$2.6 billion (eBay Inc. Media Center, 2005). For the year 2008, Skype posted revenue of US\$550 million (eBay Inc. Media Center, 2009b). In April 2009, eBay announced that it plans to separate Skype from eBay by an initial public offering in 2010 (eBay Inc. Media Center, 2009a).

By the end of 2008, Skype had more than 405 million users worldwide. eBay cited preliminary data released by TeleGeography Research which indicates that Skype accounted for 8\% of the world's international calling minutes in 2008. 
eBay also states that 30\% of Skype users use Skype for business purposes, and more than $25 \%$ of Skype-to-Skype calls include video.

\section{Facebook}

Facebook is a "social utility that helps people communicate with friends, family and work colleagues". The company develops technologies that facilitate the sharing of information through a 'social graph', the digital mapping of people's real-world social connections.

Facebook was founded in February 2004 (Facebook Inc. Press Room, 2009a). It is currently privately owned and does not release financial information.

By February 2009, Facebook had more than 175 million users. More than 50\% of users are not at college, and more than $70 \%$ of users are outside the United States. The average user has 120 friends on the site (Facebook Inc. Press Room, 2009b). Extrapolating the investment by Digital Sky Technologies in 2009 of US\$200 million for a 1.96\% stake implies a valuation for Facebook's preferred stock of US $\$ 10$ billion. ${ }^{237}$

\section{Yahoo!}

Yahoo! Inc. offers a web portal that provides consumers a homepage, internet search engine and email, amongst other services. Internet surveys indicate that Yahoo! web sites are the second most visited sites on the internet.

Yahoo! Inc. was founded in 1994 and incorporated in 1995. Yahoo! Inc. posted revenue of US\$7.2 billion and net income of US\$424 million for 2008 (Yahoo! Inc., 2009).

Yahoo! Inc. earns revenue by offering advertising space and marketing services on its websites. With respect to the New Zealand internet market, Yahoo!Xtra is a joint venture between Yahoo!7 and Telecom New Zealand. Yahoo!7 holds a $51 \%$ stake in the joint venture company and Telecom holds $49 \%$. Yahoo! 7 is a joint venture between Australia's Seven Network and Yahoo! Inc.

\section{Wikipedia}

Founded in 2001, Wikipedia is a multilingual, Web-based, free-content encyclopaedia which is written by volunteers. In 2008, it attracted 684 million

\footnotetext{
237 Reported by The New York Times by Miller (2009).
} 
visitors. There are more than 10 million articles in more than 250 languages (Wikipedia contributors, 2009).

\section{Amazon.com}

Amazon.com is an online retailer that sells a wide variety of goods and services including clothes, music CDs, books, software, consumer electronics, and DVDs amongst other things.

Amazon.com, Inc. was incorporated in 1994. In 1998, Amazon.com, Inc. posted net sales of $\$ 609$ million and a loss from operations of ( $\$ 112$ million) (Amazon.com Inc., 1999). In 2008, Amazon.com, Inc. posted net sales of \$19 billion and income from operations of $\$ 842$ million (Amazon.com Inc. investor relations, 2009). Amazon.com entered the S\&P 100 on 31 December 2008 (Standard \& Poor's, 2008). 


\section{Appendix B: Two-part tariffs in the presence of heterogeneous consumers}

Income plays a key role in a consumer's consumption of any service. It is no different when two-part tariff determines consumers' outlay for a service. In the case of a basic telephony service, the two-part tariff generally takes the form of a monthly subscription fee for access to a telephony network, and a usage price for making a call over the telephony network. Payment of an access fee, say, for subscribing to a telephony service, directly reduces the income available to spend on calls as well as non-telephony services. Thus income determines the extent of the benefits from subscribing compared to not subscribing, and thus subscription and consumption decisions.

This general issue for telecommunications has not been systematically treated in the literature. A theory of consumer behaviour and two-part tariffs is presented which ties together the access fee and call price within a coherent model of consumer behaviour. The model of consumer behaviour has standard assumptions of utility maximisation where there is a two-part tariff, and consumption and participation in that market are jointly a normal good. The model is used to analyse optimal two-part tariffs with endogenous participation.

\section{B.1 Literature on the theory of two-part tariffs}

A feature of the literature on two-part tariffs is that a wide range of simplifying assumptions is made when addressing a particular problem and these assumptions are often not consistent with each other.

Laffont \& Tirole (2000, pp. 60-66, 68, 70), and Mitchell (1978) propose that the socially optimal two-part tariffs should be analysed as complementary access and call services where the access fee and call price are determined by RamseyBoiteux pricing principles. Ramsey-Boiteux pricing principles determine the contribution to common costs from the access fee and usage call, where the contribution from the access fee is proportional to the inverse of the access fee elasticity and the contribution from the usage price is proportional to the inverse of call price elasticity. That is, the mark up included in the access fee and call price is proportional to the inverse of the price elasticity of demand for access and call services. ${ }^{238}$ This treats access and calling as separate services. In

${ }^{238}$ Laffont \& Tirole (2000, p. 64). 
addition, Laffont \& Tirole (2000, p. 73) propose that prices may deviate from Ramsey-Boiteux prices if some other social objective is to be met, for example an obligation to make telephony services universally available to a population. This implies that the pricing associated with the social objective is not efficient whereas a tariff based on Ramsey-Boiteux pricing is efficient. Boiteux (1971) and Ramsey (1927) exclude wealth effects and consider only uniform price-per-unit demand, so have little relevance to determining optimal two-part tariffs.

The literature makes a variety of assumptions regarding the role, or lack of, for income as a determinant of consumer behaviour under two-part tariffs. Coase (1946) and Oi (1971) assume that income does not affect demand. Schmalensee (1981) assumes the marginal utility of income is a constant equal to one irrespective of whether or not consumers subscribe to the service. Furthermore, Ng \& Weisser (1974), Goldman, Leland, \& Sibley (1984), and Wilson (1993, pp. 165-176) implicitly assume that the marginal utility of income is continuous in the transition from non-subscriber to subscriber. These assumptions are inconsistent with the proposition that income affects subscription decisions.

Tirole (1988, pp. 143-144) proposes a model of consumer behaviour that assumes different marginal utility of income between subscribing and not, which is in part consistent with a general proposition that an increase in income increases subscription. However, Tirole also assumes that utility is separable between calling and non-telephony services, which is inconsistent with the proposition that calling increases with income.

Oi (1971), Feldstein (1972), Littlechild (1975), Auerbach \& Pellechio (1978), and Mitchell \& Vogelsang (1991, p. 80) assume that the consumer surplus, and therefore the willingness to pay for access, equals the area under the demand curve. For this assumption to be theoretically valid, the demand for calling cannot be a function of income. This is also generally inconsistent with the proposition that consumers on higher incomes subscribe whereas those on lower incomes do not subscribe: that is, that subscription is a normal good.

Stole (1995) develops a Hotelling location model in an oligopoly setting where firms use nonlinear tariffs to discriminate. ${ }^{239}$ Stole's model differentiates

239 Armstrong \& Vickers (2001) also use a Hotelling location model, arguing that price discrimination tends to be desirable in sufficiently competitive conditions, with the exception where consumers are segmented into separately identifiable markets. 
consumers' preferences along a horizontal dimension for a firm's brand and vertical dimension for quality or quantity scale. A fundamental distinction between the horizontal and vertical dimensions is that consumers with a high horizontal preference for one brand will have a low preference for another. Conversely, a high vertical preference for a particular quantity or quality is constant across all brands. Stole concludes that the optimal price schedule depends on the type of private information (brand or quality) that the consumer possesses.

Stole's (1995) use of term 'participation decision' differs from that used here. For Stole, consumers choose to participate in a service by subscribing to or purchasing one of a range of differentiated services based on their brand preference. In the present work, consumers choose whether or not to participate in a telephony service. In principle, no limit is placed on the number of telephony services that a consumer subscribes too. For example, the model presented in this appendix accommodates the situation where consumers subscribe to a telephony service and decide whether or not to subscribe in addition to a mobile service. ${ }^{240}$

There is no doubt that consumers' tastes and preferences vary, and income may influence preferences. This spatial representation of consumer preferences does not explicitly take into account the effect of income on a consumer's participation decisions. Income's role in consumers' participation decisions is

Rochet \& Stole (2002) consider the optimal nonlinear prices with the spatial model of consumer preferences and show that a duopoly outcome is similar to a monopoly outcome, and if the two firms have the same marginal cost and competition is sufficiently intense, then the result is cost-plus-fee pricing. Yin (2004) also considers oligopoly competition amongst firms using a Hotelling location model and finds that two-part tariffs result in greater welfare relative to uniform prices. Hoernig \& Valletti (2007) use a Hotelling location model to compare the tariff structures adopted by media outlets, such as cable-tv firms, where firms offer various combinations of subscription and pay-per-view fees. They argue that consumer welfare tends to reduce as the reliance of subscription-based pricing increases because a subscription reduces affordability, mixing content from different sources.

Blonski (2002) adapts the Hotelling location model to consider the effect of network externalities on optimal two-part tariffs, while making the explicit assumption that consumers are not differentiated by income, and noting that, for his purpose, it does not matter if consumer "differentiation is generated by wealth, taste, or both" (Blonski, 2002, p. 99, footnote 3). It is proposed here that it does matter whether differentiation is generated by wealth or taste.

${ }^{240}$ See section 3.4.2 for numerical example illustrating consumer participation in mobile services. 
distinct from acting as a proxy for the variation in consumer tastes. ${ }^{241}$ To assume that variation in income and variation in preferences are essentially the same implies that income does not have an effect on calling and that utility is separable. This leads to ambiguity regarding a theory that explains the participation decision.

\section{B.2 Influence of income on consumer behaviour}

Suppose all consumers in the population have the same preferences and that income differentiates consumers. Consumers derive utility from making telephone calls $x$ and consuming non-telephony goods $z$ :

$$
u(x, z)
$$

Utility is twice continuously differentiable everywhere, strictly increasing, and is strictly concave for all individuals. That is, it is assumed that $u_{x}(x, z)>0$, $u_{z}(x, z)>0, u_{x x}(x, z)<0$ and $u_{z z}(x, z) u_{x x}(x, z)-u_{x z}^{2}(x, z)>0$, where the subscript indicates the first and second order partial derivative taken with respect to variables, calls and non-telephony goods. This implies that at a consumer's optimal consumption choice, given a budget constraint, utility is a concave function on income.

Individuals consume some non-telephony goods (for example food), and they have the option to not make telephone calls as there are other modes of communication, which implies:

$$
\begin{aligned}
& x \geq 0 \\
& z>0
\end{aligned}
$$

If a unit of the non-telephony goods has a unit price, and an individual with total income $y$ does not make any calls, then the utility derived is:

$$
u(0, y)
$$

A necessary condition for an individual to subscribe to the telephony service and make calls is that their utility from subscribing and calling is greater than or equal to their utility from not subscribing:

${ }^{241}$ Tirole (1988, pp. 143-144) claims that variation in income and variation in tastes are equivalent. 


$$
u(x, z) \geq u(0, y)
$$

The arguments of the utility functions on either side of the inequality are not the same, resulting in a discontinuity in demand due to the participation decision. The term on the left-hand side of the greater-than-or-equal-to sign is the utility derived from subscribing and calling, whereas the term on the right-hand side is the utility derived from not subscribing and not calling. If the term on the left is strictly greater than the term on the right then the individual is an inframarginal subscriber. If the equality holds, then the individual is a marginal subscriber. In this case, the individual is assumed to subscribe even though they are indifferent to subscribing and not subscribing. If the condition does not hold then the individual will not subscribe.

Suppose that subscribers' outlay on the telephony service is determined by a two-part tariff that includes a fixed monthly fee $f$ for access to the network and a price $p$ per call. A subscriber's total outlay on non-telephony goods and the telephony service must satisfy the budget constraint:

$$
z+p x+f \leq y
$$

where $y$ is an individual's income. Individuals base their consumption decision on the trade-off between calling and consuming non-telephony goods. If they subscribe they will pay the access fee, resulting in a reduction in the available funds to outlay on calls and non-telephony goods. It follows that utility is not a homogeneous function of telephone calls and non-telephony goods, as the ratio of non-telephony goods to calls is not constant along the income-consumption path: this is due to the access fee. ${ }^{242}$

Following from the concavity of utility and the budget constraint, a subscriber's optimal demand for calls and non-telephony goods is $x(p, y-f)$ and $z(p, y-f)$. Substituting these demand functions into equation (31) gives an alternative representation of the subscription decision in terms of the indirect utility:

242 The income-consumption path is the locus of all tangencies of the indifference curves to various budget constraints, holding price constant (Silberberg, 1990, p. 317). 


$$
v(p, y-f) \geq u(o, y)
$$

This is an individual's participation constraint. Furthermore, it is assumed there is an income $i$ that will satisfy the equality:

$$
v(p, i-f)=u(\mathrm{o}, i)
$$

The novelty of this work is the explicit consideration of a normal-good assumption in relation to the participation decision, and its implication for the construct of the utility function. ${ }^{243}$ It seems reasonable to expect that inframarginal subscribers are those individuals with income $y>i$, whereas individuals with income $y<i$ do not subscribe. Two consistent conditions are proposed that are sufficient to result in normal participation behaviour.

The first condition is required for normal participation when there is no access fee, and that tariff is a uniform price per unit. That is, given $f=0$ and a choice of call price $p^{*}$ such that $x\left(p^{*}, i\right)=0$, then subscription increases with income if:

$$
v_{y y}\left(p^{*}, i\right)>u_{z z}(\mathrm{o}, i)
$$

Assuming that the first condition holds, the second condition is sufficient for normal participation behaviour when the access fee takes a positive value, and there is a two-part tariff. That is for $f>0$ and thus $x(p, i-f)>0$, subscription increases with income if:

$$
v_{y y}(p, i-f) \geq u_{z z}(x(p, i-f), z(p, i-f))
$$

Together these two conditions result in normal participation behaviour. That is, for a given two-part tariff and an individual who does not subscribe, continuing to increase the individual's income will eventually result in the individual subscribing and making calls.

243 Oi (1971), Feldstein (1972), Littlechild (1975), Auerbach \& Pellechio (1978), Schmalensee (1981), Tirole (1988, p. 143), and Mitchell \& Vogelsang (1991, p. 80) put forward the general proposition that participation is determined by comparing utility or consumer surplus at two the separate arguments of participating and not participating. Where this thesis departs from this earlier work is to explicitly consider the normal good aspect of the participation decision. 
To show that the first condition leads to normal participation, suppose $f=0$ and a call price $p^{*}$ is chosen such that $x\left(p^{*}, i\right)=0$ for marginal subscribers with income $i$. It follows that marginal subscribers are indifferent between subscribing and not subscribing, at the same argument, $x=0$ and $z=i$. Irrespective of whether or not the marginal subscribers subscribe, they do not make any calls and spend all of their income on non-telephony goods. Furthermore, as $f=0$, and $x\left(p^{*}, i\right)=0$ is optimal choice with subscription, then the first order conditions of the marginal subscribers' optimisation problem is: 244

$$
v_{y}\left(p^{*}, i\right)=u_{z}(\mathrm{o}, i)
$$

Therefore, the second order condition implied by (35) is required to ensure that those with income $y>i$ subscribe, whereas those with income $y<i$ do not subscribe. ${ }^{245}$ If the inequality in (35) does not hold, and the increase in the marginal utility of income of subscribing is less than not subscribing, then consumers with income slightly less than $i$ would gain utility from subscribing, and individuals with an income greater than $i$ would lose utility from subscribing. This would contradict normal participation behaviour.

An additional consequence of the first condition is that not only does participation increase with income at $x\left(p^{*}, i\right)=0$ but also calling is a normal good, $x_{y}\left(p^{*}, i\right)>0$. This can be shown by first taking derivate of (35) with respect to $y$ :

$$
u_{x x}^{*} x_{y}^{*_{2}}+2 u_{x z}^{*} x_{y}^{*} z_{y}^{*}+u_{z z}^{*} z_{y}^{*_{2}}>u_{z z}^{*}
$$

\footnotetext{
244 Silberberg (1990, pp. 313-315) shows that the condition described by equation (37) holds at the optimal consumption choice.

245 Schmalensee (1981) assumes that the marginal utility of income is constant. Although, equation (41) allows either $v_{y y}(p, i-f)=0$ or $u_{z z}(0, i)=0$, it does not allow both $v_{y y}(p, i-f)=0$ and $u_{z z}(0, i)=0$. Furthermore, as discussed below, there is a discontinuous increase in the marginal utility of income.
} 
The arguments of the functions in this expression have been left out in order to simplify notation, and asterisks have been added as a reminder that the derivates are being evaluated at the argument $x=0$ with $z=i$. Substituting $z_{y}^{*}=1-p^{*} x_{y}^{*}$, which derived from the budget constraint into equation (38) and simplifying gives:

$$
\left(u_{x x}^{*}-2 p^{*} u_{x z}^{*}+p^{* 2} u_{z z}^{*}\right) x_{y}^{*}+\left(u_{x z}^{*}-p^{*} u_{z z}^{*}\right) 2>0
$$

In addition to the conduct implied by equation (35), as income increases for $y \geq i$, consumption follows the income-consumption path determined by $u_{x}^{*}-p^{*} u_{z}^{*} \equiv 0 . .^{246}$ Taking the derivative of the first order condition at the optimal consumption choice $u_{x}^{*}-p^{*} u_{z}^{*} \equiv 0$, substituting $z_{y}^{*}=1-p^{*} x_{y}^{*}$, and simplifying leads to:

$$
\left(u_{x x}^{*}-2 p^{*} u_{x z}^{*}+p^{*} u_{z z}^{*}\right) x_{y}^{*}+u_{x z}^{*}-p^{*} u_{z z}^{*}=0
$$

Comparing equations (39) and (40) indicates that:

$$
u_{x z}^{*}-p^{*} u_{z z}^{*}>0
$$

Comparing this result with (40), and recognising that the term within brackets of (40) is negative due to the (quasi-)concavity of the utility function, implies $x_{y}^{*}>0 .{ }^{247}$ That is, if $f=0$, normal participation behaviour requires that an increase in income will increase the demand for calls.

For $f>o$, the second condition, (36), with the first condition, (35), implies:

$$
v_{y}(p, i-f)>u_{z}(0, i)
$$

That is, a positive access fee results in a discontinuous increase in the marginal utility of income as the marginal subscriber is indifferent between not subscribing and subscribing. Whereas, with no access fee there is no

\footnotetext{
${ }^{246}$ The income-consumption path is the locus of all tangencies of the indifference curves to various budget constraints, holding prices constant (Silberberg, 1990, p. 317).

247 Quasi-concavity is sufficient for $u_{x x}^{*}-2 p^{*} u_{x z}^{*}+p^{*_{2}} u_{z z}^{*}<0$ (Silberberg, 1990, p. 307).
} 
discontinuous change in marginal utility, as (37) indicates. The effect of this discontinuity is that consumers with income $y<i$ do not subscribe, whereas those with income $y>i$ do subscribe.

In order to show that (42) follows from the first and second conditions, consider a sufficient, though not necessary, condition that is consistent with equation (42). Suppose for $x \geq 0$ that the full derivative $d u_{z}(x, z) / d x>0$ subject to $u(x, z)=u(0, i)$, and that $u_{z}(x, z)$ is smooth. This is the same as the marginal utility of income increasing with traversing a marginal subscriber's indifference curve as $x$ increases. ${ }^{248}$ Expanding the full derivative with respect to $x$ gives:

$$
u_{x z}(x, z)-\frac{u_{x}(x, z)}{u_{z}(x, z)} \cdot u_{z z}(x, z)>0
$$

This expression, but evaluated at $x=0$ and $z=0$, is the same as (41). This suggests that (42) holds for values of $f$ close to zero, as $u_{z}(x, z)$ is smooth. It also suggests that equation (42) will hold for $x>0$ if the full derivative $d u_{z}(x, z) / d x \geq 0$, subject to $u(x, z)=u(0, i)$. In other words, taking an extreme scenario, equation (42) will hold for $x>0$ if $d u_{z}(x, z) / d x=0$ for $x>0$ because of the first condition imposed on the utility by (35). Therefore expanding the full derivative of $d u_{z}(x, z) / d x \geq 0$, subject to $u(x, z)=u(0, i)$ gives:

$$
u_{x z}(x, z)-\frac{u_{x}(x, z)}{u_{z}(x, z)} \cdot u_{z z}(x, z) \geq 0
$$

However, this expression is implied by the second condition, equation (36). This is demonstrated by taking the same steps used to derive equation (41) from (35), to derive (44) from (36).

A further implication of the second condition is that for $f>0, x_{y}(p, i-f) \geq 0$. For positive values of the access fee, income might not have an effect on the demand for calling, which is in contrast to the scenario where $f=0$ when

${ }^{248}$ Note that the utility maximising first order conditions for a subscriber implies that $v_{y}(y, p-f)=u_{z}(x(y, p-f), z(y, p-f))$. 
$x_{y}\left(p^{*}, i\right)>0$. This result can be inferred from equation (40). If equation (44) equals zero, then this is comparable to the term $u_{x z}^{*}-p^{*} u_{z z}^{*}=0$ in equation (40), which implies $x_{y}(p, i-f)=0$.

\section{B.3 Income variation}

Income is distributed so that the proportion of a population with income $y$ is given by the uni-modal density function $m(y)$. Consumers in the population are assumed to have the same preferences. In other words, consumers' preferences for calling and other non-telephony goods are described by the same utility function, equation (28). As a result, any variation in demand between consumers is solely due to the variation in income.

The population size is assumed to be large enough for $m(y)$ to be treated as continuous and differentiable within the domain $0<y<\infty$. An example of $m(y)$ is the log-normal distribution; nevertheless, a specific functional form is not necessary to derive the following results. The uni-modal assumption is not necessary to derive results, but its inclusion simplifies the exposition by avoiding the possibility of multiple solutions.

The total number of subscribers is then:

$$
M(i)=\int_{i}^{\infty} m(y) d y
$$

and the aggregate of individual subscribers' demand for calling is determined by:

$$
X(p, f, i)=\int_{i}^{\infty} x(p, y-f) m(y) d y
$$

where $i$ is the income of the marginal subscriber defined by equation (34), and $x(p, y-f)$ is the subscribers' with income $y$ demand for calls that maximises their utility for the given access fee $f$ and call price $p$.

\section{B.4 Supply of telephony service}

A monopoly supplies the telephony service and earns a profit:

$$
\Pi(p, f, i)=p X(p, f, i)+(f-g) M(i)-H(X(p, f, i))
$$


where the variables $p, f$ and $i$ are respectively the call price, the access fee, and a marginal subscriber's income.

Network costs are separated into network elements with properties that are representative of networks in practice. The marginal cost of providing a consumer with access to the network is represented by the parameter $g .{ }^{249}$ The marginal cost of access is constant with respect to the number of consumers joining the network. In reality, the cost of access is an incremental cost, such as the cost of installing an access line. However, as noted, it is assumed here that the number of subscribers is sufficiently large to treat $M(i)$ as a continuous function.

In addition to access network elements there are core network elements, which in the case of a standard telephone network includes switching and transmission equipment. The cost of the core network element is represented by the cost function $H(X)$, which is the minimum cost to supply the total demand for calling. It is assumed that the marginal cost of a call is positive, $H_{X}(X)>0$ and concave in calling, $H_{X X}(X) \leq 0$. This states the cost of the core network is an increasing, concave function of total demand for calling. A key aspect of this assumption is that the core network is a common cost.

\section{B.5 Profit maximising two-part tariff}

By choosing $p, f$ and $i$, the objective of the monopoly supplying the telephony service is to maximise profit:

$$
\begin{array}{ll}
\frac{\max }{p, f, i} & \Pi(p, f, i)=p X(p, f, i)+(f-g) M(i)-H(X(p, f, i)) \\
\text { s.t. } & G(p, f, i)=v(p, i-f)-u(o, i) \equiv 0
\end{array}
$$

249 Oi (1971), Feldstein (1972), Ng \& Weisser (1974), Auerbach \& Pellechio (1978), and Goldman, Leland \& Sibley (1984) also consider the situation where consumers share a common cost, but they assume only one input cost that is attributable to individual consumers, which is for usage. In addition to the complication of determining the optimal recovery of a common cost, the input cost structure analysed by these studies is not consistent with a telephony service, as the input cost for providing access to a telephony network is significant. Schmalensee (1981), and Brown \& Sibley (1986, pp. 200,201 ) assume that costs are attributable to an individual consumer and that there is a cost to providing access and a cost for a call, as assumed here. 
As income is distributed heterogeneously, the income of the marginal subscriber, $i$, is a choice variable in addition to $p$ and $f$. Of particular interest is the effect the income distribution has on the optimal values of $p$ and $f$.

Taking the first order conditions of a suitable Lagrangian function gives:

$$
\begin{aligned}
L_{p}= & X(p, f, i)+\left(p-H_{X}\right) X_{p}(p, f, i)+\lambda \cdot v_{p}(p, i-f) \equiv 0 \\
L_{f}= & \left(p-H_{X}\right) X_{f}(p, f, i)+M(i)+\lambda v_{f}(p, i-f) \equiv 0 \\
L_{i}= & -\left(p-H_{X}\right) x(p, i-f) m(i) \\
& \quad-(f-g) m(i)+\lambda\left(v_{i}(p, i-f)-u_{z}(0, i)\right) \equiv 0 \\
L_{\lambda}= & v(p, i-f)-u(0, i) \equiv 0
\end{aligned}
$$

The function arguments for the marginal cost for calling have been left out in order to simplify the notation. Factoring out $\lambda$ from $L_{p}$ and $L_{f}$, recognising that $v_{f}(p, i-f)=-v_{y}(p, i-f)$, utilising Roy's identity, and rearranging leads to:

$$
\left(p-H_{X}\right)=\frac{\int_{i}^{\infty}(x(p, y-f)-x(p, i-f)) m(y) d y}{-\int_{i}^{\infty}\left(x_{p}(p, y-f)+x(p, i-f) \cdot x_{y}(p, y-f)\right) m(y) d y}(50)
$$

Assuming calling increases with income then $x(p, y-f)-x(p, i-f)>0$, and, due to (quasi-)concavity of $u(x, z), x_{p}(p, y-f)+x(p, i-f) \cdot x_{y}(p, y-f)<0$. In the case of maximising profit this implies that call price is greater than the marginal cost of a call. In contrast, if income has no effect on the demand for calling, then the call price equals the marginal cost of a call. ${ }^{250}$

Now turning to the access fee $f$, the extent of the difference between the access fee and the access cost $g$ will depend on the income distribution and the demand for calling, and the difference between the marginal subscribers' marginal utility of income with and without subscription. To show this, start by

250 This result is consistent with Schmalensee's (1981, p. 458) proposition that the profit maximising call price equals marginal cost if a marginal subscriber's demand for calls and the average demand for calls are the same. A marginal subscriber's demand for calls and the average demand for calls are the same in equation (50) when calling does not increase with demand. 
assuming that income has no effect on the demand for calling. This assumption will be subsequently relaxed in order to examine the effect of the call-income effect on the optimal two-part tariff.

\section{Solution if call demand does not increase with income}

Setting call price equal to the marginal cost of calling, $p=H_{X}$, and factoring the Lagrange multiplier $\lambda$ out of the two first order conditions $L_{i}$ and $L_{f}$ gives:

$$
(f-g)=\frac{\left(v_{i}\left(H_{X}, i-f\right)-u_{z}(\mathrm{o}, i)\right) M(i)}{v_{i}\left(H_{X}, i-f\right) m(i)}
$$

As $v_{i}\left(H_{X}, i-f\right)>u_{z}(\mathrm{o}, i)-$ due to the normal participation equation (42) assuming $f>0-$ and all the functions are positive in value, then $(f-g)>0$.

Interpreting equation (51) as the inverse price elasticity rule for the aggregate demand for access, holding the call price constant, may suggest:

$$
(f-g)=-\frac{f}{\varepsilon}
$$

where $\varepsilon$ is the access price elasticity for aggregate participation in the telephony market, which is determined by the expression:

$$
\varepsilon=\frac{f M_{f}(i)}{M(i)}
$$

The derivative of the market size with respect to access fee, holding call price constant, and using equation (13) to derive $i$ as an implicit function of $f$ and $p$, is:

$$
M_{f}(i(p, f))=\frac{-m(i) \cdot v_{i}(p, i-f)}{v_{i}(p, i-f)-u_{z}(o, i)}
$$

Substituting this term into the equation (53) and the result in (52) and comparing with (51) shows that the access fee follows the inverse elasticity rule for aggregate access demand, assuming the income has no effect on the demand for calls, even though it has an effect on consumers' participation decisions. 
However, interpreting equation (51) as the inverse price elasticity does not imply it is valid to apply the Ramsey-Boiteux pricing principle more generally to the call price. The optimal access fee is not related to the inverse of the price elasticity of access, and the usage price is not related to the inverse of the price elasticity of usage. Even though $M_{f}\left({ }^{*}\right)<0$ and $x_{p}<0$, this does not imply that price is above marginal cost in both cases as might be expected in a standard application of Ramsey-Boiteux pricing. As equation (50) shows, the size of the margin between call price and marginal cost depends on the size of the effect of income on call demand, and if income has no effect then the optimal call price equals marginal cost.

\section{Solution if call demand increases with income}

Assuming call demand increases with income, factoring $\lambda$ out of $L_{f}$ and $L_{i}$, noting that $v_{f}(p, i-f)=-v_{i}(p, i-f)$, and rearranging yields:

$$
\begin{aligned}
(f-g)= & \frac{v_{i}(p, i-f)-u_{z}(\mathrm{o}, i)}{v_{i}(p, i-f) \cdot m(i)} \\
& \left(M(i)-\left(p-H_{X}\right) \int_{i}^{\infty} x_{y}(p, y-f) \cdot m(y) d y\right) \\
& -\left(p-H_{X}\right) x(p, i-f)
\end{aligned}
$$

Comparing this equation to (51) shows that the contribution to profits from calling $\left(p-H_{X}\right)$ has a direct influence on the optimal access fee. That is $(f-g)$ decreases with an increase in $\left(p-H_{X}\right)$. It seems possible that if the magnitude of the effect of income on the demand from calling is sufficiently large then $(f-g)<0$. Equation (50) implies that the sign of $\left(p-H_{X}\right)$ is positive, and its magnitude increases if the effect of income on call demand increases. If the effect of income on call demand increases, then signs on relevant terms within (55) imply that the magnitude of $(f-g)$ will reduce. As (55) suggests, whether or not $(f-g)<0$ will depend on the particular characteristics of the utility function and the distribution of income. 


\section{B.6 Constrained, consumer-surplus maximising two-part tariff}

The objective is to find the two-part tariff that maximises consumer surplus subject to a breakeven constraint on the monopoly and the participation constraint:

$$
\begin{aligned}
& \frac{\max }{p, f, i} \quad V(p, f, i)=\int_{0}^{i} u(0, y) m(y) d y+\int_{i}^{\infty} v(p, y-f) m(y) d y \\
& \text { s.t. } \\
& G_{1}=p X(p, f, i)+(f-g) M(i)-H(X(p, f, i)) \equiv 0 \\
& G_{2}=v(p, i-f)-u(0, i) \equiv 0
\end{aligned}
$$

The objective function $V(p, f, i)$ is the sum of the consumer surplus of the population of both non-participants and participants. ${ }^{251}$ The objective function is subject to the breakeven constraint $G_{1}$ on the monopoly's profits and the participation constraint $G_{2}$.

The solution to this problem is equivalent to finding the saddle-point of the Lagrangian:

$$
\begin{aligned}
L & =\int_{0}^{i} u(0, y) m(y) d y+\int_{i}^{\infty} v(p, y-f) m(y) d y \\
& \left.+\lambda_{1}(p X(p, f, i)+(f-g) M(i)-H(X(p, f, i)))\right) \\
& +\lambda_{2}(v(p, i-f)-u(o, i))
\end{aligned}
$$

${ }^{251} \mathrm{Ng} \&$ Wesser (1974), and Schmalensee (1981), Goldman, et al. (1984), Brown and Sibley (1989 p. 200), and Wilson's (1993, p. 164) analysis of two-part tariffs measures the total benefit of a service by aggregating individuals' indirect utility function. This present work takes this same general approach. 
The first order conditions are:

$$
\begin{aligned}
& L_{p}=\int_{i}^{\infty} v_{p}(p, y-f) m(y) d y \\
& +\lambda_{1}\left(X(p, f, i)+\left(p-H_{X}\right) \int_{i}^{\infty} x_{p}(p, y-f) m(y) d y\right)+\lambda_{2} v_{p}(p, i-f) \equiv 0 \\
& L_{f}=\int_{i}^{\infty} v_{f}(p, y-f) m(y) d y \\
& \quad+\lambda_{1}\left(\left(p-H_{X}\right) \int_{i}^{\infty} x_{f}(p, y-f) m(y) d y+M(i)\right)+\lambda_{2} v_{f}(p, i-f) \equiv 0 \\
& L_{i}=-\lambda_{1}\left(\left(p-H_{X}\right) x(p, i-f) m(i)+(f-g) m(i)\right) \\
& \quad+\lambda_{2}\left(v_{i}(p, i-f)-u_{z}(\mathrm{o}, i)\right) \equiv \mathrm{o} \\
& L_{\lambda_{1}}=p X(p, f, i)+(f-g) M(i)-H(X(p, f, i)) \equiv 0 \\
& L_{\lambda 2}=v(p, i-f)-u(\mathrm{o}, i) \equiv 0
\end{aligned}
$$

The call price can be solved by factoring out $\lambda_{2}$ from $L_{p}$ and $L_{i}$, then factoring $\lambda_{2}$ from $L_{f}$ and $L_{i}$, taking the resulting two expressions and factoring $\lambda_{2}$ out, noting that $x_{f}(p, y-f)=-x_{y}(p, y-f), v_{f}(p, y-f)=-v_{y}(p, y-f)$, the breakeven constraint and using Roy's identity to derive:

$$
\begin{aligned}
& (X-\bar{x} M)+\left(p-H_{X}\right) \int_{i}^{\infty}\left(x_{p}+x_{y} \bar{x}\right) m d y+ \\
& \frac{\left(\bar{x}-x^{i}\right) v_{i} m}{v_{i}-u_{z}}\left(\left(p-H_{X}\right)\left(x^{i}-\hat{x}\right)+\left(\hat{H}-H_{X} \hat{x}\right)\right)=0
\end{aligned}
$$

The function arguments have been left out in order to simplify the notation.

The function $x^{i}=x(p, i-f)$ is a marginal subscriber's demand for calling as already defined. The function $\hat{x}$ is the simple average number of the demand for calls per subscriber:

$$
\hat{x}=\frac{\int_{i}^{\infty} x(p, y-f) m(y) d y}{\int_{i}^{\infty} m(y) d y}
$$


$\hat{H}$ is the average cost of the core network per subscriber:

$$
\hat{H}=\frac{H(X(p, f, i))}{\int_{i}^{\infty} m(y) d y}
$$

and the term $\bar{x}$ is:

$$
\bar{x}=\frac{\int_{i}^{\infty} v_{p}(p, i-f) m(y) d y}{\int_{i}^{\infty} v_{f}(p, i-f) m(y) d y}
$$

The function $\bar{x}$ can be interpreted as the weighted average of the demand for calls, where the weights are the product of the marginal utility of income and the population density normalised by the integral of this product for all subscribers. That is, applying Roy's identity and $v_{f}(p, y-f)=-v_{y}(p, y-f)$ to the above equation yields:

$$
\bar{x}=\frac{\int_{i}^{\infty} x(p, y-f) v_{y}(p, y-f) m(y) d y}{\int_{i}^{\infty} v_{y}(p, y-f) m(y) d y}
$$

If income has no effect on the demand for calling then $\hat{x}=x^{i}$ and $\hat{x}=\bar{x}$. In this case, equation (59) implies that $p=H_{X}$ is the welfare-maximising call price. ${ }^{252}$ This is the same as the profit-maximising solution. Of particular relevance is that no explicit allowance is made in the price for the infra-marginal cost of $H\left({ }^{*}\right)$, as a solution consistent with Ramsey pricing would generally conclude.

If the demand for calling increases with income, then the sign of $\left(p-H_{X}\right)$ will depend on how, with respect to income, both marginal utility of income and calling changes.

To start, if the marginal utility of income and the marginal demand of calling with respect to income are both concave functions with respect to income, and

${ }^{252}$ This result is consistent with Ng \& Weisser's (1974, p. 340) proposition that the welfare-maximising call price equals marginal cost if a marginal subscriber's demand for calls and the average demand for calls are the same. A marginal subscriber's demand for calls and the average demand for calls are the same in equation (59) when calling does not increase with demand. 
that marginal utility of income is more concave than the demand for calling, then $\left(p-H_{X}\right)>0$. In other words, if the increase in calling due to an increase in income is greater than the increase in utility then $\left(p-H_{X}\right)>0$. With respect to the total sum of subscribers, this implies: ${ }^{253}$

$$
\begin{aligned}
\frac{\int_{i}^{\infty} x(p, y-f) v_{y}(p, y-f) m(y) d y}{\int_{i}^{\infty} v_{y}(p, y-f) m(y) d y} & \leq \\
\frac{\int_{i}^{\infty} x(p, y-f) x_{y}(p, y-f) m(y) d y}{\int_{i}^{\infty} x_{y}(p, y-f) m(y) d y} & \\
& \frac{\int_{i}^{\infty} x(p, y-f) m(y) d y}{\int_{i}^{\infty} m(y) d y}
\end{aligned}
$$

That is, the probability density function $m(y) / \int_{i}^{\infty} m(y) d y$ stochastically dominates probability density function $x_{y}(p, y-f) m(y) / \int_{i}^{\infty} x_{y}(p, y-f) m(y) d y$, which in turn stochastically dominates the probability density function $v_{y}(p, y-f) m(y) / \int_{i}^{\infty} v_{y}(p, y-f) m(y) d y$.

If this is the case, then the two terms which are not multiplied by $\left(p-H_{X}\right)$ are either positive or equal to zero and those terms multiplied by $\left(p-H_{X}\right)$ are negative:

$$
\begin{aligned}
& (X-\bar{x} M) \geq 0 \\
& \frac{\left(\bar{x}-x^{i}\right) v_{i} m}{v_{i}-u_{z}}\left(\hat{H}-H_{X} \hat{x}\right)>0 \\
& \int_{i}^{\infty}\left(x_{p}+x_{y} \bar{x}\right) m d y<0 \\
& \frac{\left(\bar{x}-x^{i}\right) v_{i} m}{v_{i}-u_{z}}\left(x^{i}-\hat{x}\right)<0
\end{aligned}
$$

253 In the particular case of the numerical example examined in section 3.4 of this thesis, $\left(p-H_{X}\right)>0$. There, utility takes the form of a Stone-Geary function, which implies that the marginal utility of income and the derivative of demand with respect to income are constant with respect to changes in income. That is, the equality holds in (64). 
By recognising that $X=\hat{x} M$, the first expression, at the top of this list, is either greater than or equal to zero, depending on whether marginal utility of income decreases or is constant with respect to income. The second expression is positive, due to the assumption that income increases with demand and the marginal utility of income is positive hence $\left(\bar{x}-x^{i}\right)>0$. In addition, $\left(\hat{H}-H_{X} \hat{x}\right)>$ o because the cost of the core network is an increasing, concave function of the total demand for calling. The third expression is negative due to the assumption that the marginal utility of income is the same or more concave than the marginal demand for calling with respect to income. ${ }^{254}$ The fourth and final expression is negative due to the demand increasing with calling, which implies $\left(x^{i}-\hat{x}\right)<0$. Taken together, the signs of these terms imply that $\left(p-H_{X}\right)>0$.

The assumptions set out in (64) are not necessary for $\left(p-H_{X}\right)>0$. A more general but sufficient condition would result in the sum of the two terms in (59) that are not multiplied by $\left(p-H_{X}\right)$ to be positive (negative) and those terms multiplied by $\left(p-H_{X}\right)$ are negative (positive):

$$
\begin{aligned}
& (X-\bar{x} M)+\frac{\left(\bar{x}-x^{i}\right) v_{i} m}{v_{i}-u_{z}}\left(\hat{H}-H_{X} \hat{x}\right)>(<) \mathrm{o} \\
& \int_{i}^{\infty}\left(x_{p}+x_{y} \bar{x}\right) m d y+\frac{\left(\bar{x}-x^{i}\right) v_{i} m}{v_{i}-u_{z}}\left(x^{i}-\hat{x}\right)<(>) 0
\end{aligned}
$$

These conditions would allow for a broader set of assumptions than in (64). The only constraint is that the sum of the two terms in (66) are of opposite signs. If the two terms have the same sign then the optimal call price is such that $\left(p-H_{X}\right)<0$.

254 Slutsky's equation implies that $\int_{i}^{\infty}\left(x_{p}+x_{y} x\right) m d y<0$ (Silberberg, 1990, p. 330). The assumption that the marginal utility of income is the same or more concave than the marginal demand for calling with respect to income implies $\int_{i}^{\infty}\left(x_{p}+x_{y} \bar{x}\right) m d y \leq \int_{i}^{\infty}\left(x_{p}+x_{y} x\right) m d y<0$ This can be shown by rearranging the terms to give $\bar{x} \leq \int_{i}^{\infty} x x_{y} m d y / \int_{i}^{\infty} x_{y} m d y$, which is assumed by equation (64). 
This highlights a qualitative difference between the welfare maximising and profit-maximising call price. That is, if demand increases with respect to income, then the profit-maximising price will be $\left(p-H_{X}\right)>0$ as it does not take into consideration the effect of a higher call price on the inframarginal subscribers' utility, whereas the welfare-maximising price may be $\left(p-H_{X}\right)<0$ due to the value attributed to the inframarginal subscribers' utility.

Where it has no effect on the demand for calling, the infra-marginal cost of the core network is recovered by the access fee. The access price mark up over the access cost can be determined from the breakeven constraint, $G_{1}$, to be:

$$
(f-g)=\frac{H(X(p, f, i))-H_{X} X(p, f, i)}{M(i)}
$$

Regarding the sign and magnitude of $(f-g)$, the profit constraint $G_{1}$ implies that even if $\left(p-H_{X}\right)>0$, the sign and magnitude of $(f-g)$ will depend on the magnitude of the call price and the average total cost of calling:

$$
(f-g)=\frac{H(X(p, f, i))-p X(p, f, i)}{M(i)}
$$

If the effect of income on calling is sufficiently large, it seems possible that $(f-g)<0$. The sign $(f-g)$ depends on the size of the common cost and the size of the contribution to common costs from calling. If either the common cost is large (small) relative to the contribution from calling then there is an increased likelihood that the access fee will be greater (less) than the cost of access.

If income has no effect on the demand for making calls then $(f-g)>0$, as the core network is assumed to exhibit economies of scale. The mark up is the total cost of the core network less the revenue earned from calls, averaged over the total number of subscribers. This result qualitatively differs from the profitmaximising case, described by (51). Whether or not quantitatively the mark up determined by (67) differs from (51) will depend on the particular form of the demand and cost functions. 
This result contradicts the Ramsey-Boiteux pricing rule. Here, the allocation of common cost is not determined by a price elasticity of demand for access or calling, rather it is determined simply by the presence or absence of an income effect. This highlights the qualitative difference between the Ramsey-Boiteux pricing rule and an income effect explanation for the optimal recovery of common costs.

\section{B.7 Summary}

A theory of consumer behaviour and two-part tariffs is presented that ties together the access fee and call price within a coherent model of consumer behaviour. The model of consumer behaviour is based on the standard assumptions of utility maximisation, with the additional assumptions that consumers have the option to not subscribe to a telephony service, and that consumers who do not subscribe will subscribe with an increase of income - i.e. normal participation behaviour. The model is used to analyse optimal two-part tariffs with endogenous participation.

The model shows that the optimal access fee and call prices do not correspond to prices implied by the Ramsey-Boiteux pricing principle. The welfare-maximising and profit-maximising call price is equal to the marginal cost if income has no affect on the demand for calls. Whereas, the call price implied by the RamseyBoiteux principle is the sum of the marginal cost and a mark-up that is in proportion to the inverse of the price elasticity of demand for the service. Furthermore, when the demand for calls does not increase with income, the optimal access fee includes a mark up that covers all common costs, including profit. For profit maximisation, this mark up is determined by the distribution of income and the marginal consumer's marginal benefit from subscribing. For welfare maximisation, this mark-up is determined by the breakeven constraint on the monopoly.

If the demand for calls increases with income, then the optimal profitmaximising price is greater than the marginal cost of a call, and a numerical example suggests that the optimal welfare-maximising price may be greater than the marginal cost of a call. The effect of an increase to the call price is to reduce the optimal access fee for both profit-maximising and welfare-maximising scenarios. 


\section{Appendix C: Launch dates of commercial mobile and digital subscriber line broadband services}

\begin{tabular}{|l|l|l|}
\hline & Mobile technologies255 & $\begin{array}{l}\text { Commercial launch of } \\
\text { digital subscriber lines } \\
\text { services256 }\end{array}$ \\
\hline Australia & May 2003 & August 2000 \\
\hline Austria & April 2003 & November 1999 \\
\hline Belgium & September 2005 & October 1999 \\
\hline Canada & February 2002 & 1996 \\
\hline Czech Republic & August 2004 & March 2003 \\
\hline Denmark & October 2003 & July 1999 \\
\hline Finland & October 2004 & May 2000 \\
\hline France & November 2004 & November 1999 \\
\hline Germany & May 2004 & August 1999 \\
\hline Greece & May 2004 & June 2003 \\
\hline Hungary & August 2005 & September 2000 \\
\hline Iceland & September 2007 & April 2000 \\
\hline Ireland & November 2004 & May 2002 \\
\hline Italy & March 2003 & December 1999 \\
\hline Japan & October 2001 & September 2000 \\
\hline Korea & October 2000 & April 1999 \\
\hline Luxembourg & June 2003 & 2001 \\
\hline Mexico & January 2003 & September 2001 \\
\hline Netherlands & June 2004 & June 2000 \\
\hline New Zealand & July 2002 & June 1999 \\
\hline Norway & December 2004 & December 2000 \\
\hline Poland & November 2002 & 2001 \\
\hline Portugal & May 2004 & December 2000 \\
\hline Slovak Republic & January 2006 & 2003 \\
\hline Spain & May 2004 & 1999 \\
\hline Sweden & May 2003 & October 2000 \\
\hline Switzerland & December 2004 & October 2000 \\
\hline United Kingdom & March 2003 & July 2000 \\
\hline United States & December 2001 & 1997 \\
\hline & & \\
\hline
\end{tabular}

255 (OECD, 2009a, pp. 23-25 Table 1).

${ }^{256}$ (OECD, 2009b, p. 136 Table 4.15). 


\section{References}

2degrees mobile (2009a). 2degrees launches no-contract "Pay-Now" New Zealand"s best prepaid mobile rates from http://www.2degreesmobile.co.nz/c/document library/get file?uuid=8 $\underline{\text { f1f58e0-0361-4d62-9d8d-c43e87bff28c\&groupId=10128 }}$

2degrees mobile (2009b). Opening Statement: MTAS Conference Retrieved 22 September, 2009, from http://www.comcom.govt.nz//IndustryRegulation/Telecommunications LInvestigations/MobiletoMobileTermination/ContentFiles/Documents/ 2degrees\%20written\%20opening\%20statement.PDF

Alexa Internet. Global Top Sites (2009). Global Top Sites Retrieved 2 March 2009, 2009, from http://www.alexa.com/site/ds/top sites?ts mode=global\&lang=none

Alexa Internet. Top Sites in New Zealand (2009, 13 January 2009). Top Sites in New Zealand Retrieved 2 March 2009, 2009, from http://www.alexa.com/site/ds/top sites?cc=NZ\&ts mode=country\&lan $\mathrm{g}=$ none

Alger, D., \& Leung, J. (1999). The relative costs of local telephony across five countries Retrieved September, 2009, from http://www.iscr.org.nz/f257.5118/5118 relative costs local 010399.pd $\underline{f}$

Alleman, J., \& Rappoport, P. (2002). Modelling regulatory distortions with real options. The Engineering Economist, 47(4), 390-417.

Alleman, J., \& Rappoport, P. (2006). Optimal Pricing with Sunk Costs and Uncertainty. In R. Cooper, A. Lloyd, G. Madden \& M. Schipp (Eds.), The Economics of Online Markets and Information Communications and Technology Networks: Contribution to Economics Series (pp. 143-155). Heidelberg: Physica-Verlag.

Amazon.com Inc. (1999, 1998). Form 10-K Amazon.com, Inc. Annual Report for the year ended December 31, 1998.

Amazon.com Inc. investor relations (2009). Amazon.com, Inc. Consolidated Statements Press Release: Amazon.com, Inc.

Apple Inc. (2008). Apple Inc. Form 10-K 2008 Annual Report. Retrieved from https://www.apple.com/investor/

Armstrong, M. (1998). Network Interconnection in Telecommunications. The Economic Journal, 108(448), 545-564.

Armstrong, M. (2002). The Theory of Access Pricing and Interconnection. In M. E. Cave, S. K. Majumdar \& I. Vogelsang (Eds.), Handbook of Telecommunciations Economics (Vol. 1, pp. 295-384): Elsevier B.V. 
Armstrong, M., Doyle, C., \& Vickers, J. (1996). The Access Pricing Problem: A Synthesis. The Journal of Industrial Economics, 44(2), 131-150.

Armstrong, M., \& Sappington, D. E. M. (2007). Recent Developments in the Theory of Regulation. In M. Armstrong \& R. H. Porter (Eds.), Handbook of Industrial Organisation (Vol. 3, pp. 1557-1700): Elsevier B.V.

Armstrong, M., \& Vickers, J. (2001). Competitive Price Discrimination. The RAND Journal of Economics, 32(4), 579-605.

Auerbach, A. J., \& Pellechio, A. J. (1978). The Two-Part Tariff and Voluntary Market Participation. The Quarterly Journal of Economics, 92(4), 571587.

Berkman Center (2009). Next Generation Connectivity: A review of broadband Internet transitions and policy from around the world. The Berkman Center for Internet \& Society at Harvard University. from http://www.fcc.gov/stage/pdf/Berkman Center Broadband Study 13 Oct09.pdf

Besen, S., Milgrom, P., Mitchell, B., \& Srinagesh, P. (2001). Advances in Routing Technologies and Internet Peering Agreements. The American Economic Review, 91(2), 292-296.

Blonski, M. (2002). Network externalities and two-part tariffs in telecommunication markets. [doi: DOI: 10.1016/So167-6245(01)000555]. Information Economics and Policy, 14(1), 95-109.

Blumenthal, M. S., \& Clark, D. D. (2001). Rethinking the design of the Internet: the end-to-end arguments vs. the brave new world. ACM Transactions on Internet Technology, 1(1), 70-109.

Boiteux, M. (1971). On the Management of Public Monoplies Subject to Budgetary Constraints. Journal of Economic Theory, 3, 219-240.

Boylaud, O., \& Nicoletti, G. (2000). Regulation, Market Structure and Performance in Telecommunications: Economics Department Working Papers No.237. Organisation for Economic Co-operation and Development, Economics Department Working Papers from http://www.oecd.org/dataoecd/13/26/1884238.pdf

Boylaud, O., \& Nicoletti, G. (2001). Regulation, Market Structure and Performance in Telecommunications. OECD Economic Studies, 32.

Boyle, G., Howell, B., \& Zhang, W. (2008). Catching Up in Broadband Regressions: Does Local Loop Unbundling Really Lead to Material Increases in OECD Broadband Uptake? New Zealand Institute for the Study of Competition and Regulation. from http://www.iscr.org.nz/f410,11598/11598 LLUBroadbando1c rev 300 708.pdf

Bresnahan, T. F. (1989). Emipirical studies of industries with market power. In R. Schmalensee \& R. D. Willig (Eds.), Handbook of Industrial Organisation (Vol. II, pp. 1011-1057). Amsterdam: Elsevier Science Publishers B.V. 
Brown, S. J., \& Sibley, D. S. (1986). The theory of public utility pricing. New York: Cambridge University Press.

Brynjolfsson, E., Hu, Y., \& Smith, M. D. (2003). Consumer Surplus in the Digital Economy: Estimating the Value of Increased Product Variety at Online Booksellers. Management Science, 49(11), 1580-1596.

Brynjolfsson, E., \& Smith, M. D. (2000). Frictionless Commerce? A Comparison of Internet and Conventional Retailers. Management Science, 46(4), $563-585$.

Burnell, S., Evans, L., \& Yao, S. (1996). The Optimal Network Interconnection Contract under Partial Bypass in Oligopolistic Network Industries. New Zealand Institute for the Study of Competition and Regulation, and School of Economics and Finance, Victoria University of Wellington.

Cabral, L. M. B. (1995). Conjectural variations as a reduced form. Economics Letters, 49(4), 397-402.

Carlton, D. W., \& Perloff, J. M. (2004). Modern Industrial Organization (Fourth ed.). New York: Addison-Wesley.

Carter, M., \& Wright, J. (1999). Interconnection in Network Industries. Review of Industrial Organisation, 14(1), 1-25.

Cava-Ferreruela, I., \& Alabau-Munoz, A. (2006). Broadband policy assessment: A cross-national empirical analysis. Telecommunications Policy, 3O, $445-463$.

Chen, C.-M., Tsai, H.-C., \& Mao, C.-K. (2008). Income, affordable and threshold effects on FMS in the developed and developing economies.

Telecommunications Policy, 32, 626-641.

Church, J., \& Gandal, N. (1992). Network Effects, Software Provision, and Standardization. The Journal of Industrial Economics, 4O(1), 85-103.

Church, J., Gandal, N., \& Krause, D. P. (2002). Indirect Network Effects and Adoption Externalities.

http://econ.tau.ac.il/research/abstract.asp?id=302002: The Foerder Institute for Economic Research.

CityLink (2009). The CityLink Story - Our Background Retrieved 4 September, 2009, from http://www.citylink.co.nz/about/background.html

Clark, E., \& Easaw, J. Z. (2007). Optimal access pricing for natural monopoly networks when costs are sunk and revenues are uncertain. European Journal of Operational Research, 178, 595-602.

Coffman, K. G., \& Odlyzko, A. M. (2002a). Growth of the Internet. In I. P. Kaminow \& T. Li (Eds.), Optical Fiber Telecommunications IV B: Systems and Impairments (pp. 17-56). London: Academic Press.

Coffman, K. G., \& Odlyzko, A. M. (2002b). Internet Growth: Is there a "Moore's Law" for data traffic? In J. Abello, P. M. Pradalos \& M. G. C. Resende (Eds.), Handbook of Massive Data Sets (pp. 47-93): Kluwer Academic Publishers. 
Commerce Commission (2003, December). Telecommunications Act 2001, Section 64 Review and Schedule 3 Investigation into Unbundling the Local Loop Network and the Fixed Public Data Network: Final Report Retrieved 18 September, 2009, from http://www.comcom.govt.nz//IndustryRegulation/Telecommunications IInvestigations/LocalLoopUnbundling/ContentFiles/Documents/finalre port.PDF

Commerce Commission (2004, 10 June). Unbundled Partial Circuits Proposal, from

http://www.comcom.govt.nz//IndustryRegulation/Telecommunications LInvestigations/Unbundling-

PartialCircuits/ContentFiles/Documents/Letter\%20to\%20Telecom\%200 n\%20UPC\%20Service\%2010\%20June\%202004.pdf

Commerce Commission (2006, 2 February). Telecommunications Act:

Completion of broadband monitoring programme, from

http://www.comcom.govt.nz/media-

releases/detail/2006/telecommunicationsactcompletionofb

Commerce Commission (2008a, 8 December). Draft TSO Cost Calculation Determination for TSO Instrument for Local Residential Telephone Service for period between 1 July 2007 and 30 June 2008, from http://www.comcom.govt.nz//IndustryRegulation/Telecommunications /TelecommunicationsServiceObligations/ContentFiles/Documents/publ ic final draft ts00708.pdf

Commerce Commission (2008b). Public Version of results of 2005-06 and 2006-07 TCF telecommunications industry questionaire.xls, from http://www.comcom.govt.nz//IndustryRegulation/Telecommunications /MonitoringandReporting/ContentFiles/Documents/Public\%20version \%20of\%20results\%20of\%20Telecommunications\%20Industry\%20Quest ionnaire\%20for\%202005-06\%20and\%202006-070.XLS

Compass (2009). About Compass, from http://www.compass.net.nz/about.asp

comScore (2008, May 2008). Top Global Web Properties Retrieved 2 March 2009, from http://www.comscore.com/press/data.asp

comScore Press Release (2009, February 19, 2009). comScore Media Metrix Ranks Top 5o U.S. Web Properties for January 2009 Retrieved 2 March 2008, 2009, from

http://www.comscore.com/press/release.asp?press=2730

Courts of New Zealand (2010). The History of the Supreme Court Retrieved 15 October, 2010, from

http://www.courtsofnz.govt.nz/about/supreme/history

Crandall, R. W., Ingraham, A. T., \& Singer, H. J. (2004). Do unbundling policies discourage CLEC facilities-based investment. Topics in Economic Analysis \& Policy, 4(1), 1-23.

David, P. A. (1985). Clio and the Economics of QWERTY. The American Economic Review, 75(2), 332-337. 
De Boer, D. B., Enright, C., \& Evans, L. (2000). The Internet Service Provider (ISP) markets of Australia and New Zealand Retrieved 17 September, 2010, from http://www.iscr.org.nz/f241,4849/4849 ausnz 020600.pdf

De Boer, D. B., \& Evans, L. (1996). The Economic Efficiency of Telecommunications in a Deregulated Market: The case of New Zealand. Economic Record, 72(216), 24-35.

Dessein, W. (2003). Network competition in nonlinear pricing. RAND Journal of Economics, 34(4), 1-19.

Dewenter, R., \& Haucap, J. (2007). Access Pricing: An Introduction. In R. Dewenter \& J. Haucap (Eds.), Access Pricing: Theory and Practice (pp. 1-37). Amsterdam: Elsevier B.V.

Distaso, W., Lupi, P., \& Manenti, F. M. (2006). Platform competition and broadband uptake: Theory and empirical evidence from the European union. Information Economics and Policy, 18(1), 87-106.

Dixit, A. K., \& Pindyck, R. S. (1994). Investment Under Uncertainty. Princeton, New Jersey: Princeton Unversity Press.

Dockner, E. J. (1992). A Dynamic Theory of Conjectural Variations. The Journal of Industrial Economics, 4O(4), 377-395.

Donald, B. G., \& Heydon, J. D. (1978). Introduction and restrictive trade practices (Vol. 1). Sydney: Law Book Co.

Driskill, R. A., \& McCafferty, S. (1989). Dynamic duopoly with adjustment costs: A differential game approach. Journal of Economic Theory, 49(2), 324338.

eBay Inc. Media Center (2005). eBay to Acquire Skype: eBay Inc.

eBay Inc. Media Center (2009a). eBay Inc. Announces Plan for 2010 Initial Public Offering of Skype: eBay Inc.

eBay Inc. Media Center (2009b). Skype Fast Facts Q4 2008: eBay Inc.

Economides, N. (2005). The Economics of the Internet Backbone. In S. K. Majumdar, I. Vogelsang \& M. E. Cave (Eds.), Handbook of Telecommunications Economics, Technology Evolution and the Internet (Vol. 2, pp. 375-412). Amsterdam: Elsevier B.V.

Economides, N., Seim, K., \& Viard, V. B. (2008). Quantifying the benefits of entry into local phone service. RAND Journal of Economics, 39(3), 699730 .

Eldering, C. A., Sylia, M. L., \& Eisenach, J. A. (1999, October). Is there a Moore's Law for Bandwidth? IEEE Communications Magazine, 117-121.

Enable Networks (2009). Company History Retrieved 14 September, 2009, from http://enablenetworks.co.nz/general/company-history.html

European Commission (1998). Notice on the application of the competition rules to access agreements in the telecommunications sector: framework, 
relevant markets and principles (98/C 265/o2) Official Journal of the European Communities. from http://eur-

lex.europa.eu/LexUriServ/LexUriServ.do?uri=OJ:c:1998:265:0002:002 8:en:PDF

European Commission (2000). Regulation (EC) No 2887/2000 ot the European Parliament and of the Council of 18 December 2000 on unbundled access to the local loop Official Journal of the European Communities. from http://eurlex.europa.eu/LexUriServ/LexUriServ.do?uri=OJ:L:2000:336:0004:00 04:EN:PDF

Evans, D. S., \& Schmalensee, R. (2002). Some Economic Aspects of Antitrust Analysis in Dynamically Competitive Industries. Innovation Policy and the Economy, 2, 1-49.

Evans, L. (1996). Residential Telecom Sevices and Prices in New Zealand Since Deregulation. Agenda, 3(4), 399-406.

Evans, L. (2007). Proposed evidence in chief of Lewis Tudor Evans to be called by Telecom, in the case between The Commerce Commission and Telecom New Zealand, CIV 2000-485-673.

Evans, L., \& Hahn, R. (2010). Regulating Dynamic Markets: Progress in Theory and Practice, New Zealand Institute for the Study of Competition and Regulation. Retrieved 3 August, 2010, from http://www.iscr.org.nz/f574,16477/16477 Regulating dynamic market S 510 v11 May 28 2010.pdf

Evans, L., Quigley, N., \& Zhang, J. (2003). Optimal Price Regulation in a Growth Model with Monopolistic Suppliers of Intermediate Goods. The Canadian Journal of Economics / Revue canadienne d'Economique, 36(2), 463-474.

Evans, L., \& Quigley, N. C. (2000). Contracting, Incentives for Breach, and the Impact of Competition Law. Journal of World Competition, 23(2), 7994.

Facebook Inc. Press Room (2009a). Facebook Company Timeline Retrieved 16 March, 2009, from http://www.facebook.com/press/info.php?timeline

Facebook Inc. Press Room (2009b). Facebook Statistics Retrieved 16 March 2009, from http://www.facebook.com/press/info.php?statistics

Farrell, J., \& Klemperer, P. (2007). Coodination and Lock-In: Competition with Switching Costs and Network Effects. In M. Armstrong \& R. H. Porter (Eds.), Handbook of Industrial Organisation (Vol. 3, pp. 1967-2072): Elsevier B.V.

Farrell, J., \& Saloner, G. (1985). Standardization, Compatibility, and Innovation. The RAND Journal of Economics, 16(1), 70-83.

Farrell, J., \& Saloner, G. (1992). Converters, Compatibility, and the Control of Interfaces. The Journal of Industrial Economics, 4O(1), 9-35. 
Farrell, J., \& Shapiro, C. (1990). Horizontal Mergers: An Equilibrium Analysis. The American Economic Review, 8o(1), 107-126.

Feldstein, M. S. (1972). Equity and Efficiency in Public Sector Pricing: The Optimal Two-Part Tariff. The Quarterly Journal of Economics, 86(2), 176-187.

Figuières, C., Jean-Marie, A., Quérou, N., \& Tidball, M. (2004). Theory of Conjectural Variations. Singapore: World Scientific Publishing Co. Pte. Ltd.

Frazer, K. D. (1995). NSFNET: A Partnership for High-Speed Networking, Final Report, 1987-1995: Merit Network, Inc.

Free Internet Access Ltd, CallPlus Ltd, \& Attica Communications Ltd (2000). Submission [to the] Ministerial Inquiry into Telelcommunications, from http://www.med.govt.nz/upload/29927/059.pdf

Friedman, J. W. (1983). Oligopoly Theory. Cambridge: Cambridge University Press.

FX Networks (2008). Input to the Standard Terms of Determination Retrieved 4 September, 2009, from http://www.comcom.govt.nz//IndustryRegulation/Telecommunications /StandardTermsDeterminations/UnbundledLocalLoopBackhaulService/ ContentFiles/Documents/FX\%20Networks\%20crosssubmission\%200n\%20UCLL UBA\%2obackhaul\%20draft\%20STDs.PDF

Gans, J. S. (2007). Access Pricing and Infrastructure Investment. In R. Dewenter \& J. Haucap (Eds.), Access Pricing: Theory and Practice (pp. 41-63). Amsterdam: Elsevier B.V.

Goldman, M. B., Leland, H. E., \& Sibley, D. S. (1984). Optimal Nonuniform Prices. The Review of Economic Studies, 51(2), 305-319.

Google Inc. (2009). Investor Relations, Financial Tables, from http://investor.google.com/fin data.html

Google Inc. Press Center (2006, October 9, 2006). Google To Acquire YouTube for $\$ 1.65$ Billion in Stock, from http://www.google.com/intl/en/press/pressrel/google youtube.html

Grajek, M., \& Roller, L.-H. (2009). Regulation and investment in network industries: evidence from European Telecoms ESMT Working Paper No 09-004. from https://www.esmt.org/fm/479/ESMT-09-004.pdf

Grenadier, S. R. (2002). Option Exercise Games: An Application to the Equilibrium Investment Strategies of Firms. The Review of Financial Studies, 15(3), 691-721.

Grimes, A., Ren, C., \& Stevens, P. (2009). The need for speed: impacts of internet connectivity on firm productivity Motu Economic and Public Policy Research Working Paper 09-15. from http://motuwww.motu.org.nz/wpapers/og 15.pdf 
Grzybowski, L. (2008). The Competitiveness of Mobile Telephony across the European Union. International Journal of the Economics of Business, 15(1), 99-115.

Hatfield, D. N., Mitchell, B. M., \& Srinagesh, P. (2005). Emerging Network Technologies. In S. K. Majumdar, I. Vogelsang \& M. E. Cave (Eds.), Technology Evolution and the Internet (Vol. 2, pp. 29-77): Elsevier B.V.

Hausman, J. (1998). The effect of sunk costs in telecommunications regulation. In J. Alleman \& E. Noam (Eds.), Topics in Regulatory Economics and Policy: The New Investment Theory of Real Options and Its Implications for Telecommunications Economics (Vol. 34, pp. 191-204). New York: Springer.

Hausman, J. (2000). The effect of sunk costs in telecommunications cost models. In J. Alleman \& E. Noam (Eds.), The New Investment Theory of Real Options and its Implication for Telecommunications Economics (pp. 191-204): Springer.

Hausman, J., Pakes, A., \& Rosston, G. L. (1997). Valuing the Effect of Regulation on New Services in Telecommunications. Brookings Papers on Ecomic Activity. Microeconomics, 1997, 1-54.

Hausman, J., \& Sidak, J. G. (2005). Did Mandatory Unbundling Achieve its Purpose? Empirical Evidence from Five Countries. Journal of Competition Law and Economics, 1(1), 173-245.

Hoernig, S. H., \& Valletti, T. M. (2007). Mixing goods with two-part tariffs. [doi: DOI: 10.1016/j.euroecorev.2006.11.004]. European Economic Review, 51(7), 1733-1750.

Höffler, F. (2007). Cost and benefits from infrastructure competition. Estimating welfare effects from broadband access competition. [doi: DOI: 10.1016/j.telpol.2007.05.004]. Telecommunications Policy, 31(67), 401-418.

Hori, K., \& Mizuno, K. (2004). Network investment and competition with access-to-bypass.

Hori, K., \& Mizuno, K. (2006). Access pricing and investment with stochastically growing demand. [doi: DOI: 10.1016/j.ijindorg.2005.09.010]. International Journal of Industrial Organization, 24(4), 795-808.

IDC, \& Epitiro Technologies (2008). Report for the Commerce Commission on New Zealand Broadband Quality, Q4 December 2008, from http://www.comcom.govt.nz//IndustryRegulation/Telecommunications /MonitoringandReporting/ContentFiles/Documents/Epitiro\%20Report. pdf

Ingraham, A. T., \& Sidak, J. G. (2003). Mandatory unbundling, UNE-P, and the cost of equity: does TELRIC pricing increase risk for incumbent local exchange carriers? . Yale Journal on Regulation, 2O(2), 389-406.

Internet Engineering Task Force (2002, December). Some Internet Architectual Guidelines and Philosophy, RFC 3439, from http://www.rfc-

editor.org/rfc/pdfrfc/rfc3439.txt.pdf 
Internet Engineering Task Force - Network Working Group (1989a).

Requirements for Internet Hosts -- Communications Layers (Vol. RFC

1122, pp. 1-116): Internet Engineering Task Force.

Internet Engineering Task Force - Network Working Group (1989b).

Requirements for Internet Hosts --Applications and Support (Vol. RFC 1123, pp. 1-116): Internet Engineering Task Force.

Internet Engineering Task Force - Network Working Group (2002). Some Internet Architectual Guidelines and Philosophy. [Official specification for the Internet community]. $R F C$ 3439, 1-28.

Internet Systems Consortium (2009a). ISC Domain Survey FAQ Retrieved 30 March 2009, 2009, from https://www.isc.org/solutions/survey/faq

Internet Systems Consortium (2009b). ISC Internet Domain Survey Background Retrieved 30 March 2009, 2009, from https://www.isc.org/solutions/survey/background

Internet Systems Consortium (2009c). ISC Internet Host Count History Retrieved 30 March 2009, 2009, from https://www.isc.org/solutions/survey/history

InternetNZ External Peering Group (2007). Issues regarding Internet peering and interconnection in New Zealand (No. Draft Report Version 0.99): InternetNZ.

John Fairfax Holdings Limited Press Release (2006). Fairfax to Acquire Trade $\mathrm{Me}, \mathrm{New}$ Zealand's Leading Internet Business.

Kaestner, R., \& Kahn, B. (1990). The effects of regulation and competition on the price of AT\&T intrastate telephone service. Journal of Regulatory Economics, 2(4), 363-377.

Karel, A. (2003). The Development and Implications of Free ISPs in New Zealand, from http://www.iscr.org.nz

Katz, M. L., \& Shapiro, C. (1985). Network Externalities, Competition, and Compatibility. The American Economic Review, 75(3), 424-440.

Katz, M. L., \& Shapiro, C. (1992). Product Introduction with Network Externalities. The Journal of Industrial Economics, 4O(1), 55-83.

Katz, M. L., \& Shapiro, C. (1994). Systems Competition and Network Effects. The Journal of Economic Perspectives, 8(2), 93-115.

Kende, M. (2002). The Digital Handshake: Connecting Internet Backbones. Commlaw Conspectus: Journal of Communications, Law and Policy, 11(1), 45-70.

Kogan, L. (2001). An equilibrium model of irreversible investment. [doi: DOI: 10.1016/So304-405X(01)00077-0]. Journal of Financial Economics, 62(2), 201-245.

Kordia (2009). History and Ownership Retrieved 4 September, 2009, from http://www.kordiasolutions.com/node/1084 
Kordia Media Release (2007). Orcon: From start-up to SOE, from http://www.kordiasolutions.com/files/kordia orcon media story fro m start up to soe.pdf

Laffont, J.-J., Rey, P., \& Tirole, J. (1998a). Network Competition: I. Overview and Nondiscriminatory Pricing. The RAND Journal of Economics, 29(1), 1-37.

Laffont, J.-J., Rey, P., \& Tirole, J. (1998b). Network Competition: II. Price Discrimination. The RAND Journal of Economics, 29(1), 38-56.

Laffont, J.-J., \& Tirole, J. (1994). Access pricing and competition. European Economic Review, 38(9), 1673-1710.

Laffont, J.-J., \& Tirole, J. (2000). Competition in Telecommunications. Cambridge, Massachusetts: The MIT Press.

Leahy, J. V. (1993). Investment in Competitive Equilibrium: The Optimality of Myopic Behavior. The Quarterly Journal of Economics, 108(4), 11051133.

Liebowitz, S. J., \& Margolis, S. E. (1994). Network Externality: An Uncommon Tragedy. The Journal of Economic Perspectives, 8(2), 133-150.

Liebowitz, S. J., \& Margolis, S. E. (2002). Network Effects. In M. E. Cave, S. K. Majumdar \& I. Vogelsang (Eds.), Handbook of Telecommunciations Economics (Vol. 1, pp. 75-96): Elsevier B.V.

Littlechild, S. C. (1975). Two-Part Tariffs and Consumption Externalities. The Bell Journal of Economics, 6(2), 661-670.

MacAvoy, P. W. (1998). Testing for Competitiveness of Markets for Long Distance Telephone Services: Competition Finally? Review of Industrial Organization, 13(3), 295-319.

Mao, C.-K., Tsai, H.-C., \& Chen, C.-M. (2008). FMS patterns: Penetration vs. traffic substitution in different groups of countries Technological Forecasting \& Social Change, 75, 356-384.

Miller, C. C. (2009, 26 May). Russians Spend Big for a Piece of Facebook. The New Your Times. Retrieved 12 June, 2009, from http://www.nytimes.com/2009/05/27/technology/internet/27facebook. html? $\quad r=1 \& s c p=3 \& s q=$ facebook\&st=cse.

Minister for State Owned Enterprises (1987). Telecommunications Deregulation.

Minister for State Owned Enterprises (1988). Address to Telecommunications Users' Association of New Zealand.

Minister of Communications (2004, 19 May). Decision on Telecom Network Recommendations - 19 May 2004 Retrieved 18 September, 2009, from http://www.med.govt.nz/templates/Page 2094.aspx 
Minister of Communications (2006a, 3 May). Government moves fast to improve Broadband Retrieved 18 September, 2009, from http://www.beehive.govt.nz/node/25636

Minister of Communications (2006b). Telecommunications Stocktake Retrieved 18 September, 2009, from http://www.beehive.govt.nz/sites/all/files/Cabinet\%2opaper\%20and\%2 ominute.pdf

Minister of Communications (2010). Decision on mobile termination rates Retrieved 17 September, 2010, from http://beehive.govt.nz/release/decision+mobile+termination+rates

Ministry of Commerce (1997). New Zealand Telecommunications 1987-1997 Retrieved 18 September, 2009, from http://www.med.govt.nz/templates/MultipageDocumentTOC $\quad 4776$ aspx

Ministry of Commerce (1998). New Zealand Telecommunications 1987-1998 Retrieved 8 September, 2009, from http://www.med.govt.nz/upload/10584/tip6.pdf

Ministry of Commerce, \& The Treasury (1995). Regulation Of Access To Vertically-Integrated Natural Monopolies: A Discussion Paper Retrieved 18 September, 2009, from http://www.med.govt.nz/templates/MultipageDocumentTOC 4543 . aspx

Ministry of Economic Development (2001). New Zealand Telecommunications 1987-2001: New Zealand Telecommunications Information Publication No. 8 Retrieved 18 September, 2009, from http://www.med.govt.nz/templates/MultipageDocumentTOC $\quad 4845$ $\underline{\operatorname{aspx}}$

Minnesota Internet Traffic Studies (2009). 2002-2008 Annual Growth Rates, 2002-2008 Retrieved 2 March 2009, 2009, from http://www.dtc.umn.edu/mints/2002-2008/analysis-2002-2008.html and http://www.dtc.umn.edu/mints/methodology.html

Mitchell, B. M. (1978). Optimal Pricing of Local Telephone Service. The American Economic Review, 68(4), 517-537.

Mitchell, B. M., \& Vogelsang, I. (1991). Telecommunications Pricing, Theory and Practice. New York: Cambridge University Press.

Moore, G. E. (1965). Cramming more components onto integrated circuits. Electronics, 38(8).

New Zealand Government Ministerial Inquiry into Telecommunications (2000). New Zealand Government Ministerial Inquiry into Telecommunications: Final Report, from

http://www.med.govt.nz/templates/MultipageDocumentTOC 1648 4.aspx

New Zealand Parliament (2006). Telecommunications Amendment Bill, from http://www.parliament.nz/en- 
NZ/PB/Legislation/Bills/7/2/1/ooDBHOH BILL7413 1-

Telecommunications-Amendment-Bill.htm

Ng, Y.-K., \& Weisser, M. (1974). Optimal Pricing with a Budget Constraint--The Case of the Two-part Tariff. The Review of Economic Studies, 41(3), 337345 .

Novy-Marx, R. (2007). An Equilibrium Model of Investment Under Uncertainty. Review of Financial Studies, 2O(5), 1461-1502.

Odlyzko, A. M. (2003, 19 August). Internet traffic growth: sources and implications. Paper presented at the Optical Transmission Systems and Equipment for WDM Network II.

OECD (2007a). Catching-Up in Broadband - What will it take? Organisation for Economic Development and Co-operation; Directorate for Science, Technology and Industry; Committee for Information, Computer and Communications Policy; Working Party on Communications and Services Policy: DSTI/ICCP/CISP(2007)8/FINAL. from http://www.oecd.org/dataoecd/34/34/39360525.pdf

OECD (2007b). OECD Communications Outlook 2007 (No. ISBN 978-92-64o0681-2). Paris: Organisation for Economic Co-operation and Development.

OECD (2008a). OECD average advertised broadband speeds, by technology, September 2008, from http://www.oecd.org/document/54/0,3343,en $2649 \quad 34225 \quad 38690102$ $1 \quad 1 \quad 1 \quad 1,00 . h t m l$

OECD (2008b). OECD Broadband Subscriber Criteria, from http://www.oecd.org/document/46/0,3343,en $2649 \quad 34225 \quad 39575598$ 111 1,00.html

OECD (2008c). OECD Information Technology Outlook (No. ISBN 978-92-6405553-7). Paris: Organisation for Economic Co-operation and Development

OECD (2009a). Mobile Broadband: Pricing and Services. Paris: Organisation for Economic Development and Co-operation, Directorate for Science, Technology and Industry Committee for Information, Computer and Communications Policy, Working Party on Communications and Services Policy.

OECD (2009b). OECD Communications Outlook Paris: Organisation for Economic Co-operation and Development.

Oi, W. Y. (1971). A Disneyland Dilemma: Two-Part Tariffs for a Mickey Mouse Monopoly. The Quarterly Journal of Economics, 85(1), 77-96.

Parker, P. M., \& Röller, L.-H. (1997). Collusive Conduct in Duopolies: Multimarket Contact and Cross-Ownership in the Mobile Telephone Industry. The RAND Journal of Economics, 28(2), 304-322. 
Pindyck, R. (2004). Mandatory Unbundling and Irreversible Investment in Telecom Network. National Bureau of Economic Research Working Paper no.10287.

Pindyck, R. (2005a). Pricing Capital under Mandatory Unbundling and Facilities Sharing. National Bureau of Economic Research Working Paper no.11225.

Pindyck, R. (2005b). Sunk Costs and Real Options in Antitrust. National Bureau of Economic Research Working Paper no.11430:

Pindyck, R. (2007). Mandatory unbundling and irreversible investment in telecom networks. Review of Network Economics, 6(3), 274-298.

Quigley, N. (2004). Dynamic Competition in Telecommunications. Commentary - C.D. Howe Institute, (194), 1-24 Retrieved 22 September, 2009, from http://www.cdhowe.org/pdf/commentary 194.pdf

Quigley, N., \& Sanderson, M. (2005). Going Mobile - Slowly, How Wireline Telephone Regulation Slows Cellular Network Development. Commentary - C.D. Howe Institute, (222), 1-33 Retrieved 22 September, 2009, from http://www.cdhowe.org/pdf/commentary 222.pdf

Ramsey, F. P. (1927). A Contribution to the Theory of Taxation. The Economic Journal, 37(145), 47-61.

Renda, A. (2010). Competition-regulation interface in telecommunciations: What's left of the essential facility doctrine. Telecommunications Policy, $34,23-35$.

Rochet, J.-C., \& Stole, L. A. (2002). Nonlinear Pricing with Random Participation. The Review of Economic Studies, 69(1), 277-311.

Rodini, M., Ward, M. R., \& Woroch, G. A. (2003). Going mobile: substitutability between fixed and mobile access. Telecommunications Policy, 27, 457476.

Rohlfs, J. (1974). A Theory of Interdependent Demand for a Communications Service. The Bell Journal of Economics and Management Science, 5(1), 16-37.

Salop, S. C. (1979). Monopolistic Competition with Outside Goods. The Bell Journal of Economics, 1O(1), 141-156.

Saltzer, J. H., Reed, D. P., \& Clark, D. D. (1984). End-to-end arguments in systems design. ACM Transactions on Computer Systems (TOCS), 2(4), 277-288.

Saunders, M. (1994). Telecommunciations regulation in New Zealand. [Letter to the editor]. Telecommunications Policy, 18(6), 495-496.

Schaller, R. R. (1997, June). Moore's Law: past, present, and future. IEEE Spectrum, 53-59. 
Schmalensee, R. (1981). Monopolistic Two-Part Pricing Arrangements. The Bell Journal of Economics, 12(2), 445-466.

Schmalensee, R. (1988). Industrial Economics: An Overview. The Economic Journal, 98(392), 643-681.

Schumpeter, J. (1942). Capitalism, Socialisim, and Democracy New York: Harper.

Silberberg, E. (1990). The Structure of Economics: A Mathematical Analysis (Second ed.). Singapore: McGraw-Hill Inc.

Solow, R. (1957). Technical Change and the Aggregate Production Function. Review of Economics and Statistics, 39(3), 312-320.

Sprint Nextel (2009). Sprint Nextel Coporation, Form 10-K 2008 Annual Report. Retrieved from http://media.corporateir.net/media files/irol/12/127149/SPRINTNEXTELCOR10K.pdf

Sraer, D. (2008). Local Loop Unbundling and Broadband Penetration. Retrieved from http://www.econ.berkeley.edu/ sraer/arcep 04.pdf

Standard \& Poor's (2006). S\&P 100 Retrieved 13 June, 2009, from http://www2.standardandpoors.com/portal/site/sp/en/us/page.topic/i ndices $100 / 2,3,2,2,00,10,17,2006,71,2,3,0,0,0,0,0 . h t m l$

Standard \& Poor's (2008). S\&P 100 Retrieved 12 June, 2009, from http://www2.standardandpoors.com/portal/site/sp/en/us/page.topic/i ndices $100 / 2,3,2,2,00,11,31,2008,0,2,3,0,0,0,0,0 . h t m l$

Standard \& Poor's (2009, June). S\&P U.S. Indices Index Methodology Retrieved March, 2009, from

http://www2.standardandpoors.com/spf/pdf/index/SP US Indices M ethodology Web.pdf

Stigler, G. J. (1964). A Theory of Oligopoly. The Journal of Political Economy, 72(1), 44-61.

Stigler, G. J. (1971). The Theory of Economic Regulation. The Bell Journal of Economics and Management Science, 2(1), 3-21.

Stole, L. A. (1995). Nonlinear pricing and oligopoly. Journal of Management Strategy, 4, 529-562.

Sutton, J. (2007). Market Structure: Theory and Evidence. In M. Armstrong \& R. H. Porter (Eds.), Handbook of Industrial Organisation (Vol. 3, pp. 2301-2368): Elsevier B.V.

Telecom (1998). Telecom Corporation of New Zealand Limited, Annual Report.

Telecom (2004a). Commerce Commission Investigation into Regulation of Mobile Termination, Telecom New Zealand's submission in respect of the Issues Paper Retrieved 4 September, 2009, from

http://www.comcom.govt.nz//IndustryRegulation/Telecommunications LInvestigations/MobileTerminationRates/ContentFiles/Documents/Mo bile\%20Termination\%20Inquiry\%20Issues\%20Paper\%20- 
\%20Telecom\%20Submission\%20-\%20PUBLIC\%20VERSION\%20\%20FINAL.pdf

Telecom (2004b, 19 May). Telecom Ready to Deliver Unbundled Services, from http://www.telecom-

$\underline{\text { media.co.nz/releases }}$ detail.asp? $\mathrm{id}=3038 \&$ page $=3 \&$ pagesize $=10 \&$ filterte

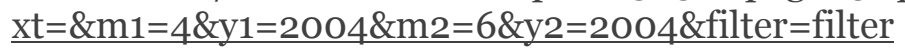

Telecom (2008). Telecom Corporation of New Zealand Limited, Results for the twelve months ended 30 June 2008. Retrieved from http://media.corporateir.net/media files/irol/91/91956/quarterly/mda q4 2008 final.pdf

Telecom (2009). Submission on schedule 3 investigation into regulation of mobile termination access service Retrieved 4 September, 2009, from http://www.comcom.govt.nz//IndustryRegulation/Telecommunications /Investigations/MobiletoMobileTermination/ContentFiles/Documents/ Telecom\%20MTAS\%20Draft\%20Report\%20Submission.PDF

Telecom Corporation of New Zealand Ltd v Clear Communications Ltd, [1995] 1 NZLR 385 (Privy Council Judicial Committee, 1994).

TelstraClear (2001). New name, new team, stronger competition, greater innovation - TelstraClear, a real choice Retrieved 22 September, 2009, from http://www.telstraclear.co.nz/company-info/media-releasetemplate.cfm?newsid $=44 \&$ myear $=2001$

The Commerce Commission v Telecom Corporation of New Zealand Ltd, [2008] 12 TCLR 168 (High Court of New Zealand 2008).

The Commerce Commission v Telecom Corporation of New Zealand Ltd, [2009] NZCA 338 (Court of Appeal of New Zealand 2009).

The Commerce Commission v Telecom Corporation of New Zealand Ltd, [2010] NZSC 111 (Supreme Court of New Zealand 2010).

The National Broadband Map (2009). Suppliers details Retrieved 14 September, 2009, from http://broadbandmap.govt.nz/suppliers-details/

Tirole, J. (1988). The Theory of Industrial Organisation. Cambridge, Massachusetts: The MIT Press.

Touche Ross (1988). Competition in Telecommunications Networks. Wellington: New Zealand Government, Department of Trade and Industry.

Trade Me (2009). Trade Me Site Statistics Retrieved 16 March 2009, 2009, from http://www.trademe.co.nz/Community/SiteStats.aspx

Twose, H. (Producer). (2008, 23 January) Vodafone shuts down ihug brand. nzherald. Podcast retrieved from http://www.nzherald.co.nz/business/news/article.cfm?c id=3\&objectid $=10488214$.

Vector (2004). Vector's telecommunications business becomes Vector Communications (01/03/04) Retrieved 4 September, 2009, from 
http://www.vector.co.nz/news/vectors-telecommunications-businessbecomes-vector-communications-010304

Verizon (2009). Verizon Communications Inc. Form 10-K, 2008 Annual Report. Retrieved from

http://investor.verizon.com/sec/sec frame.aspx?FilingID=6435582

Vickers, J. (1995). Competition and Regulation in Vertically Related Markets. The Review of Economic Studies, 62(1), 1-17.

Vodafone (2009). Company information Retrieved 22 September, 2009, from http://www.vodafone.co.nz/about/company-information/

Vogelsang, I. (2003). Price regulation of access to telecommunications networks. Journal of Economic Literature, 41, 830-862.

Wallsten, S. (2006). Broadband and Unbundling Regulations in OECD

Countries. AEI-Brookings Joint Center For Regulatory Studies:

Working Paper 06-16. from http://regmarkets.org/admin/authorpdfs/redirectsafely.php?fname $=$. ./pdffiles/phpSV.pdf

Wallsten, S., \& Hausladen, S. (2009). Net neutrality, unbundling, and their effects on international investment in next-generation networks. Review of Network Economics, 8(1), 90-112.

Wikipedia contributors (2009, 8 March 2009). Wikipedia: About Retrieved 16 March 2009 2009, from http://en.wikipedia.org/w/index.php?title=Wikipedia:About\&oldid=275 711008

Willig, R. D. (1978). Pareto-Superior Nonlinear Outlay Schedules. The Bell Journal of Economics, 9(1), 56-69.

Wilson, R. B. (1993). Nonlinear Pricing New York: Oxford University Press.

Woosh (2009). About the company Retrieved 30 August 2009, from https://www.woosh.com/ContentClient/WhyWoosh/WhyWooshCompa ny.aspx

WorldxChange Ltd (2000). WorldxChange Communications submission to the Ministerial Inquiry into Telecommunications, from http://www.med.govt.nz/upload/29927/049.pdf

Yahoo! Inc. (2009). Form 10-K, Fiscal Year Ended 31, 2008.

Yin, X. (2004). Two-part tariff competition in duopoly. International Journal of Industrial Organization, 22, 799-820. 